University of Tennessee Health Science Center

UTHSC Digital Commons

$5-2009$

\title{
Symbiotic Caregivers: A Qualitative Case Study of African American Custodial Grandparents and Their Grandchildren
}

Stella Enyichi Nwokeji

University of Tennessee Health Science Center

Follow this and additional works at: https://dc.uthsc.edu/dissertations

Part of the Nursing Commons

\section{Recommended Citation}

Nwokeji, Stella Enyichi , "Symbiotic Caregivers: A Qualitative Case Study of African American Custodial Grandparents and Their Grandchildren" (2009). Theses and Dissertations (ETD). Paper 195. http://dx.doi.org/10.21007/etd.cghs.2009.0228. 


\title{
Symbiotic Caregivers: A Qualitative Case Study of African American Custodial Grandparents and Their Grandchildren
}

\begin{abstract}
Data from the U.S. Census Bureau's 2005-2007 American Community Survey show that there are 11,436 grandparents in Shelby County, Tennessee, who are responsible for grandchildren. In Memphis only, there are 9,213 grandparents who are responsible for their grandchildren (U.S. Census Bureau, 2000). The Child Welfare League of America (CWLA) 2003 report (2003) showed that 42\% of Tennessee grandparents who were responsible for grandchildren who are living with them live in households where the children's parents are not present. Casper and Bryson (1998) noted that grandparent-headed households are more prevalent in African American communities and are at high risk for poverty. Circumstances surrounding grandparents' assuming the role of parent include grandparents' sense of responsibility, parents' neglect of the grandchild's needs, sexual abuse of the child by a parent, parents' need to work, parents' need for a break, economic problems, inadequate housing, and teenage pregnancy (CWLA, 2003; Kennedy \& Keeney, 1988; Minkler \& Fuller-Thompson, 1999; Poe, 1992; Ruiz, 2000; Tompkins, 2007). In addition, the authors noted other circumstances for the parents of these grandchildren, including drug-addiction or alcohol problems, incarceration, divorce, inadequate parenting skills, and health problems such as AIDS or physical disability, mental illness, and parent death.

The purpose of this qualitative case study was to describe the symbiotic caregiving of African American custodial grandparents (i.e., grandmothers) and their grandchildren. Symbiotic caregiving will be defined as two way caregiving activities and experiences that exist between both grandparents and grandchildren or between custodial grandparents and their grandchildren. It is a reverse and reciprocal relationship where grandparents, especially custodial grandparents feel a sense of responsibility and attachment to their grandchildren and vice versa.
\end{abstract}

The sample was 18 African American grandmothers ages 65-85 years and 18 grandchildren ages 8-17 years. The sample was recruited through the Shelby County Relative Caregiver Program in Memphis, TN. The findings show that different circumstances led to grandparents assuming caregiving for their custodial grandchildren. Some of these circumstances are related to the instability of the grandparents' biological children. These biological parents most times are not involved in their children's lives and do not help with rearing their children. Harper and Hardesty (2001) described the grandparent/grandchild relationship as puervitic. The term puervitic is used in the context to show that grandparents are raising their grandchildren without assistance from their own biological children. Caregiving activities performed by grandchildren include both instrumental and emotional tasks. Grandparents saw the activities of their grandchild as a way to prepare the grandchildren for adult roles, while the grandchildren assumed their roles in order to help with their grandparents' physical inability. Grandparents' caregiving activities included daily rearing of their grandchildren, ensuring that their grandchildren have adequate nutrition, education, health care and moral support.

Both members of the dyad had a different perception of their roles as caregiver to each other. Grandparents envisioned themselves as parents helping to mold their grandchildren as they would with their own children. In contrast, the grandchildren saw their own roles as helping their grandmother, who was the only person who cared about them when other people around them did not. Financial stress was one of the major concerns of the grandparents. They echoed the sentiments of other grandparents in the literature that grandparents need financial rescue to raise their grandchildren effectively. The results indicated that the grandparents and their grandchildren form a close and reciprocal relationship, much as a filial relationship that exists between parents and their children.

The implication for nursing and research includes the need to recognize that custodial grandchildren are 
part of their grandparents' lives. The grandchildren may need to be incorporated into the care and welfare of their grandparents as they may be the only individuals available to help some grandparents. With researchers acknowledging the existence and importance of grandchildren as caregivers, more research studies should focus on understanding the grandparent-grandchild dyad.

\section{Document Type}

Dissertation

Degree Name

Doctor of Philosophy (PhD)

\section{Program}

Nursing

\section{Research Advisor}

Carolyn Graff, Ph.D., RN

\section{Keywords}

African Americans, caregivers, case study, grandparents, custodial grandparents, qualitative study

\section{Subject Categories}

Medicine and Health Sciences | Nursing

\section{Comments}

Two year embargo expired May 2011 
SYMBIOTIC CAREGIVERS: A QUALITATIVE CASE STUDY OF AFRICAN AMERICAN CUSTODIAL GRANDPARENTS AND THEIR GRANDCHILDREN

\author{
A Dissertation \\ Presented for \\ The Graduate Studies Council \\ The University of Tennessee \\ Health Science Center
}

\author{
In Partial Fulfillment \\ Of the Requirements for the Degree \\ Doctor of Philosophy \\ From the University of Tennessee
}

By Stella Enyichi Nwokeji

May 2009 
Copyright (C) Stella Nwokeji, 2009 All rights reserved 
The measure of the greatness of a country is determined by: its treatment of its underprivileged, its treatment of its children, its treatment of its aged.

\section{- Hubert Humphrey}




\section{DEDICATION}

This dissertation is dedicated to my wonderful husband, who has been my pillar and has shown me so much love and encouragement.

To my wonderful children for their steadfast love, support, and patience throughout this endeavor.

To my parents, my parents in-law, and my brothers and sisters, Chidi, Tobechukwu, Ugonna, Nneoma, and Ezenwanyi for their love, support, and understanding. 


\section{ACKNOWLEDGEMENTS}

I would like to acknowledge and thank so much my advisor Dr. Carolyn Graff, who provided more than mentorship guidance. She truly believed in me, and her guidance, encouragement, and support are invaluable. I would also like to thank very much my other committee members, Dr. Mona Wicks, Dr. Pam Hinds, Dr. Ruthbeth Finerman, and Dr. Kedia Satish for their indispensable academic guidance, encouragement, and support. My appreciation goes to Belinda Hardy, Juanita Williams, and the staff of the Shelby County Relative Caregiver Program, Dr. Roberts and the staff of UT Boling Center Leadership Education in Neurodevelopmental and Related Disabilities (LEND) program for their support and understanding. I am grateful to a special sister and friend, Dr. Queen Henry Okafor, and her family for their constant support. Thank you to the study participants for welcoming me into their homes with passion to tell their stories. A very special prayer goes to one of the grandmother participants who passed away two weeks after I interviewed her. You welcomed me into your home with warmth and affection. May your soul rest in perfect peace. Amen!

Thanks and prayers for my little sister, Chinwendu. Your brief life experience was an inspiration to me during preparation of this dissertation. You will continue to have a special place in my heart.

My deepest thanks go to my wonderful husband, Emmanuel, my partner in life. You believed in me, supported, and encouraged me. Thank you for your patience during this endeavor.

Many thanks to my lovely children, Briana Chiamaka, Brittany Ijeoma, Brian Igweze, and Brandon Chukwuka. Your smiles, hugs, and more especially those "I love you" and "we are here for you" notes really helped mommy. I love you all so much!

Special thanks to my parents, Cornelius and Josephine Okereke. I appreciate your love, support and understanding. Thank you for instilling in me and my siblings the importance of education. Much appreciation also goes to my parents-in-law, Hillary and Grace Nwokeji. You are more than parents- in-law to me. Thank you for your unconditional love, support, and encouragement. Special gratitude goes to my brothers and sisters, Chidi, Tobechukwu, Ugonna, Nneoma, and Ezenwanyi. Thank you so much for your encouragement, patience, and support. The same goes to my brothers- and sister in-law. 


\begin{abstract}
Data from the U.S. Census Bureau's 2005-2007 American Community Survey show that there are 11,436 grandparents in Shelby County, Tennessee, who are responsible for grandchildren. In Memphis only, there are 9,213 grandparents who are responsible for their grandchildren (U.S. Census Bureau, 2000). The Child Welfare League of America (CWLA) 2003 report (2003) showed that 42\% of Tennessee grandparents who were responsible for grandchildren who are living with them live in households where the children's parents are not present. Casper and Bryson (1998) noted that grandparent-headed households are more prevalent in African American communities and are at high risk for poverty. Circumstances surrounding grandparents' assuming the role of parent include grandparents' sense of responsibility, parents' neglect of the grandchild's needs, sexual abuse of the child by a parent, parents' need to work, parents' need for a break, economic problems, inadequate housing, and teenage pregnancy (CWLA, 2003; Kennedy \& Keeney, 1988; Minkler \& Fuller-Thompson, 1999; Poe, 1992; Ruiz, 2000; Tompkins, 2007). In addition, the authors noted other circumstances for the parents of these grandchildren, including drug-addiction or alcohol problems, incarceration, divorce, inadequate parenting skills, and health problems such as AIDS or physical disability, mental illness, and parent death.
\end{abstract}

The purpose of this qualitative case study was to describe the symbiotic caregiving of African American custodial grandparents (i.e., grandmothers) and their grandchildren. Symbiotic caregiving will be defined as two way caregiving activities and experiences that exist between both grandparents and grandchildren or between custodial grandparents and their grandchildren. It is a reverse and reciprocal relationship where grandparents, especially custodial grandparents feel a sense of responsibility and attachment to their grandchildren and vice versa.

The sample was 18 African American grandmothers ages 65-85 years and 18 grandchildren ages 8-17 years. The sample was recruited through the Shelby County Relative Caregiver Program in Memphis, TN. The findings show that different circumstances led to grandparents assuming caregiving for their custodial grandchildren. Some of these circumstances are related to the instability of the grandparents' biological children. These biological parents most times are not involved in their children's lives and do not help with rearing their children. Harper and Hardesty (2001) described the grandparent/grandchild relationship as puervitic. The term puervitic is used in the context to show that grandparents are raising their grandchildren without assistance from their own biological children. Caregiving activities performed by grandchildren include both instrumental and emotional tasks. Grandparents saw the activities of their grandchild as a way to prepare the grandchildren for adult roles, while the grandchildren assumed their roles in order to help with their grandparents' physical inability. Grandparents' caregiving activities included daily rearing of their grandchildren, ensuring that their grandchildren have adequate nutrition, education, health care and moral support. 
Both members of the dyad had a different perception of their roles as caregiver to each other. Grandparents envisioned themselves as parents helping to mold their grandchildren as they would with their own children. In contrast, the grandchildren saw their own roles as helping their grandmother, who was the only person who cared about them when other people around them did not. Financial stress was one of the major concerns of the grandparents. They echoed the sentiments of other grandparents in the literature that grandparents need financial rescue to raise their grandchildren effectively. The results indicated that the grandparents and their grandchildren form a close and reciprocal relationship, much as a filial relationship that exists between parents and their children.

The implication for nursing and research includes the need to recognize that custodial grandchildren are part of their grandparents' lives. The grandchildren may need to be incorporated into the care and welfare of their grandparents as they may be the only individuals available to help some grandparents. With researchers acknowledging the existence and importance of grandchildren as caregivers, more research studies should focus on understanding the grandparent-grandchild dyad. 


\section{TABLE OF CONTENTS}

CHAPTER 1. INTRODUCTION....................................................................................... 1

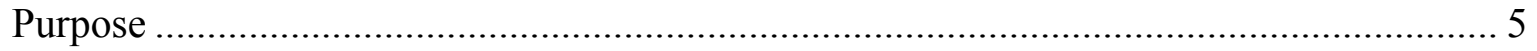

Research Questions............................................................................................. 5

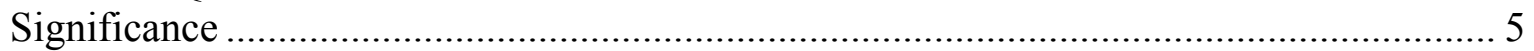

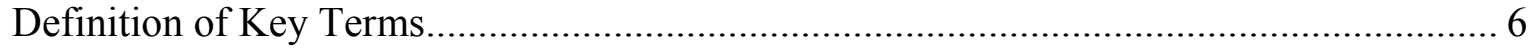

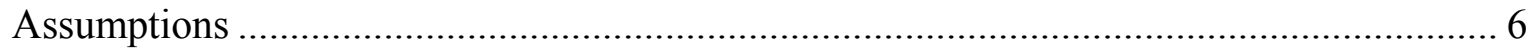

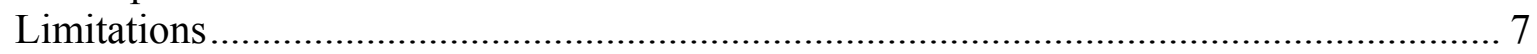

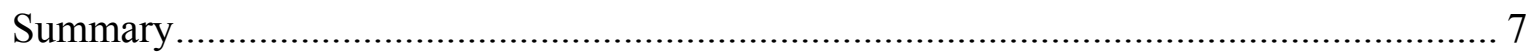

CHAPTER 2. LITERATURE REVIEW ..............................................................99

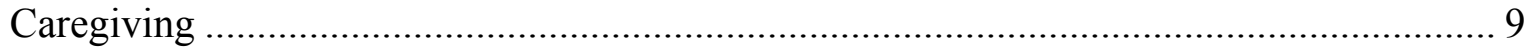

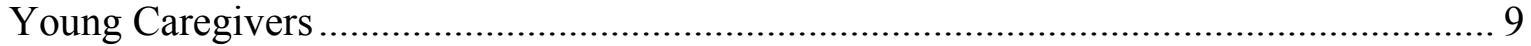

Description of Caregiving Tasks .......................................................................... 11

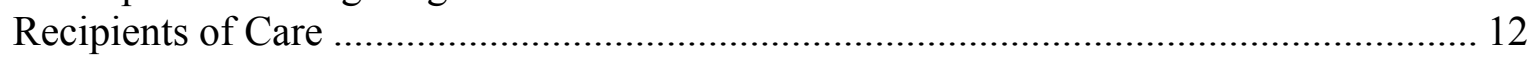

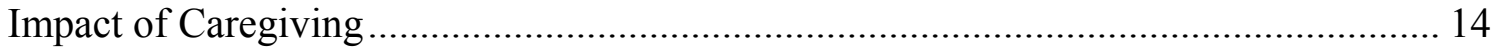

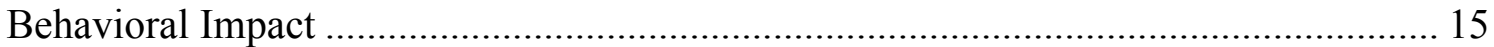

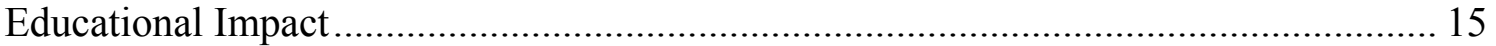

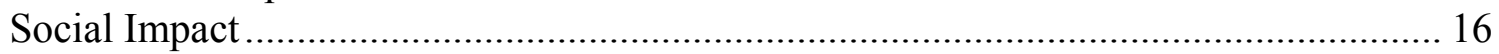

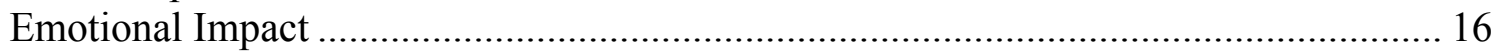

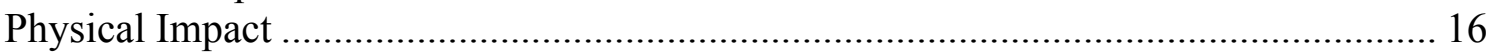

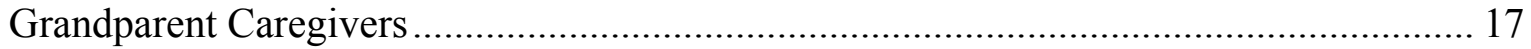

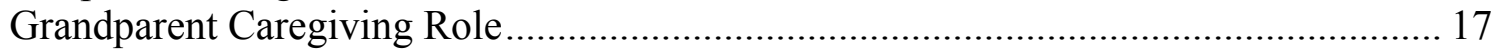

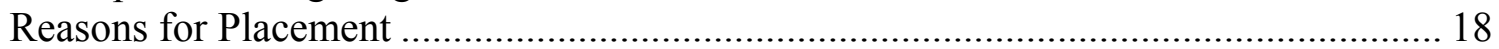

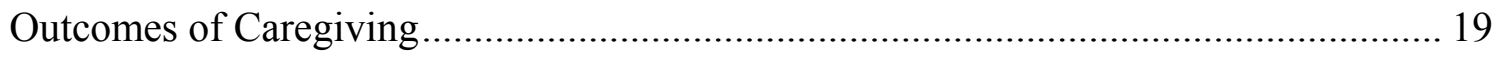

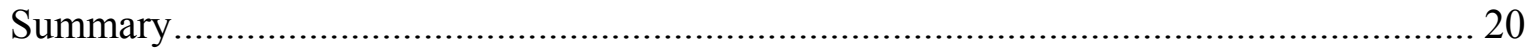

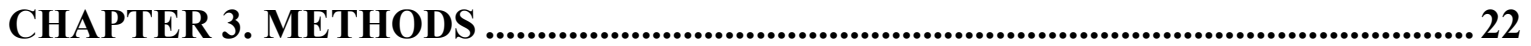

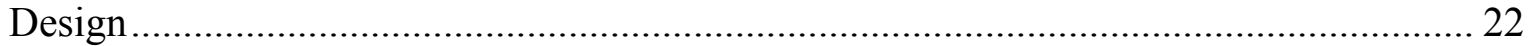

Overview of Case Study Methodology ......................................................................... 22

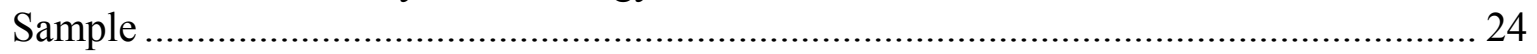

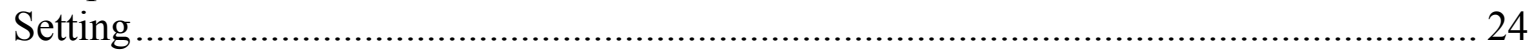

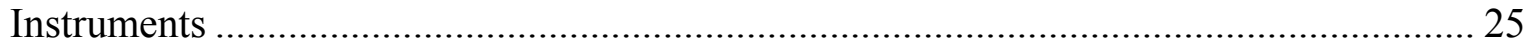

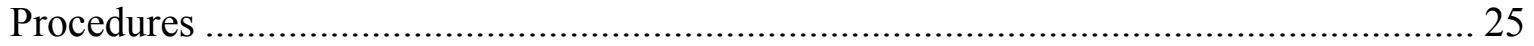

Protection of Human Subjects ................................................................................. 26

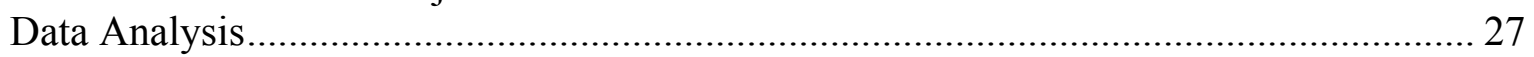

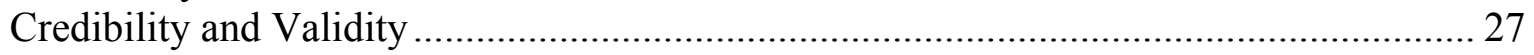

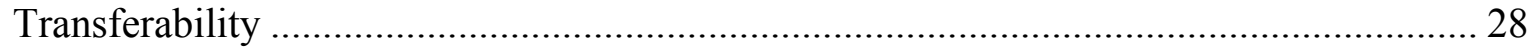

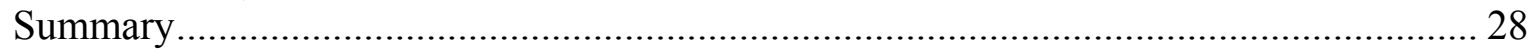

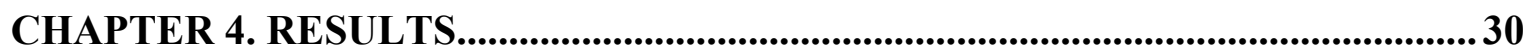

Characteristics of Grandparents and Grandchildren................................................... 30

Themes Evolving from Grandparent and Grandchild Dyads ..................................... 30 


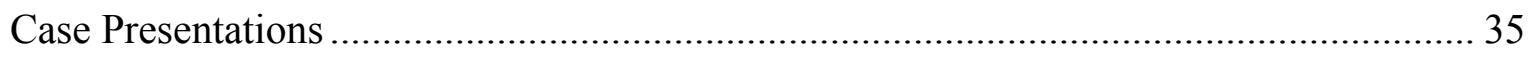

Theme 1: Journey to Custodial Grandparenting .............................................................. 35

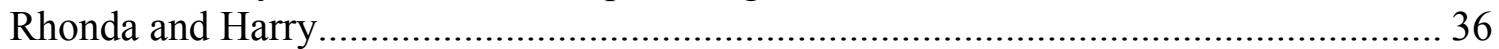

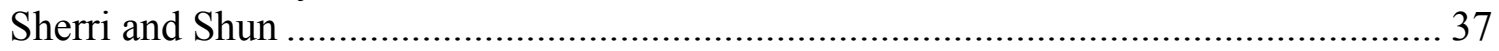

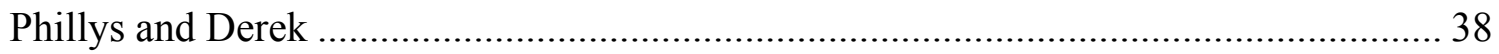

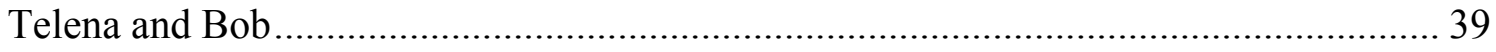

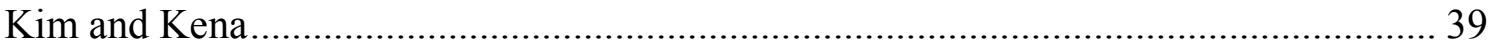

Theme 2: Financial Stress and Financial Needs ............................................................. 40

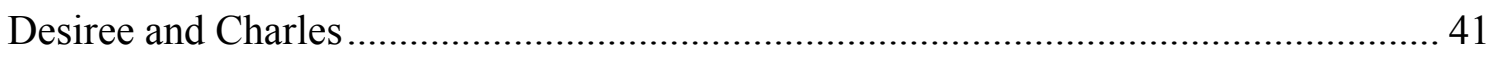

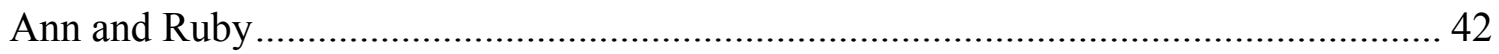

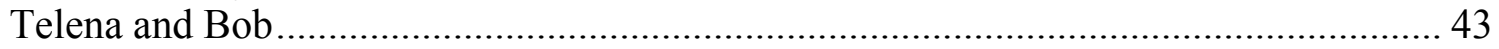

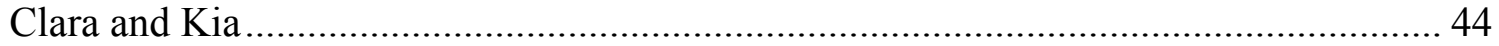

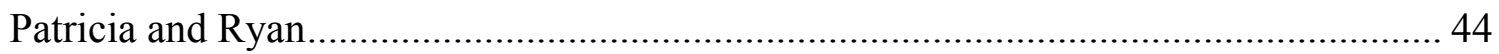

Theme 3: Grandparent and Grandchild Perception of Caregiving Role ........................... 45

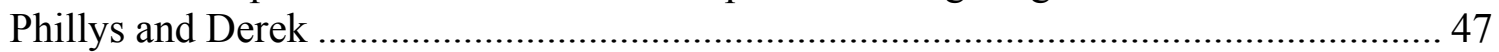

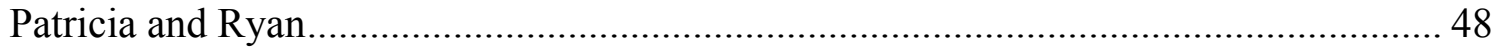

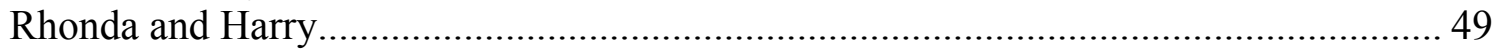

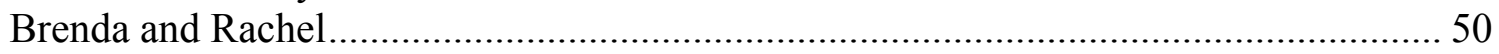

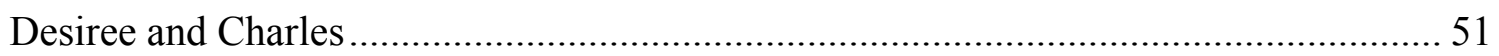

Theme 4: Grandparent and Grandchild's Caregiving Activities ...................................... 53

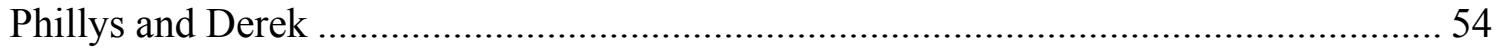

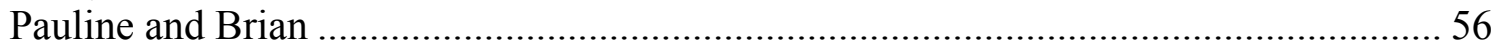

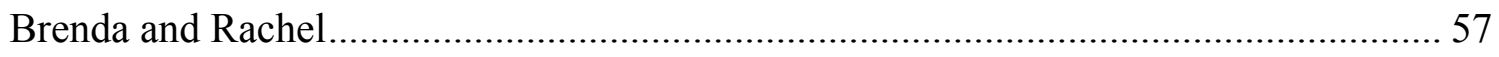

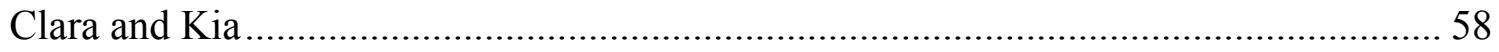

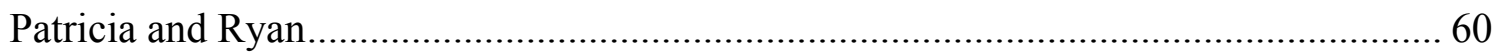

Theme 5: Grandparent and Grandchild Symbiotic Relationship......................................... 62

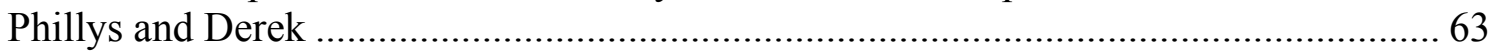

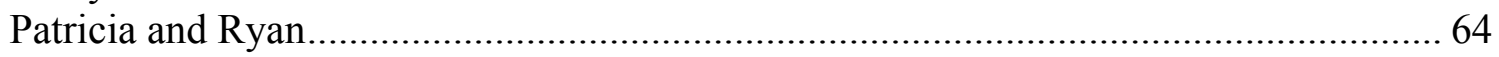

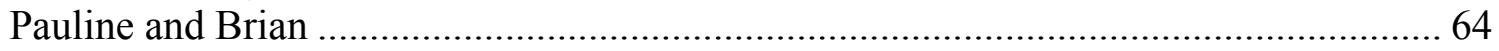

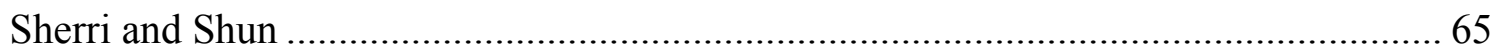

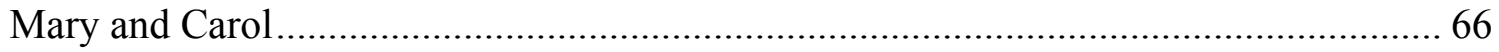

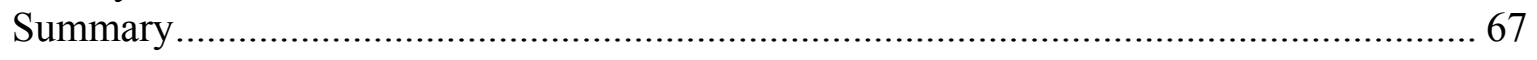

CHAPTER 5. DISCUSSION ….....................................................................................69

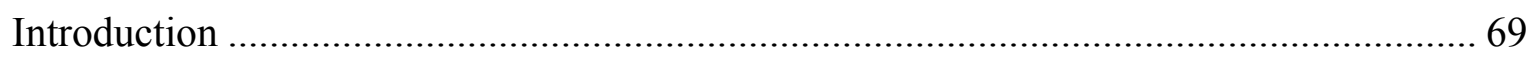

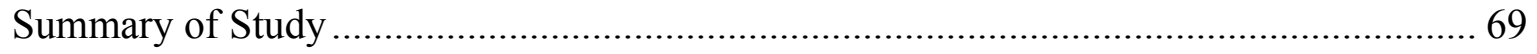

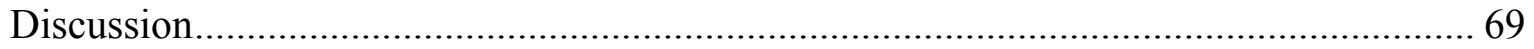

Question 1: Circumstances Leading to Symbiotic Caregiving........................................ 70

Question 2: Custodial Grandchildren Caregiving Activities............................................ 71

Question 3: Effect of Caregiving on Grandparents and Grandchildren .......................... 72

Question 4: Grandparent and Grandchild Symbiotic Relationship ................................ 73

Additional Finding: Perception of Assumption of Caregiving Role by Dyad ................ 74

Limitations and Strengths ........................................................................................... 75

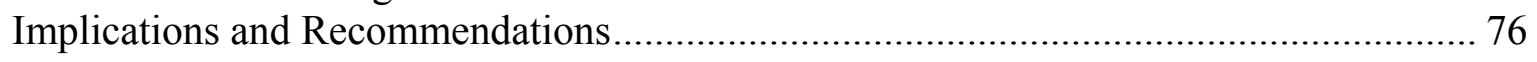

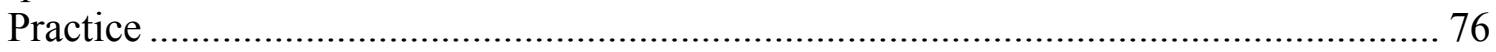

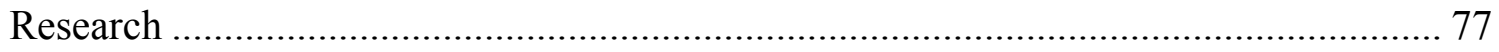


LIST OF REFERENCES............................................................................................... 79

APPENDIX A. GRANDPARENTS' DEMOGRAPHIC DATA FORM .......................90

APPENDIX B. GRANDCHILDREN'S DEMOGRAPHIC DATA FORM .................92

APPENDIX C. INTERVIEW SCHEDULE FOR GRANDPARENTS .........................93

APPENDIX D. INTERVIEW SCHEDULE FOR GRANDCHILDREN .....................94

APPENDIX E. INSTITUTIONAL REVIEW BOARD APPROVAL ...........................95

APPENDIX F. CONSENT FORM.........................................................................................97

APPENDIX G. ASSENT OF MINOR/CONSENT FORM............................................... 101

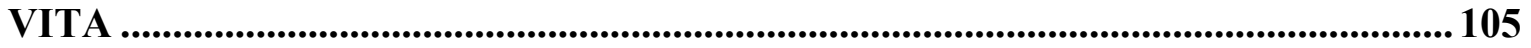




\section{CHAPTER 1. INTRODUCTION}

In this $21^{\text {st }}$ century, the needs and concerns of children who live with their custodial grandparents must be identified and addressed. "With the aging of the nation's population and the changing of the composition and complexion of the family, come new challenges. The extended and expanded responsibilities of long-term care of persons with special medical needs because of illness, disabilities, or aging are borne by family caregivers" (Siskowski, 2003, p. 2). According to the U.S. Census Bureau, 5.8 million grandparents co-reside with their grandchildren younger than 18 years and 2.4 million of these grandparents are caregivers to their grandchildren who are younger than 18 years (Simmons \& Dye, 2003). The age range for the grandparents is 30 to 80 years and higher. About 29\% of these grandparents are African American (Child Welfare League of America [CWLA], 2003). "In Tennessee, there are 101,510 children living in grandparent-headed households (7.3\% of all children in the state)" (CWLA, 2003, p. 1). Almost $2 \%$ of children in the state, or 24,774 , live in households headed by other relatives. Of the 61,252 Tennessee grandparents who reported that they were responsible for their grandchildren, 31\% are African American and 9,660 live in Memphis. The remainder of grandparents included $1 \%$ Hispanic and $66 \%$ White (CWLA, 2003). These findings are consistent with those reported by others (Denham \& Smith, 1989; Kivett, 1991), i.e., compared to other races, African American grandmothers are more likely to take up a surrogate parental role of their grandchildren.

The CWLA report (2003) showed that $42 \%$ of the Tennessee grandparents who are responsible for grandchildren, who are living with them, live in households where the children's parents are not present. Casper and Bryson (1998) noted that grandparentheaded households are more prevalent in African American communities and are at high risk for poverty. Circumstances surrounding grandparents' assuming the role of parent include grandparents' sense of responsibility, parents' neglect of the grandchild's needs, sexual abuse of the child by a parent, parents' need to work, parents' need for a break, economic problems, inadequate housing, and teenage pregnancy (CWLA, 2003; Kennedy \& Keeney, 1988; Minkler \& Fuller-Thompson, 1999; Poe, 1992; Ruiz, 2000; Tompkins, 2007). In addition, the authors noted other circumstances for the parents of these grandchildren to include drug-addiction or alcohol problems, incarceration, divorce, inadequate parenting skills, and health problems such as AIDS, physical disability, mental illness, and parent death.

Most of these grandparents are at the age where chronic illness is increasing in prevalence. The changing demography of these baby boomers means a major shift from acute to chronic care (Bilchik, 2000). Caregiving for these elderly family members, especially custodial grandparents, is growing. According to Levine, Hunt, Halper, Hart, Lautz, and Gould (2005), “. . . the 2.4 million grandparents raising 1 or more grandchildren now will need help when these youngsters are in their $20 \mathrm{~s}$. We speculate that, in the future, care recipients will be even older that they are now, and caregivers will be younger" (p. 2075). Some grandchildren who live with grandparents, especially in deprived families, have assumed the role of caring for their grandparents (Early, 
Cushway, \& Cassidy, 2006). These youngsters may view their caregiving as a responsibility for a grandparent who has done or given so much for them in their present circumstances. There is a sense of responsibility and a feeling of giving or paying back in child-grandparent caregiving relationships (Tompkins, 2007). This is similar to the cultural phenomenon, filial piety, which is described in Asian cultures (Lee, 2007).

Filial piety is the virtue of devotion to one's parents and is seen in some African American cultures today. In African American families, grandmothers are known to be available in times of crisis. Timberlake and Chipungu (1992) reported that African American grandparents are "traditionally available for family resources and supplemental parents in times of crisis" (p. 221). In addition, Burton and Dilworth-Anderson (1991) described African American grandmothers as a "family stabilizer" (p. 312).

Family caregiving is likely associated with older adults, care of the chronically or terminally ill, and grandparents' caregiving roles. According to Johnson (1988), more research has focused on traditional roles of grandparents, legal position of grandparents in custodial issues, grandparent satisfaction, changes in family, meaning and significance of grandparenting, and the influence of grandparents on grandchildren. There is no doubt that grandparents play "a significant role in the entire life cycle" (Blau, 1984, p. 46). However, the trends in the healthcare system and family compositions call for a change in paradigm. Today, family caregiving includes grandchildren (younger caregivers) as providers of care to grandparents. However, little literature exists that focuses on the young caregivers and, specifically, African American grandchildren as young caregivers.

There is a significant gap in the literature on the experiences of African American custodial grandparents and their grandchildren's reverse caregiving roles and the impact of their situations on each other. The literature that exists on caregiving in African American families focuses on grandparents' traditional roles and "grandmothers caring functions" (Flaherty, 1988, p. 191). Few studies have looked at young adult children and grandchildren as primary caregivers to elderly relatives who may or may not be their grandparents (Dellmann-Jenkins, Blankemeyer, \& Pinkard, 2000; Giarrusso, Silverstein, $\&$ Bengston, 1996). Young children, especially custodial grandchildren have a special bond with their grandparents. A distinct relationship exists between "grandmothers' overall value of raising their grandchildren, timing of role assumption, and current situational context" (Timberlake \& Chipungu, 1992, p. 216). Grandchildren may feel that they have to reciprocate the gesture by caring for their grandparents.

Children as young as five years old are spending time caring for an adult or someone at home rather than attending school (Sadler, 2003). The National Alliance for Caregiving's landmark study showed that 1.4 million children in the United States between the ages of 8 and 18 provide care for an older adult. A total of 400,000 of these youngsters are under the age of 11 years (Hunt, Levine, \& Naiditch, 2005). Findings from this national survey on child caregivers showed that children who are caregivers are doing this alone with no support (Hunt, Levine, \& Naiditch, 2005). At the same time, these children are participating in the social and educational activities on the same level with their peers who are not caregivers. Caregiving has negative effects on the physical 
health of the caregiver and can result in intergenerational conflict. Furthermore, it can lead to restriction in personal and social lives of caregivers which in turn results in strained family relationship (Sayles-Cross, 1999).

For both symbiotic caregivers, caregiving can be stressful and burdensome. Grandparents may be stressed, depressed, and have burdens and concerns associated with their reverse role. The grandparents are faced with changes in their daily activities and their personal, marital, and social lives. Grandparents are "finding the luster of their golden years dulled by responsibilities they never anticipated" (Smolowe, 1990, p. 86). At the age when some of these grandparents should be enjoying their lives, they are caring for their grandchildren. According to National Association of Social Workers [NASW] (1988), grandparents are faced with numerous factors that affect rearing of their grandchildren. These include fixed budget, interference from grandchildren's parents, relearning parental skills, and limited assistance from the government, the welfare system, to be precise. Furthermore, grandparents deal with other problems not only related to their grandchildren's lives but also related to the lives of their own biological children. The grandparents battle drug problems of their biological children, custody issues between them and their biological children (Graff, Nwokeji, Williams, Hardy, Davis, \& Roberts, 2007; Pantier, 1993), marital problems, strained relationships (Graff et al., 2007; Palmer, 1990), and health problems (Blustein, Chan, \& Guanais, 2004; Bowers \& Myers, 1999; Butler \& Zakari, 2005; Dowdell, 2004; Fuller-Thompson \& Minkler, 2005; Graff et al., 2007; Jendrek, 1993; Lee, Colditz, Berkman, \& Kawachi, 2003; Minkler \& Fuller-Thompson, 1999; Musil, 1998).

Likewise, caregiving impacts the lives of children who are young caregivers. Early caregiving by children impacts their childhood. It also affects their family member's lives and family structure which can lead to tension and stress within the family (Frank, Tatum, \& Tucker, 1999). In most cases, it puts a financial burden on the family. Behavioral impact of early caregiving on young caregivers includes stigma, isolation, loneliness, embarrassment, resentment, physical fights by school mates, and rejection (Cree, 2003; Keigher, Zabler, Robinson, Fernandez, \& Stevens, 2005; Pakenham, Chiu, Bursnall, Cannon, \& Okochi, 2006). The impact of early caregiving on young caregivers can also include detrimental educational consequences, truancy, struggle with school work (Cree, 2003; Nigel, Stainton, Jackson, Cheung, Doubtfire, \& Webb, 2003; Siskowski, 2006), social isolation, and lack of recognition by friends (Cree, 2003; Early et al., 2006; Gates \& Lackey, 1998; Nigel et al., 2003; Pakenham et al., 2006; Siskowski, 2006). The physical impact of caregiving on young caregivers includes lack of sleep, fatigue, and eating disorders (Cree, 2003; Gates \& Lackey, 1998; Nigel et al., 2003).

According to Shifren (2001) and Siskowski (2006), the impact of caregiving on social, behavioral, and educational lives of young caregivers is limited. The National Alliance for Caregiving noted that "in the U.S., little is known about the understudied and underserved young children who outnumber the combined total of students in grades 3-12 in New York City, Chicago, and the District of Columbia" (Hunt et al., 2005, p. 1). All previous studies have been on caregivers older than 18 years. In the report of findings on 
young caregivers in the U.S., Hunt et al. (2005) noted that "Family caregiving today is truly an equal opportunity job. But one part of the caregivers population has been overlooked-children" (p. 1). With all major U.S. surveys of caregiving, including people 18 years or older, the experiences of children providing care rather than requiring care should be recognized and understood. In addition, a study conducted in the U.S. has dealt with the experiences of former young caregivers. Lackey and Gates (2001) examined the issues with adults who were former young caregivers. The study found caregiving was difficult. These adults reported that their family life, school, and time with friends were most likely affected by caregiving.

Most studies of the experiences of young caregivers have been conducted in the United Kingdom, New Zealand, and Australia. According to Meredith (1992), the Children and the Community Care Acts were developed in the United Kingdom to examine issues of caregiving. The Young Carers Project which is a part of the Carers' National Association was established to look at issues on caregiving that had been previously raised by the Children and the Community Care Acts. The Carers' National Association raised awareness about young caregivers (Aldridge \& Becker, 1993a; Meredith, 1992). This was accomplished by the development of the Children Act, National Health Service, and Community Care Act.

Although an estimated 10,000 children in the United Kingdom are young caregivers, these figures may be unreliable, so that the actual number of children who are primary or young caregivers is not known (Aldridge \& Becker, 1993a). Furthermore, the lack of research about youth as caregivers shows that the needs of young caregivers are not met or not given the required attention. In a study conducted in the United Kingdom, Aldridge and Becker (1993b) found that young caregivers who take care of an ill adult run the risk of physical and psychological problems. These young caregivers perform activities such as lifting which restrict their daily lives. The impact of caregiving can be seen on lifestyles, health of the caregivers, and behavioral and emotional needs of caregivers. Additionally, education and social life such as friendships and outdoor activities can be compromised by caregiving. In some cases, these children often miss school or arrive late at school. These are, of course, added pressures to already stressed lives of these young caregivers.

As the reverse caregiving role in this country grows, it is crucial to have a clear understanding of factors and relationships that enable custodial grandparents and grandchildren to take up these roles. This growth indicates the need to conduct studies to help understand the needs of these symbiotic caregivers. Given the few studies related to young caregivers of grandparents and the lack of studies focusing on their subjective experiences, research using qualitative methodology is warranted to increase existing knowledge of these grandchildren's and grandparents' symbiotic caregiving. 


\section{Purpose}

Numerous studies have shown that grandparents (i.e., grandmothers) provide care to their grandchildren, yet little attention has been paid to the grandparent-grandchildren symbiotic caregiving roles (Bowers \& Myers, 1999; Bulter \& Zakari, 2005; Dowdell, 2004; Dowdell, 2005; Goodman \& Rao, 2007; Fuller-Thomason \& Minkler, 2001; Lee, Colditz, Berkman, \& Kawachi, 2003; Minkler \& Roe, 1993; Ruiz, 2000; Smith \& Palmieri 2007; Tompkins, 2007). The purpose of this case study is to describe the symbiotic caregiving relationship of African American custodial grandparents and their

grandchildren. Symbiotic caregiving will be defined as two way caregiving activities and experiences that exist between both custodial grandparents and the grandchildren in their custody. It is a reverse and reciprocal relationship where custodial grandparents feel a sense of responsibility and attachment to their grandchildren and vice versa. By better understanding grandparents' and grandchildren's activities and experiences, health professionals can gain insight into the grandparent-grandchild relationship so that unmet needs and at risk situations can be identified and addressed.

\section{Research Questions}

Following are the key research questions that directed this study:

1. What are the circumstances leading to symbiotic caregiving among custodial grandparents and their grandchildren?

2. What caregiving activities do custodial grandchildren engage in?

3. How does caregiving affect their lives?

4. What is the nature of the relationship between grandparents and grandchildren as symbiotic caregivers?

\section{Significance}

The primary significance of this study will be to expand our knowledge of grandparent and grandchild symbiotic caregiving relationship. According to Gates and Lackey (1998) "Nurses usually are not as aware of young caregivers as are teachers" (p. 15). The nursing profession needs to understand the caregiving needs of custodial grandparents who raise grandchildren and the grandchildren being raised. When there is awareness of the experiences of this population as caregivers and the relationship that exists between child caregivers and the recipients of their care, health professionals can identify and assess the individuals who are at risk for emotional stress, role strain, or intergenerational conflict from caregiving (Lee, 2007). Second, findings from this proposed study will help in understanding the need to assess grandchildren as young caregivers and include today's grandchildren in caregiving of the grandparents. As Aldridge and Becker (1993c) state, to neglect children as young caregivers is not simply an oversight, but an abuse of the rights of these children, their dignity, and their childhood. 
Third, the knowledge about the "skipped generation families" (Burnette, 1997, p. 22) will help with understanding the long-term caregiving bond. The phrase "skipgeneration household(s)" describes a household with the absence of biological parents in children's lives (Burnette, 1997; Minkler \& Roe, 1993). Information gathered through the proposed study will offer health professionals and governmental agencies insight into incorporating grandchildren in the care of their grandparents even years after the young caregivers are adults. According to Casper and Bryson (1998), "Grandparents and their grandchildren would benefit greatly if policies and programs intended to help traditional parent-child families in times of need could be extended to grandchildren" (p. 14). Ultimately, the findings from this proposed study will establish groundwork for future studies to examine further the experiences of grandparents and young caregivers and the characteristics of their relationships. Understanding these relationships will allow health professionals to better identify and meet grandparent and grandchild needs.

\section{Definition of Key Terms}

The following key terms were used in this study:

- Caregiving - The act of providing services to an individual in need (Eisodorfer, 1991).

- Case-A custodial grandparent and a grandchild in the grandparent's custody who have a symbiotic relationship as defined below.

- Custodial grandparents-African American maternal or paternal grandparents between the ages of 65 and 85 years who have formal custody of one or more grandchildren. Grandparents fulfill the role of parenting, which includes daily physical care and decision-making responsibility for the grandchildren. Grandparents were enrolled in the Shelby County Relative Caregiver Program.

- Symbiotic caregiving - Two way caregiving activities and experiences that exist between custodial grandparents and their grandchildren. It can be seen as a reverse and reciprocal relationship where custodial grandparents feel a sense of responsibility and attachment to their grandchildren and vice versa (Nwokeji \& Graff, 2007).

- Symbiotic relationship - The reciprocal caregiving relationship between custodial grandparents and their grandchildren.

- Young caregivers - Grandchildren between the ages of 8 and 17 years who take the responsibility of providing care and support at home for their grandparents (Dearden, Becker, \& Aldridge, 1994; Dearden \& Becker, 1999). Grandchildren in our study lived with their custodial grandparents who were enrolled in the Shelby County Relative Caregiver Program.

\section{Assumptions}

Qualitative methodologies require that the researcher bracket all preconceived assumptions or knowledge of the phenomena or study of interest (Creswell, 1998; Patton, 
2002). This helps prevent bias in the researcher's approach to data collection and datanalysis. Extensive efforts were made by the researcher to identify and bracket personal preconceived assumptions and knowledge of caregiving between grandparents and grandchildren.

Assumptions for this study included the following:

1. The study sample was homogeneous for race (African American grandparents).

2. The study sample was homogeneous for grandparent gender (grandmothers).

3. The socioeconomic status of study participants was considered low based on the criteria for enrollment in the Shelby County Relative Caregiver Program (i.e., household income cannot exceed twice the current federal poverty guideline).

4. The interview process and actual interview were scheduled to avoid conflict with grandchildren's school schedules.

5. The researcher's identification and bracketing of personal knowledge of caregiving between grandparents and grandchildren helped prevent bias in the researcher's approach to data collection and data analysis (Creswell, 1998; Patton, 2002).

\section{Limitations}

The following were considered limitations in this study.

1. Grandparents and grandchildren may respond to questions in a way they perceive the researcher expects, thereby diminishing the credibility of the study findings.

2. Transferability or the degree to which findings can be transferred to other groups, settings, or contexts may be limited due to the geographical restriction and the small, homogeneous, convenience sample (Lincoln \& Guba, 1985).

3. Grandparents' willingness to participate may be influenced by their desire to obtain support services for themselves and their grandchildren.

4. Younger grandparents were under represented due to the inclusion criteria for age (65 to 85 years).

5. Grandchildren under the age of 8 years and over the age of 17 years were under represented due to the inclusion criteria for age (8 to 17 years).

\section{Summary}

There have been numerous research studies on grandparents as caregivers to their grandchildren. However, very few research studies are published on the grandchildren as caregivers. Similarly, there is a paucity of research on the symbiotic caregiving relationship between grandparents and their grandchildren. Of all the research that has been reported around the world on grandparents and grandchildren caregiving, as of the time of this present study, no studies have looked at the symbiotic caregiving relationship that exists between grandparents and their grandchildren. More importantly, no study has utilized qualitative case study analysis to explore this relationship and its effect on both 
grandparents and grandchildren. 


\section{CHAPTER 2. LITERATURE REVIEW}

Most published literature on caregiving has focused on adult family members providing care to members who are mentally impaired or chronically ill (Harris, 2003). There is also a body of literature on the impact of caregiving on grandparents. However, the experiences of custodial grandparents and their grandchildren as young caregivers have not been examined. This review of literature will address areas crucial to the conduct of this study, specifically, caregiving, youth caregivers, and grandparent caregivers. Also, description of caregiving tasks, recipients of care, impact of caregiving on young caregivers and grandparents, grandparent caregiving roles, reasons for placement of grandchildren with their grandparents, and grandparents' outcomes related to caregiving will be discussed. Finally, a summary will be provided.

\section{Caregiving}

Examining the literature on caregiving is important in understanding grandparents and young caregivers as caregivers to each other. According to Eisdorfer (1991), caregiving is an act of providing services to anyone in need. Therefore, a caregiver is a person who has the primary responsibility of providing care to an individual that is chronically ill, terminally ill, physically disabled, or mentally disabled. Caregiving is also caring for persons of all ages, providing unpaid care, and all types of assistance which can be short- or long-term care (Donelan, Hill, Hoffman, Scoles, Feldman, Levine, $\&$ Gould, 2002). Caregivers who offer significant amounts of time to caregiving may experience decline in health and they may experience isolation and loss of productivity due to the distraction of caregiving from their career or social life (Donelan et al., 2002; Polen \& Green, 2001).

Caregiving is stressful and burdensome. Care providers experience either physical or mental changes associated with caregiving which is referred to as burden (Poulshock \& Deimling, 1984). Furthermore, Chiriboga (1987) defined burden as both an objective entity and a subjective entity that look at the specific behavior of care recipients and the effects of these behaviors on caregivers. Caregiver burden can be either subjective or objective. It is defined as the amount of time and energy needed to provide care to another person (Biegel, Sales, \& Schultz, 1991). Pearlin, Mullan, Semple and Skaff (1990) stated that objective burden is the caregiving related stress associated with providing care, tasks, and activities of caregiving. Subjective burden is seen as the caregiver's perception of burden (Montgomery, Gonyea, \& Hooyman, 1985).

\section{Young Caregivers}

The review of literature on young caregivers is crucial to understanding the children and the role they play in symbiotic caregiving. Young caregivers are young people who have a family member with an illness or disability and who often assume 
responsibility for their care (Pakenham et al., 2006). In the United Kingdom, young caregivers are referred as young carers - children under 18 who provide primary care for sick, disabled, or elderly relatives in the home (Aldridge \& Becker, 1993b; Jenkins \& Wingate, 1994). Family dynamics are changing. The trend in single parent households or grandparent households is exposing children to take up roles usually meant for adults. A family composed of a custodial grandparent with a disability or chronic illness is likely to have children involved in caregiving. These young caregivers are pseudo adults. Growing up includes caregiving for an elderly parent or grandparents. Young caregivers play the dual-role of students and caregivers. In summary, young caregiving affects many aspects of young children's lives including attendance in school, grades in school, social life, and friendship to mention but a few. Unfortunately, young caregivers and the impact of young caregiving is under recognized.

According to Jenkins and Wingate (1994), "a substantial obstacle in addressing the needs and concerns of young carers" (p. 733) includes healthcare providers' failure to identify young caregivers, lack of awareness of young caregivers' existence, and young caregivers' reluctance to identify themselves for "fear of professional intervention" ( $p$. 733). Furthermore, Aldridge and Becker (1993b) identified lack of resources and services available for young caregivers as reasons why health professionals ignore, or are unable or unwilling to identify children as caregivers. Young caregivers are left to carry responsibilities and take up roles which affect their physical, psychological, mental, and social wellbeing. Most times, they feel obliged to take on these roles. Some resist the roles, as evidenced by negative behavioral consequences. Young caregivers may perform a wide range of roles including personal care (e.g., showering and bathing), household chores (e.g., feeding, cooking, and cleaning), emotional support (e.g., providing a comforting atmosphere), and caring for and looking after siblings (Dearden \& Becker, 1999; Lackey \& Gates, 2001; Nigel et al., 2003). Caregiving is most difficult when young caregivers support a parent with drug/alcohol problems, mental illness, or chronic illness (Dearden \& Becker, 1999; Gates \& Lackey, 1998; Nigel et. al, 2003).

Pakenham et al. (2006) reported on the psychosocial impact of caregiving on young people. They empirically validated themes from their tool, the Young Caregiver of Parents Inventory (YCOPI). They assessed key themes reported in qualitative studies on young caregivers and compared young caregivers and noncaregivers. In addition the study focused on the psychosocial impact of caregiving. The authors compared 100 young caregivers and 145 noncaregivers between the ages of 10 and 25 years. The data analysis showed that the impact of young caregiving was both positive and negative.

Evidence from the study suggested that young caregivers reported "higher levels of young caregiving impact (i.e., higher responsibilities, perceived maturity, worry, activity restrictions, and isolation)" (Pakenham et al., 2006, p. 123). The authors noted the interference of early caregiving with school, social life, and employment. Other negative impact included the stigma and embarrassment associated with caring for parents, grandparents, or any member of the family. A limitation was the sampling of young caregivers and noncaregivers which may not be representative of the two populations and affects the generalizability of the study findings (Pakenham et al., 2006). 
The authors' reliance on participant self-report, their definition of noncaregivers, and their wide age range of young caregivers were additional limitations of this study.

\section{Description of Caregiving Tasks}

Research studies on young caregivers or young carers have been linked to the types of tasks performed by these young people. Description of care performed by young caregivers can be categorized by the following sub-groups: domestic care, general support, emotional support, personal care, and child care for siblings (Pakenham et al., 2006). Interestingly, another sub-group is represented in a study conducted by Nigel et al. (2003) where a 15 year old participant saw himself taking up a parenting role which the author referred to as role reversal.

Lackey and Gates (2001) conducted a study of adults $(\mathrm{N}=51$ who claimed to have performed care activities during their childhood. The study was conducted in urban and rural areas of the Midwestern U.S. The participants were 19 years and older and were engaged in caregiving between the ages of 10-18 years. The authors collected data using the Caregiving Activities Checklist, a semi-structured interview guide, and a demographic form. The semi-structured interview form was used to elicit information on the negative and positive effects of caregiving, and the caregiving effect on family, school, and church. Lackey and Gates (2001) collected data on the individual in the family who made decisions and offered advice to fellow caregivers and their parents.

Results from the study showed that 11 of the participants had a high school education or less and 18 participants had "current modal income range" (Lackey \& Gates, 2001 , p. 323) of $\$ 25,000-\$ 50,000$ per year. Specific caregiving tasks were grouped into four categories namely (a) personal care (e.g., bathing, taking to bathroom, dressing and feeding); (b) medical care (e.g., giving pills or shots, catheter care or colostomy care, and changing dressings); (c) household care (e.g., cleaning, cooking, baby-sitting, and shopping) and (d) spending time (e.g., visiting with the person, praying, reading, and playing games). Effects of caregiving on the family, school, friends, dating, and leisure yielded both positive and negative implications. Participants described the positive impact of caregiving as allowing them "to be able to help, 'to be part of the family,' provided opportunity to feel 'appreciated,' 'needed,' 'important,' and 'useful'" (Lackey $\&$ Gates, p. 324). Negative effects of caregiving were participants" "unresolved anger and guilt" (Lackey \& Gates, p. 325) or fear of having a chronic or terminal illness as the care recipients.

In his research on young caregivers in United Kingdom (U.K.), Australia, the U.S., and Sub-Saharan Africa, Becker (2007) found that the description of caregiving tasks differed globally. A care activity that is considered inappropriate in developed countries can be seen as appropriate care built on love in a developing country. In the U.S., young caregivers perform activities such as assisting with feeding, bathing, dressing, reading, household chores, errands, shopping, providing translation, and assisting with medical care (Aldridge \& Becker, 1993a; Aldridge \& Becker, 1993b; Gates 
\& Lackey, 1998; Hunt et al., 2005; Nigel et al., 2003; Shifren \& Kachorek, 2003). Siskowski (2006) reported on young caregivers' activities as personal care, medical care, household management, supervision, and emotional support and translation in medical settings. Similar to activities reported by Siskowski (2006), sibling responsibilities and emotional support are performed in the U.K, Australia, and Africa (Cree, 2003; Doran, Drever, \& Whitehead, 2003; Early et al., 2006; Keigher et al., 2005; Watson, 1999).

Robson, Ansell, Huber, Gould, and Young (2006) reported similar kinds of care activities in Africa. The authors investigated young caregivers in the midst of the HIV/AIDS pandemic in African-Lesotho, Tanzania, and Zimbabwe. In Lesotho, South Africa, Robson et al. (2006) explored the range of caregiving activities performed by young carers who took care of their grandparents, parents, or siblings. They also explored the impact of caregiving responsibilities and its effect on educational lives of Tanzanian students. Lastly, the negative and positive effects of caregiving on young children and their families were explored in Zimbabwe. Findings suggested that young children on the continent of Africa are providing care to family members because of the HIV/AIDS pandemic. The authors reported categories of care activities as intimate caregiving, general caregiving, domestic chores, and childcare.

In a similar study, Esu-Williams et al. (2006) assessed the strategy to help build and use young people as caregivers and support persons to people living with AIDS in rural Zambia. The authors used a curriculum to train 12 local health professionals who, in turn, trained 300 youths from 30 clubs. The authors described clubs as school and community anti-AIDs voluntary organizations that help students and members of the community get involved in HIV prevention. Qualitative and quantitative data were collected using in-depth and semi-structured interviews from 16 out of 30 clubs. The results showed that these youths could perform varied care activities such as clinic transportation, help with walking, counseling, cooking, housework, help with medications, bathing, dressing, gardening, and farming.

\section{Recipients of Care}

Young caregivers provide care to siblings when a family member becomes physically or mentally incapable of caring for the siblings or when a family member dies. According to Robson et al. (2006), young caregivers in Lesotho, South Africa are caring for their siblings because they and their siblings are orphans due to the loss of their parents from HIV/AIDS or having family members debilitated by HIV infection. The pandemic situation of HIV/AIDS in the U.S., Europe, and Africa has left children providing care to siblings.

In a study of 61 young caregivers, Cree (2003) found that $13 \%$ admitted caring for a sibling because of a family member's illnesses or disabilities, $41 \%$ reported caring for one parent, and "the rest cared for a mix of parents, siblings and others" (p. 303). The illnesses or disabilities were noted as "physical disability, mental health, problematic behaviors (alcohol abuse), and learning disability (autism, dyslexia)" (p. 303). In other 
studies, similar reasons of chronic illness, learning disability, physical disability, brain injury, mental problems, sensory impairment, and intellectual impairment were reported (Early et al., 2006; Gates \& Lackey, 1998; Nigel et al., 2003; Pakenham et al., 2006; Watson, 1999). Early et al. (2006) developed a 5-factor, 31-item Young Carers Perceived Stress Scale (YCPSS). The scale was tested on 108 young carers between the ages of 12 to 18 years. The authors reported that $28 \%$ of the samples were adolescents who were caring for their siblings.

Family members with different disabilities have been reported to be recipients of care from children. These disabilities prevented family members from performing their duties. In most African countries, women take the responsibilities of domestic tasks of cooking, farming, and nurturing. In an event that a family member especially the mother is disabled due to HIV infection, children take over responsibilities for the family. It is no surprise that a study by Esu-Williams et al. (2006) found young people providing care and support to people living with HIV/AIDS. Children are left to pick up some, if not all, the responsibilities when a family member is incapable.

In a study of young caregivers of mothers with HIV, the participants, four African-American and three European-American mothers, admitted that their children take responsibility for them as family members (Keigher et al., 2005). The authors used the data collected from these mothers to "develop a meaningful 'typology' of the care provided by the children" (Keigher et al., p. 886). They used narratives to examine the experiences of these children who care for their mothers who have HIV infection. The stories were told by seven women with HIV, who are single parents and have one to six children each. Keigher et al. described an experience of one family. Ms. R. is a single mother who has HIV, depression, and Hepatitis C. She has three children ages, 18, 10, and 6 and she depends on them to help. She describes the caregiving experience of her 18 year old daughter and 6 year old son, "My daughter is my caretaker. She learned about the medications and the side effects that they might cause. She knows how to test my blood. She is going to be a big help to me too. She went to a class for how to take care of me" (Keigher et al., p. 894). Her six year old “...became 'Mommy's little helper.' He'd get me things, rub my back and he'd go with me for chemo. He'd help me clean the tube in my chest. He liked to push the fluid in, or he'd help to give me a shot. He cried when I lost my hair, so I bought washable magic markers, and I used to let him draw on my bald head" (Keigher et al., p. 894).

Young caregiver roles are more pronounced if the disabled family member is a parent or grandparent. Shifren and Kachorek (2003) conducted semi-structured interviews with young caregivers who provided care for their mothers and fathers. The authors noted negative effects of caregiving on children's health. They reported that "early caregiving is not associated with poor mental health in adulthood for many young caregivers. However, some individuals do appear to be at risk for depression in adulthood (p. 338). Similar trends of negative effects of young caregiving were seen in other studies (Cree, 2003; Early et al., 2006; Gates \& Lackey, 1998; Keigher et al., 2005; Levine et al., 2005; Nigel et al., 2003; Pakenham et al., 2006; Robson et al., 2006; Shifren, 2001; Siskowski, 2006). 


\section{Impact of Caregiving}

Caregiving has significant impact on young caregivers' behavior, education, socialization, and emotional and physical health. Early caregiving by children can take away their lives as children and deprive them of their childhood (Aldridge \& Becker, 1993b; Frank et al., 1999). It also affects their family member's lives and family structure which can lead to tension and stress within the family. In most cases, it puts a financial burden on the family, yet there are positive aspects of caregiving to the family. Development of a tight family bond, strong relationships, and closeness has been reported by young caregivers taking care of a parent or grandparent. Most of the authors in these studies described the negative impact of caregiving on young caregivers.

Pakenham et al. (2006) used the YCOPI to investigate the psychosocial impact of young caregiving on the young caregivers. The factors measured by the YCOPI include caregiving responsibilities, perceived maturity, worry about parents, activity restrictions, isolation, caregiving compulsion, caregiving discomfort, and caregiving confidence. They found that young caregivers perceived maturity, sense of independence, caregiving confidence, personal growth, and enhanced self-efficacy as positive aspects of young caregiving. Similarly, Levine et al. (2005) noted that early caregiving may lead to a career in health and social service professions. Furthermore, higher income is a possibility as these young caregivers pursue higher education and careers in health related fields.

In a study to determine the effects of caregiving experiences on adult development of U.S. caregivers under the age of 21 years, Shifren (2001) interviewed 14 participants between the ages of 23 to 58 years old who were former young caregivers. The participants provided primary care to one or both of their parents when they were 21 years old and younger. The study utilized brief phone interviews with a semi-structured questionnaire to understand the effect of caregiving. Using the Early Caregiving Experiences and Mental Status instrument, the author looked at the long term impact of caregiving on young caregivers' adult development and aging. The authors reported more positive mental health than negative mental health as consequences of early caregiving. The findings were based on the analyses of 12 out of 14 participants who actually completed the brief phone interview and questionnaire.

Two years later, Shifren and Kachorek (2003) used methods similar to those used by Shifren (2001) to understand the effects of young caregiving on the mental health of young caregivers when they become adults. A sample of 24 participants completed and returned the questionnaire. The sample included 22 females, two males, 19 European Americans, one Asian American, two African Americans, and two Latino Americans. The authors reported the average age of the participants to be 36 years with an age range of 21 to 58 years. The researchers focused their data collection on early caregiving experience, mental health, and parent-child relationship. The Center for Epidemiologic Studies Depression Scale (CES-D) and semi-structured interview were used to examine early caregiving experience and assess negative or positive mental health. Shifren and Kachorek (2003) reported that the early age at which individuals started caregiving and 
the actual duration of the caregiving experience were not associated with mental health problems.

However, caregiving experiences of longer duration were associated with less positive current mental health. Shifren and Kachorek (2003) concluded that "beginning primary caregiving at a young age, even during childhood, does not have long-term negative consequences for all individuals providing such care" (p. 344). All participants in this study were 21 years old or under during the period of caregiving. Caregiving can be a positive experience, a sign of maturity, confidence and life satisfaction to some of the young caregivers, as well as provide opportunities for learning skills, closeness with family, feeling important, and feeling appreciated (Gates \& Lackey, 1998; Lackey, \& Gates, 2001; Robson et al., 2006). Nigel et al. (2003) echoed similar effects on young caregivers. They reported that young caregivers viewed caregiving as a "positive useful experience" (p. 41) that contributed to their maturity; development of life skills; and value of family life, love, and feeling of closeness.

\section{Behavioral Impact}

Keigher et al. (2005) and Pakenham et al. (2006) focused on the behavioral impact of early caregiving and found that young caregivers felt stigmatized, isolated, lonely, embarrassed, resentful, and rejected by school mates. Their aggression and fighting in school were thought to be related to caregiving responsibilities. These young caregivers tended to displace their anger, stress, and frustration at home to their school environment. The worries and problems of young carers $(\mathrm{N}=61)$ in Edinburgh were the focus of the study by Cree (2003). This study was conducted in four stages which involved detailed literature review, completion of questionnaire by young carers, nomination of participants who wanted to meet the researcher and tell more, and finally verbal and written feedback to the participants. Cree found that young carers had behavior problems. For example, one participant admitted trashing her room when she is angry. Another participant lost his temper with friends at schools and ended up in frequent physical fights.

\section{Educational Impact}

According to Siskowski (2006), young minority students who are caregivers, especially black and male students, are at a greater risk for detrimental educational consequences. In the secondary analysis, the author used existing data from What Works Survey compiled in 2002 from the students in 54 public schools in Palm Beach County to discover the effect of family health situations on young caregivers. The study focused on (a) the extent of students' family health situations and students' participation in caregiving, (b) self-reports of students regarding the effect of their family situation on their learning and academic performance, and (c) general characteristics of public school students with family health situations and those with a dual role as a student-caregiver. Of the 6,714 students in the study, about 39\% agreed or strongly agreed that being a 
caregiver hindered their learning. The author concluded that family health situations have adverse effects on the learning and academic performance of young caregivers.

Keigher et al. (2005) reported poor school attendance, pressure at school from teachers, poor concentration, and sleeping in class among young caregivers. Cree (2003) reported a high level of truancy with young caregivers. Nigel et al. (2003) noted that young caregivers struggled in school work and had issues related to keeping up with school work. In addition, caregiving took precedence over school, and two participants dropped out of school to provide care to a family member or sibling. The sibling or family member's behavior or disability disrupted homework and some young caregivers used lunch time to catch up on missed school work. Keigher et al. (2005) acknowledged that one participant in their study saw going to school as a way to escape from the situation at home. Others have reported that school serves as a respite for the young caregivers (Gates \& Lackey, 1998; Lackey \& Gates, 2001; Keigher et al., 2005; Nigel et al., 2003; Robson et al., 2006; Siskowski, 2006).

\section{Social Impact}

Being a caregiver puts pressure and stress on the social lives of young children. Socialization is hindered because of the caring responsibility (Nigel et al., 2003). Most young caregivers are from low socio-economic groups and less likely to travel for socialization (Nigel et al., 2003). Socially, young caregivers may encounter social restriction; not having friends; caregiving role inhibiting friendship; problems with friends all the time; activity restriction; isolation; higher responsibilities; helplessness; worry; and lack of recognition by friends, teachers, and health care providers (Cree, 2003; Early et al., 2006; Gates \& Lackey, 1998; Nigel et al., 2003; Pakenham et al., 2006; Siskowski, 2006).

\section{Emotional Impact}

The emotional impact of caregiving on young caregivers was reported by Cree (2003), Gates and Lackey (1998), Keigher et al. (2005), Nigel et al. (2003), Pakenham et al. (2006). Several studies have focused on the worries and problems that young caregivers face. Young caregivers worried about missing school, the care recipient's health, their own future, their appearance, younger siblings, friendship, and family relationships. They reported feelings of sadness, fear, anger, depression, anxiety, and stress (Cree, 2003; Gates \& Lackey, 1998; Keigher et al., 2005; Nigel et al. 2003; Pakenham et al., 2006).

\section{Physical Impact}

Young caregivers have physical health problems associated with early caregiving. These children are performing unsupervised tasks meant for adults. It is risky when no 
instruction is given to the young caregiver on various aspects of caregiving. Young caregivers may be put at risk for health problems and/or physical harm. Some young caregivers worry about being bullied at school. They reported using self-harm or taking drugs or alcohol to shut off from worries and problems of caregiving. Young caregivers have frequent mental health problems such as panic attacks, thoughts of suicide, and worries about their own health. Some have difficulties with sleeping, eating, and fatigue (Cree, 2003; Gates \& Lackey, 1998; Nigel et al., 2003).

\section{Grandparent Caregivers}

Reviewing grandparent studies, we find that grandparents take up a caregiving role due to different factors. Each has a different motivation and perception of the caregiving role. Grandparents may view their motivation to take up grandparenting as the only option or as a desire to provide a safe and loving environment for their grandchildren. For others it could be the only option in a society where human services will take the children. In most instances, the grandparents do not have any other choices than to assume the role. Apart from the obvious reasons for placement of grandchildren with grandparents, many take on the responsibilities out of a sense of obligation (Minkler \& Roe, 1993).

In a study by Minkler and Roe (1993), grandparents performed both parenting and grandparenting roles. Parenting promotes daily wellbeing of children, and includes responsibilities for the child's upbringing and decision making regarding the children's lives (Gage, Everett, \& Bullock, 2006; Jendrek, 1993). In a study to examine active and latent functions of grandparents during divorce, Johnson (1988) found that grandparents set up boundaries of what constitutes parenting and grandparenting. Grandparents saw each role as distinct in its way of functioning. When grandparents take up parenting, they are viewed as tough and strict. They are also seen more as disciplinarians. This takes away from the nice and gentle grandparents grandchildren are accustomed to.

\section{Grandparent Caregiving Role}

Grandparent caregiver roles can be formal or informal. Formal roles are associated with legal relationships such as custody. Informal relationships may mean coresidency of grandchildren with grandparents or grandparents providing child care to the grandchildren. Timberlake and Chipungu (1992) and Flaherty (1988) discussed the traditional roles of African American grandparents in the African American community and their strengths in family extendedness. Jendrek (1993) studied effects of grandparent caregiving on grandparents' lifestyles. The author noted that the effects of caregiving on grandparents' lifestyles differ depending on the type of care provided by grandparents. The effects were grouped into four categories namely, changes in relationships with friends, changes in lifestyle, changes in relationships with family, and changes in relationships with their spouse. The author reported different caregiver roles for grandparents as full custody, temporary custody, adoptive, assumed guardianship, live in 
without legal relationship and regular grandparents. Three major categories of grandparents were noted from the 114 samples. The categories were (a) grandparents living with grandchildren with whom there is a legal relationship, (b) grandparents living with grandchildren with whom they do not have a legal relationship, and (c) grandparents who provide care such as day care to grandchildren who do not live with them. These categories are custodial grandparents, grandparents living with grandchildren, and grandparents taking day-care roles, respectively (Jendrek, 1993). Bowers and Myers (1999) explored the differences between grandmothers who provided different levels of caregiving and the consequences of these levels of caregiving. The authors reported that grandparents are functioning in full-time and part-time caregiving roles.

Baydar and Brooks-Gunn (1998) used cluster analysis to identify four groups of grandmothers that included the homemaker, young-and-connected, remote, and frail. Homemaker and young-and-connected grandparents helped provide care for grandchildren. Other roles inside and outside the family, not necessarily providing care were fulfilled by remote and frail grandparents. Goodman and Rao (2007) reported on the role of grandparents in caregiving, and the coping of grandparents and grandchildren in the transition role. These authors examined how grandchildren viewed grandparents' roles and the changes in both parties' lives and relationships. The participants included six grandparents and five grandchildren living in a community along the U.S. and Mexican border. Three fulfilling roles of the grandparents used for the study were transitional, custodial, and co-parenting. Circumstances leading to grandparent caregiving determined the role a grandparent plays.

\section{Reasons for Placement}

There are several reasons why grandparents take care of their grandchildren. Some grandparents assume parenting and caregiving roles to protect or guide their grandchildren. Assumption of these roles can be immediate depending on the circumstances. Ruiz (2000) reported two patterns of caregiving role assumption by grandparents (i.e., immediate assumption and gradual assumption). Immediate assumptions reflect sudden role of caregiving "without warning" (Ruiz, p. 154). Gradual assumptions refer to grandparents who had "previous, and sometimes regular, experience caring for grandchildren" (Ruiz, p. 154). The analysis showed that grandparents are raising grandchildren for a variety of reasons. However, circumstances for the placement cut across ethnic and racial communities and the underlying reasons for assumption of grandparent roles were obligation, love, and opportunity.

Parental substance abuse was reported in most research studies as a reason for placement. The studies did not specify whether the substance was illegal drugs or prescription medications but did specify alcohol as a substance abused by the parents. Two studies used qualitative questionnaires and interviews to gather the data about grandparenting due to parental drug and alcohol abuse (Ruiz, 2000; Tompkins, 2007). Ruiz reported that $45 \%$ of grandparent participants assumed care of grandchildren due to

drug and alcohol problems of grandchildren's parents. The study by Tompkins noted in 
three separate and unrelated cases in the study, grandparents reported inappropriate parental lifestyles which included parental drug use. Goodman and Rao (2007) and Smith and Palmieri (2007) studied circumstances that led to grandparents taking custody of their grandchildren. These circumstances were related to grandchildren's parents being incarcerated, being unable to take care of their children, and having poor parenting skills. These circumstances were seen also as contributory factors to these grandparents serving in the role of parents.

Abuse of children by parents was seen another reason for placement of children with grandparents. Child abuse was described by Bowers and Myers (1999), Dowdell (2004), and Ghuman, Weist, and Shafer (1999). Some authors specified the abuse as physical (Smith \& Palmieri, 2007; Tompkins, 2007), mental (Ruiz, 2000), emotional (Smith \& Palmieri, 2007), and sexual (Ruiz, 2000). Other reasons noted are teenage pregnancy and parental incarceration, neglect, death, and health problems which include HIV/AIDs, physical disability, emotional problems, and mental problems.

Considering the socio-economic situation of the African American community, some grandparents become caregivers due to economic instability. These instabilities are housing problems and parental unemployment. Other reasons included removal of grandchildren from parental custody, divorce, parent needing a break, maltreatment of grandchildren, and parent failures or inadequacies. Most grandparents took up caregiving roles due to court order. Finally, most grandparents volunteered to take care of the children to prevent their assignment to foster care. Some grandparents did so because they were the only available individuals to rescue the children.

\section{Outcomes of Caregiving}

Irrespective of the reasons for grandparent caregiver roles, grandparenting can be stressful. At the age when some of these grandparents should be enjoying their lives, they are caring for their grandchildren. Grandparents are stressed and depressed and have burdens and concerns associated with this reverse role. The grandparents are faced with changes in their daily activities, personal, marital, and social lives. Also affected is their life satisfaction with assuming the grandparent caregiver role. Kivett (1991) reported that grandparents could be at different levels of life satisfaction when it comes to taking care of grandchildren. The satisfaction depends on why they assumed this role. Grandparents who were forced to take up this role and who performed it for a long period of life became dissatisfied (Johnson, 1988).

Positive outcomes of caregiving were noted in grandparent-grandchild relationships. Bowers and Myers (1999) reported excellent relationships with grandparents and grandchildren. In a pilot study, Tompkins (2007) explored the relationship between three grandparents and three grandchildren and found a positive relationship between grandparents and grandchildren. In a prospective cohort study of 54,412 participants, grandparents perceived their caregiving role as both stressful and rewarding (Lee et al., 2003). Bulter and Zakari (2005), Fuller-Thomason and Minkler 
(2001), Goodman and Rao (2007), Jendrek (1993), and Ruiz (2000) noted the positive aspects of grandparent caregiving. The authors reported positive aspects as emotional closeness, empathy, love, enjoyment with spending time with grandchildren, gratitude, and personal development. Ruiz (2000) used both qualitative and quantitative analysis to examine African American custodial grandparents $(\mathrm{N}=99)$ response to caregiving. The participants described custodial caregiving as a "burden and a blessing" (p. 155).

The burden of caring for grandchildren included worsening health, financial stress, loss of social life, marital problems, and loss of friends and family, to mention but a few. Frustration, anger, shame, feeling overwhelmed, anxiety, and time constraints were reported by Bulter and Zakari (2005), Dowdell (2004), Dowdell (2005), Goodman and Rao (2007), Jendrek (1993), Minkler \& Fuller-Thompson (1999), and Musil (1998). Some grandparents expressed frustration about their grandchildren's lives, their school homework, discipline, health, and clothing (Bowers \& Myers, 1999). Other grandparents expressed anxiety over their children's behavior and inability to take care of their own children (Bowers \& Myers, 1999).

\section{Summary}

A review of the literature reveals that some of the issues of early caregiving include children missing out on their childhood, performing tasks which are inappropriate for their age, and risking bodily harm. With a generational gap, most grandparents are not equipped to assist their grandchildren with their educational needs. Consequently, grandchildren do poorly in school. Other issues include unavailability of resources to help these children. Early caregiving by children can take away their lives as children (Frank et al., 1999). Early caregiving by children also affects their families' lives and structures leading to tension and stress within the family. In most cases, it puts a financial burden on the family. Early caregiving has behavioral, educational, social, emotional, and physical health implications for children. They may be angry, anxious, and socially isolated. They may act out in school and have low academic performances. Many children risk physical harm from lifting heavy loads.

There are also positive aspects of early caregiving to grandchildren. Development of a tight family bond and strong relationship or closeness was reported by young caregivers taking care of their grandparent. Pakenham et al. (2006) found that young caregivers perceived their own maturity, sense of independence, caregiving confidence, personal growth, and enhanced self-efficacy as positive aspects of being young caregivers. Similarly, Levine et al. (2005) stated that early caregiving may lead to a career in health and social services professions. Furthermore, they noted that higher education which accounts for higher income is a possibility as these young caregivers pursue careers in health related fields.

The majority of the studies reported in the literature looked at the effect of caregiving on young caregiver and the impact of parenting on grandparents. No retrieved study looked at the symbiotic relationships that exist between African American 
grandparents and their grandchildren. 


\section{CHAPTER 3. METHODS}

This chapter addresses the design, sample, and setting for sample recruitment; procedures for data gathering; procedures for the protection of human subjects; and the data analysis method.

\section{Design}

The purpose and desired outcome of the study determined the qualitative research method used. This case study described the experiences of custodial grandparents and their grandchildren in their symbiotic caregiving activities. Through case study, the accounts of events of caregiving activities and experiences for both grandparents and grandchildren were understood.

\section{Overview of Case Study Methodology}

To understand the world of grandparents and their grandchildren, the present study utilized case study narratives. According to Stake (1995), a case study emphasizes "interpretation" rather than "producing generalizations" (p. 7). Stake defined case study as "the study of the particularity and complexity of a single case, coming to understand its activity within important circumstances" (p. xi). It gives accounts of events from different perspectives. Robson (1993) defined case study as a strategy for doing research which involves an empirical investigation of a particular contemporary phenomenon within its real life context using multiple sources of evidence (p. 146). Case study strategies look at the particularity and complexity of a case to view and understand reality of life experiences (Parse, Coyne, \& Smith, 1985; Stake, 1995). According to Yin (1994), "a case study is an empirical inquiry that investigates a contemporary phenomenon within its real-life context, especially when the boundaries between phenomenon and context are not clearly evident" (p. 13). Yin (2003) described case study as preferred when a researcher desires to look on phenomenon or behavior which he or she has no control over. With multiple case studies, researchers are more concerned with selecting and depicting cases of varying or similar patterns. Similarly, Schultz and Kerr (1986) described "most similar case" and "most different systems" as the two strategies for conducting a case study. Contrarily, Feigin, Orum, and Sjoberg (1991) noted rigor as a concern in case study methodology and not purpose, unit of analysis, or design.

Stake (1995) outlined three different types of case study. An instrumental case study gives insight into an issue; an intrinsic case study works better when a researcher is looking for a deeper understanding of an issue or case; and collective case study involves studying of several cases to gain insight into a particular phenomenon. The decision on a type of case study to use relies solely on the purpose of the study. The present study is an instrumental case study which looks "beyond the case" (Stake, 2006, p. 8). Symbiotic caregiving relationship is the quintain for this multi-case study. According to Stake 
(2006), quintain is "an object or phenomenon or condition to be studied - a target, but not a bull's eye" (p. 6). The author also described quintain as "the arena or holding company or umbrella" (p. 6) of the case to be studied.

The purpose of case study is to allow a study to "retain the holistic and meaningful characteristics of real-life events- such as individual life cycles, organization and managerial processes, neighborhood change, international relations, and the maturation of industries" (Stake, 1995, p. 3). Weiss (1998) noted that case study brings together accounts of events seen through "multiple points of views" (p. 7) to understand each conceptual contribution. Furthermore, through case study, related events are integrated to understand conditions or circumstances. Case study involves observing one participant or multiple participants as a unit in which its interpretation can lead to change in popular notion.

Girden (2001) described case study as an involvement of "extensive observation of a single individual, several individuals, or a single group of individuals as a unit" ( $p$. 23). Case study is similar to psychological case-study techniques where case study gives an account of an individual situation or circumstance (Bromley, 1986). However, the purpose of case study in psychological research is to achieve a "desirable course of action" that can be implemented (Bromley, 1986, p. 3).

This proposed study is designed to provide an in-depth study of the "immediate and specific context" (Hinds, Chaves \& Cypess, 1992, p. 65-66) of symbiotic caregiving. To seek a greater understanding of how grandparents and their grandchildren view symbiotic caregiving, a narrative case of the stories of this dyad is critical. According to Merriam (1998), "qualitative researchers are interested in understanding the meanings people have constructed that is, how they make sense of their world and the experience they have in the world" (p. 6). On the other hand, Denzin and Lincoln (2005) reported that qualitative research looks at "answers to questions that stress how social experience is created and given meaning" (p. 10). So not only do researchers look for answers, they should be open to new discoveries within their studies. Merriam urged that researchers should be open to any possibility that can lead to "serendipitous discoveries" (p. 121).

According to Gummeson (2001) multiple case study uses several cases to make either specific or general conclusions about complex interrelations of social life.

Confidence in research can be achieved through the use of multiple case methods (Miles \& Huberman, 1994). According to Yin (2003), selected cases of multiple cases predict facts that may have similar or contrary results. These cases should not be decided based on representation of the case study (Stake, 1995).

In this proposed study, cases are chosen to ensure case replication. The number of cases reflects symbiotic relationship between grandparents and their grandchildren. It also shows the similarities that exist between and among symbiotic relationships between custodial grandparents and their grandchildren. Due to the importance of this research study and the data, multiple cases were selected to describe the phenomenon of symbiotic caregiving of custodial grandparents and their grandchildren. 


\section{Sample}

In a qualitative research study, sample size is dependent on the depth or breath of information needed. While depth of information is collected with smaller sample, a larger sample seeks breadth (Creswell, 1998; Patton, 2002). The population of interest for this study is custodial grandparents and grandchildren who are enrolled at the University of Tennessee Health Science Center Shelby County Relative Caregiver Program. This sample of custodial grandparents and their grandchildren was homogenous for gender, race and possibly for socioeconomic status. The determination for the inclusion criteria for grandparent age was based on reports by the Shelby County Relative Caregiver staff of custodial grandparents who would most likely require assistance from their grandchildren.

Grandparents who participated in this study met the following criteria:

- Had custody of one or more grandchildren and lived in the same household with these grandchildren.

- Were African American.

- Were between the age of 65 and 85 years.

- Were enrolled in the Shelby County Relative Caregiver Program.

Grandchildren participating in this study met the following criteria:

- Were between age 8 and 17 years.

- Lived with their custodial grandparents.

- Provided care to their custodial grandparent at most times.

- Attended elementary, middle, or high school.

- Had adequate cognitive and communication skills to participate in an interview.

Children younger than 8 years old were not selected, because at this age in development they lack deductive reasoning and cannot apply facts to situations (Inhelder \& Piaget, 1958). Also, children older than 18 years were excluded, because at this age young adulthood is attained (Erikson, 1963). Moreover, at this stage in life, most children may be out of the home and may have jobs in the community.

With the above criteria, this convenience sample included 10-30 grandparents and 10-30 grandchildren.

\section{Setting}

The study was conducted in Shelby County, which has a population of mostly African American (51.4\%) and white (42.6\%) residents (U.S Census, 2000). All interviews were conducted in the participant's home at a time that was convenient to the participant and the researcher. Participants were also given the option to meet the researcher for the interview at a site outside their home. All interviews were audio-taped 
and field notes were recorded during interviews. Field notes described the study setting, the researcher's observation of the setting, and non-verbal cues and behaviors from grandparents and grandchildren during the interview.

\section{Instruments}

Demographic data were collected from grandparents and grandchildren. Grandparents provided information about their age, race, marital status, occupation, current employment status, highest education completed in school, and number of custodial children (Appendix A). Grandchildren provided information about their age, gender, race, grade in school, number of siblings, ages and gender of siblings, and caregiving activities (Appendix B).

Schedules were used to conduct semi-structured interviews with grandparents (Appendix C) and grandchildren (Appendix D), respectively. Grandparents were asked about caregiving responsibilities for their grandchildren, grandchild caregiving activities, circumstances leading to custodial grandparenting, grandparent-grandchild relationship, and positive and negative effects of caregiving. Grandchildren were asked about their caregiving responsibilities and experiences, grandchild-grandparent relationship, and positive and negative effects associated with caregiving.

\section{Procedures}

Grandparents and grandchildren were recruited from a convenience sample of grandparents and grandchildren who were currently participating or had participated in the Shelby County Relative Caregiver Program. The researcher attended support groups sponsored by the Program to contact potential grandparent participants. Permission was obtained from the Program director to attend support group meetings and explain the purpose and procedures of this research study. The Relative Caregiver Program director and family advocates identified and talked to potential grandparent participants who could not attend support group meetings to determine their interest in participating in the study.

Those grandparents who were interested in participating in the study, as confirmed by Relative Caregiver Program director or family advocate, were contacted by the researcher. Contact was made by telephone to determine if participants met the inclusion criteria. If a grandparent met the inclusion criteria, the grandparent was asked questions to determine if one of their custodial grandchildren met the inclusion criteria. Grandparents self-selected the grandchild who provided them with the most assistance or caregiving compared to the other grandchildren in their custody. If qualified, custodial grandchildren were informed of the purpose and procedure of this research study.

The interviews were conducted in participants' homes. Grandparents and grandchildren each participated in data collection once during two different visits to their 
homes. The initial interview was conducted with grandparents, and interviews were conducted with grandchildren at a later date. Both interviews took approximately 1 to 2 hours of each participant's time. The researcher attempted to collect all data within a three month period (i.e., June, July, and August) when grandchildren are not enrolled in school. Written consent and assent were obtained from the participants. All interviews with custodial grandchildren were scheduled to avoid disruption in the children's academic lives. Interviews were collected in two different sittings, one for grandparents and one for custodial grandchildren.

To ensure validity and credibility of participants' accounts of events, member checking was conducted after transcription of audiotapes and analysis of the data. Member checking allows participants to correct errors in the researcher's interpretation of their responses and to voluntarily give additional information not given at the initial interview. Three grandparents and their grandchildren who participated in the initial interview were contacted to participate in the member checking procedure. Member checking was conducted in the participant's home or other convenient location such as a community center or public library. Each interview for member checking required approximately 30 to 45 minutes of the grandparent's and grandchild's time. These interviews were audio-taped, transcribed, and analyzed.

\section{Protection of Human Subjects}

Approval to conduct this study was obtained from the University of Tennessee Health Science Center Institutional Review Board (Appendix E). The researcher approached the grandparents and their grandchildren who met the inclusion criteria and who agreed to participate in the study to obtain informed consent and assent, respectively. The researcher reviewed the study with each potential grandparent and grandchild participant. Permission to discuss the study was obtained before the researcher proceeded with the consent and assent forms (Appendixes F and $\mathbf{G}$ ). Each grandparent and grandchild was encouraged to read and ask questions about the form. Following review of the consent or assent form, the researcher responded to questions and clarified the study if questions arose. Written informed consent was obtained from grandparents and assent was obtained from the grandchildren before beginning the interview process.

The principal investigator emphasized that the grandparent or grandchild could withdraw from the study at anytime for any reason. A copy of the signed consent form was given to the grandparent, and a signed assent forms was given to the grandchildren. Participants' rights during the study and the use of audio-tape recorded interviews were explained to the participants. Consent, assent, and demographic forms with identifying information were locked in a cabinet and separate from research study data. All transcribed data were number coded to avoid identification of participants. Confidentiality was maintained in the process of transcribing and analyzing the data and reporting the results. Approval from the University of Tennessee Health Science Center Institutional Review Board was also obtained to conduct member checking. 


\section{Data Analysis}

Grandparent and grandchild pair demographic data forms were visually scanned for missing data. These data were entered into the Microsoft Excel computer spread sheet program, version 11 for Windows XP (Microsoft Corporation, 2003). Verification of the accuracy of the data was done by crossing entered data with the data on each demographic form. For backup copies, participants' data files were saved on a computer disk. All data were coded to protect the participant's confidentiality and ensure anonymity. Participants were made aware of this. The data were maintained and stored in a locked file box. Information was accessed as needed by a procedure that helped maintain participants' confidentiality.

Interview data collected from grandparents and grandchildren were transcribed and entered into Microsoft Word (Microsoft Corporation, 2003). These Microsoft Word files were then imported into NVivo 7 (QSR International Pty Ltd, 2007) qualitative software. NVivo7 software for qualitative data analysis is "a quick and easy tool for storing and retrieving data. It provides the necessary tools to manage data, create codes, and search texts to aid in the analysis of data" (Netskills, n.d., p. 1). To ensure constant evaluation and assessment, the researcher interviewed participants and analyzed data concurrently, as Merriam suggested (1998).

A researcher, who does not perform the above procedure, takes a risk that the data have been "unfocused, repetitious, and overwhelming in the sheer volume of material that needs to be processed" (Merriam, 1998, p. 162). This method of data analysis gave the researcher a feel of and familiarity with the data. More importantly, it allowed the researcher to re-evaluate the interview guidelines and adjust the questions in the Interview Schedules for subsequent interviews with the participants.

Frequency distribution, percentage, and measure of central tendency (i.e., mean) were used to describe and summarize the grandparent and grandchild demographic data (Rosner, 1990). Content from each interview was organized as units of data and coded. The coded data were arranged into categories. Through analysis of these categories, emerging themes were identified. Cross-case analysis was conducted to explore the connections between individual cases and dyads to themes. After data analysis and coding, three grandparent/grandchild dyads were approached for member checking to validate and establish credibility of the research findings.

\section{Credibility and Validity}

According to Lincoln and Guba (1985), in other to establish trustworthiness and transparency of a study, the research findings must be convincing and persuasive. In addition, the credibility of research findings is based on this concept. The exemplar cases, the description of the data and subsequent write up shows the authenticity of the data. According to Merriam (1998), special attention should be paid to the research process 
which will also include findings and dissemination. To validate research data, member checking was explored. Member checking was used to improve the creditability and validity of findings in qualitative research. It is the most compelling technique used to establishing credibility (Lincoln \& Guba, 1985). Creswell and Miller (2000) noted that this process consists of "taking data and interpretations back to the participants in the study so that they can confirm credibility of the information and narrative account" ( $p$. 127). Stake (1995) illustrated member checking criterion with a case study in which the researcher made her case selection considering "accessibility and hospitality" of the research participants (p. 63).

For the current study, member checking occurred after transcription, coding, and analysis of all data. Three grandparents and three grandchildren were visited after their initial interviews and after the data were analyzed. These participants were selected based on grandparent and grandchild willingness to allow the researcher to return for a second visit for this process. Unwillingness to participate is one of the short comings of member checking (Lincoln \& Guba, 1985). In addition, during their initial interviews these participants gave detailed and vivid accounts of their lives as custodial grandparents and grandchildren. The researcher chose to return to these participants to make sure that their stories had been captured accurately. During the member-checking process, the research intended to gather more data that the participants may not have shared on the initial contact. No new information was gathered with this member checking. At the end of the member checking interview, a grandparent told the researcher regarding the researcher's interpretations of the grandparent's initial interview responses, "You have covered it well." Another stated, "Yes. That's what I told you." One grandchild response to researcher's interpretation of his initial interview responses is, “... This is basically it right there."

\section{Transferability}

In-depth, descriptive data are required for transferability of the findings to other researchers (Lincoln \& Guba, 1985). The present study provides detailed descriptive information on the sample and the setting of the study. Textual units of participants' responses during data collection are included in this write up to ensure transferability. Finally, since this researcher cannot specify the transferability of this study, the above measures were taken to ensure that any researcher with future interest in transferability of the data could do so accordingly.

\section{Summary}

This qualitative case study was designed to explore and understand the symbiotic caregiving relationship that exists in the custodial grandparent/grandchild dyad. Data were gathered through interviews with both members of the dyad who responded to questions through the interview schedules. These schedules helped ascertain the symbiotic caregiving relationship, the circumstances leading to symbiotic caregiving 
relationship, the effect of this relationship on the dyad, and the caregiving activities that grandchildren were engaged in. The results of the data analysis are presented by theme in the following chapter. To give meaning and authenticity to the analysis, these themes are supported by quotes from the dyad interviews. 


\section{CHAPTER 4. RESULTS}

The purpose of the present study was to describe the symbiotic caregiving of African American custodial grandparents and their grandchildren. This chapter details demographics of the grandparents and grandchildren and results of the data gathered during face-to-face interviews.

\section{Characteristics of Grandparents and Grandchildren}

The demographic characteristics of grandparents are shown in Table $\mathbf{1}$ and include grandparents' age, highest level of education, marital status, employment status, and number of custodial grandchildren. All grandparents were women and African America. According to Casper and Bryson (1998) and Fuller-Thomson and Minkler (2000), the chances of women becoming caregivers increases with African Americans. Respondents' age ranged from 65 to 85 years with a mean age of 71.4. All grandmothers lived with their custodial grandchild.

The demographic characteristics of the grandchildren are presented in Table 2 and include the grandchildren's age, gender, grade in school, number of siblings, and age of siblings. Grandchildren ranged in age from 10 to 17 years, with a mean age of 14 years. A majority of grandchildren were between the ages of 12 and17 years, male, and in high school. More than one third of the respondents had older siblings.

Selected characteristics of participants by dyad are presented in Table $\mathbf{3}$. These include grandparent and grandchild age and gender, grandparent's highest level of education, and grandchild's current grade in school.

\section{Themes Evolving from Grandparent and Grandchild Dyads}

The results include case studies of the everyday lived reality of the symbiotic caregiving relationship that exists between grandparents and their grandchildren. The data came from audio taped semi-structured interviews of grandparents and one of their grandchildren. Grandparents identified the grandchildren that engaged most in caregiving. The results reflect the overall themes that evolved from categories of codes. Direct quotations from the interviews with grandparents and grandchildren are used to support and give credibility to the themes. Pseudonyms are used in the direct quotations and other statements to protect the participants' confidentiality and maintain their anonymity.

The data from interviews with grandparents and grandchildren were carefully reviewed and coded. Codes from each new interview were compared to the codes from previous interviews to help determine which questions to emphasize during the latter part of the data collection process. Codes from all interview data were compared and cases 
Table 1. Demographic Characteristics of Grandparents $(\mathrm{N}=18)$

Characteristic

$\mathrm{n}$

$\%$

Age

$65-75$
$76-85$

14

78

$76-85$

4

22

Gender

Female

18

100

Highest Level of Education

Less than high school

High school diploma

7

6

AA degree

2

Bachelor degree

3

39

33

11

17

Marital Status

Married

2

Widowed

11

11

Separated

61

Single

1

5

4

22

Employment Status

Employed full time

$1 \quad 5$

Employed part time

Unemployed

211

Retired

14

5

Number of Custodial Grandchildren

$\begin{array}{lll}1 & 8 & 44 \\ 2 & 4 & 22 \\ 3 & 3 & 17 \\ 4 \text { or more } & 3 & 17\end{array}$


Table 2. Demographic Characteristics of Grandchildren $(\mathrm{N}=18)$

\begin{tabular}{lll}
\hline Characteristic & $\mathrm{n}$ & $\%$ \\
\hline
\end{tabular}

Age

$8-12$
$13-17$

Gender

Male

Female
4

14

22

78

12

6

66

33

Grade Level in School

Elementary school

Middle school

High school

Number of Siblings

No sibling

$1-2$

$3-4$

$5-6$

$7-8$

Age of All Siblings*

0- 5

6- 10

11- 15

16- 20

21- 25

26- 30
3

3

12

3
12

17

17

66

$\begin{array}{lll}0-5 & 1 & 2 \\ 6-10 & 13 & 24 \\ 11-15 & 10 & 19 \\ 16-20 & 15 & 28 \\ 21-25 & 13 & 24 \\ 26-30 & 1 & 2\end{array}$

$* \mathrm{~N}=53$ 
Table 3. Select Characteristics of Participants by Dyad

\begin{tabular}{|c|c|c|c|c|}
\hline & $\begin{array}{l}\text { Grandparent } \\
\text { Grandchild }\end{array}$ & $\begin{array}{l}\text { Age } \\
\text { Age }\end{array}$ & $\begin{array}{l}\text { Gender } \\
\text { Gender }\end{array}$ & $\begin{array}{l}\text { Highest Level of Education } \\
\text { Current Level in School }\end{array}$ \\
\hline \multirow[t]{2}{*}{$\# 1$} & Shirley & 65 & $\mathrm{~F}$ & $12^{\text {th }}$ grade \\
\hline & Tim & 16 & $\mathrm{M}$ & High school \\
\hline \multirow[t]{2}{*}{$\# 2$} & Sherri & 85 & $\mathrm{~F}$ & $7^{\text {th }}$ grade \\
\hline & Shun & 16 & M & High school \\
\hline \multirow[t]{2}{*}{$\# 3$} & Nancy & 79 & $\mathrm{~F}$ & $11^{\text {th }}$ grade \\
\hline & Tommy & 13 & M & Middle school \\
\hline \multirow[t]{2}{*}{$\# 4$} & Kim & 73 & $\mathrm{~F}$ & $12^{\text {th }}$ grade \\
\hline & Kena & 12 & $\mathrm{~F}$ & Middle school \\
\hline \multirow[t]{2}{*}{$\# 5$} & Pauline & 69 & $\mathrm{~F}$ & $12^{\text {th }}$ grade \\
\hline & Brian & 15 & M & High school \\
\hline \multirow[t]{2}{*}{$\# 6$} & Rose & 70 & $\mathrm{~F}$ & Undergraduate \\
\hline & Andrew & 15 & M & High school \\
\hline \multirow[t]{2}{*}{$\# 7$} & Clara & 67 & $\mathrm{~F}$ & $12^{\text {th }}$ grade \\
\hline & Kia & 15 & $\mathrm{~F}$ & High school \\
\hline \multirow[t]{2}{*}{$\# 8$} & Rhonda & 68 & $\mathrm{~F}$ & $10^{\text {th }}$ grade \\
\hline & Harry & 10 & $\mathrm{M}$ & Elementary school \\
\hline \multirow[t]{2}{*}{$\# 9$} & Opa & 73 & $\mathrm{~F}$ & $8^{\text {th }}$ grade \\
\hline & Jeff & 16 & $\mathrm{M}$ & High school \\
\hline \multirow[t]{2}{*}{$\# 10$} & Ann & 68 & $\mathrm{~F}$ & $8^{\text {th }}$ grade \\
\hline & Ruby & 12 & $\mathrm{~F}$ & Elementary school \\
\hline \multirow[t]{2}{*}{$\# 11$} & Patricia & 68 & $\mathrm{~F}$ & $12^{\text {th }}$ grade \\
\hline & Ryan & 15 & $\mathrm{M}$ & High school \\
\hline \multirow[t]{2}{*}{$\# 12$} & Gladys & 67 & $\mathrm{~F}$ & Associate degree \\
\hline & Marcus & 11 & M & Elementary school \\
\hline \multirow[t]{2}{*}{$\# 13$} & Brenda & 78 & $\mathrm{~F}$ & $12^{\text {th }}$ grade \\
\hline & Rachel & 14 & $\mathrm{~F}$ & High school \\
\hline
\end{tabular}


Table 3. (Continued)

\begin{tabular}{|c|c|c|c|c|}
\hline \multicolumn{2}{|c|}{$\begin{array}{l}\text { Grandparent } \\
\text { Grandchild }\end{array}$} & $\begin{array}{l}\text { Age } \\
\text { Age }\end{array}$ & $\begin{array}{l}\text { Gender } \\
\text { Gender }\end{array}$ & $\begin{array}{l}\text { Highest Level of Education } \\
\text { Current Level in School }\end{array}$ \\
\hline \multirow[t]{2}{*}{$\# 14$} & Phillys & 77 & $\mathrm{~F}$ & $10^{\text {th }}$ grade \\
\hline & Derek & 13 & M & Middle school \\
\hline \multirow[t]{2}{*}{$\# 15$} & Telena & 72 & $\mathrm{~F}$ & $12^{\text {th }}$ grade \\
\hline & Bob & 16 & $\mathrm{M}$ & High school \\
\hline \multirow[t]{2}{*}{$\# 16$} & Desiree & 67 & $\mathrm{~F}$ & Associate degree \\
\hline & Charles & 17 & M & High school \\
\hline \multirow[t]{2}{*}{$\# 17$} & Eva & 66 & $\mathrm{~F}$ & Undergraduate \\
\hline & Donna & 15 & $\mathrm{~F}$ & High school \\
\hline \multirow[t]{2}{*}{$\# 18$} & Mary & 69 & $\mathrm{~F}$ & $9^{\text {th }}$ grade \\
\hline & Carol & 12 & $\mathrm{~F}$ & High school \\
\hline
\end{tabular}

$\mathrm{F}$ denotes female gender.

$\mathrm{M}$ denotes male gender. 
were cross analyzed to identify patterns. The following five themes emerged from the data: 1) journey to custodial grandparenting 2) financial stress and financial needs, 3) grandparent and grandchild perceptions of caregiving role, 4) grandchild's care giving activities, and 5) grandparent and grandchild symbiotic relationship.

From the interviews with 18 grandparents and 18 grandchildren, selected grandparent/grandchild dyads will be used as rich exemplars of the symbiotic caregiving relationship that exists between grandparents and their grandchildren. The following analysis describes the selected dyads through the grandparent and grandchild descriptions of symbiotic caregiving, effect of this relationship on their lives, reasons for grandparent caregiving, and the nature and relationship between grandparents and grandchildren. Finally, findings from the multiple case study analysis reveal the grandparents' perspectives of the needs and resources that could help them cope more effectively while raising their grandchildren and also maintaining their own lives. From the grandchildren's perspectives, the findings reveal the caregiving relationship that the grandchildren engage in and the symbiotic and close relationship that exists between grandparents and their grandchildren.

\section{Case Presentations}

Following a description of each of the five themes, selected grandparent/grandchild cases will be used to illustrate the theme. The first theme will include identifying characteristics and a brief history of circumstances leading to the symbiotic relationship. Through the remaining four themes, interpretation of grandparent/grandchild symbiotic relationship will be presented as it relates to the financial stress, burden, and dilemma facing grandparents as they raise their grandchildren. Data that are relevant to both grandparent and grandchild perceptions of their assumption of the care giving role will be presented. Finally, through these interpretations, grandchildren's caregiving roles and their activities and personal feelings towards these roles will be presented. Excerpts as direct quotations are used in the text to give credibility to participants' responses during the interviews.

\section{Theme 1: Journey to Custodial Grandparenting}

Historically, grandparents' role has been viewed as nurturing. Family members looked to grandparents especially grandmothers for guidance while grandchildren viewed grandparents as individuals that shower them with love and affection. There will likely be a change in this equilibrium when grandparents assume the role of custodial grandparent. The expected norm of grandparent behavior changes when grandparents take custody of their grandchildren.

A major theme that emerged through the interviews with grandparents and grandchildren is that the grandparents assumed the responsibility of their grandchildren

for different reasons and circumstances. This theme describes the grandparents' journey 
to assuming the custody of their grandchildren. The theme captures the significant factors that lead to grandparenting. The journey to custodial grandparenting highlights circumstances leading to custodial grandparenting. This theme emerged from categories of codes that relate to kinship responsibilities of grandparents, grandparents to the rescue, and avoidance of shame of family situation. These categories were seen in the grandparents' responses as they assume the responsibilities of their children, who were unable to raise their own children. Grandparents reported circumstances under which they started caring for their grandchild(ren) due to their biological children's problems. These circumstances included incarceration, mental illness, death, drug usage, and challenging economic situation. Grandparents assumed care of their grandchildren because they were the only available family member to take up custody, and they wanted to prevent placement of their grandchildren in foster care. Some grandparents spoke of their experiences with this process.

During the interview, many grandparents shared their reasons for being custodial grandparents. Almost all of the grandparents were raising their grandchildren without the assistance of the grandchildren's parents. This is consistent with the report by PinstonMillburn, Fabian, Schlossberg, and Pyle (1996) who found that due to the several problems seen in family structure, many grandparents were raising their grandchildren without assistance from their grandchildren's biological parents.

\section{Rhonda and Harry}

Rhonda is a 68 year old widowed African American woman. She completed $10^{\text {th }}$ grade and now works as a part-time house keeper in a residential home. Rhonda has three grandchildren, two grandsons, ages 10 and 5, and a granddaughter, age 7 . Harry is a 10 year old male who attends a local elementary school where he is in the $5^{\text {th }}$ grade. Harry has two brothers who are 18 and 10 years old. The 10 year old brother is his step brother. Harry has three sisters who are 29, 15, and 7 years old.

Rhonda took custody of Harry in July 2006 although she has had full responsibility for him since shortly after he was born. Rhonda's daughter, Kia never took responsibility for Harry and Rhonda had him with her even though he occasionally went to spend time with his mother, Kia. Rhonda was awarded custody of Harry due to her daughter Kia's negligence of her children. The increasing negligence led to a social services investigation of Kia. Rhonda stepped in to take custody of Kia's children. Rhonda explained, "And I agreed to take custody of those children. They didn't ask me to take custody of them. I told them I would. The reason why I wanted to take custody of those other two children, I wanted all three of those kids to grow up together. Because a lot of times when they put them in these foster homes and foster care, they're separated. And I wanted them to grow up as sisters and brothers together. And that was my reason for taking them."

Emotionally, Rhonda explained that at the time of the interview, she did not know the whereabouts of her daughter, Kia. According to Rhonda, Kia does not know her way 
about and has not asked for or about her children for months. She concluded that it has been a long time since she last saw her daughter. She further stated, "I can't tell you anything about his mother. The last time I heard from her, she was living over there off Covington. But where she is living at now, I don't know. "Harry's father is not active in Harry's life because he is serving in an out-of-state prison. His crime was something that Rhonda did not want to share. Rhonda's circumstances leading to grandparenting are not unique but are consistent with the literature. Bowers and Meyers (1999) reported that events leading to grandparents assuming roles of taking care of their children can be a sudden or a long and difficult event. Sudden events include removal of children from a neglectful environment while long and difficult events include death of a parent or a parent's addiction to drugs or alcohol.

\section{Sherri and Shun}

Sherri is an 85 year old widowed African American. She has $7^{\text {th }}$ grade education, is retired, and stays at home with her grandson. Her grandson, Shun, is a 16 year old male who is a high school student in the $10^{\text {th }}$ grade. Shun has five brothers whose ages are 22 , 20, 15, 11 and 7, and two sisters whose ages are 21 and 18 .

From data based on the National Survey of Families and Households, FullerThomson, Minkler, and Driver (1997) found that one out of ten grandparents were raising their grandchildren for a period of a least six months. Many grandparents started caregiving early in their grandchildren's lives and they continued for a long period of time. About $28 \%$ of the grandparents started providing care to their grandchildren as early as infancy while $72 \%$ provided care to their grandchildren under 5 years old. Although Sherri assumed the caregiving responsibility of her grandchildren when they were very young, she has custody of only Shun. Sherri described the circumstances that led to her taking custody of Shun and his cousins. She portrayed her daughter Maggie as an unfit mother and vividly narrated the events that led to her taking custody of her children. "What made me get him, she got set out her apartment. And she had those children and it was hot, in June. They were sitting under the tree. The oldest boy went over there and told me she was sitting under the tree crying. And I called her and told her to bring me the children. I say I will take your children in for three months. That will give you time for to try to get you a place. Don't bring me none of the little money that you're getting for them. Just bring me the food stamps to help me out to feed them. Well, she never brought me the food stamps. I just had to struggle and feed them. And when time come for her to get them back, she wouldn't come and get them. And the oldest boy, he had to stay at the house and help them with the younger children. It was eight of them."

Sherri inherited the responsibility of taking care of her grandchildren from her daughter who did not return for her children. This caregiving responsibility fell on Sherri who presumably thought that Maggie would eventually return to take care of her grandchildren. Emick and Hayslip (1996) described the role of kinship caregiving as often inherited where closely related kin take over as caregivers when circumstances prevent biological parents from taking care of their children. Sherri traveled miles to the 
west coast to get her grandchildren who were abandoned by their biological mother, Maggie. While Maggie was neglecting her children, she became pregnant and another child was placed into an already troubled situation. Maggie brought her new baby for Sherri to see how pretty she was and left her baby with Sherri. That was the last that Sherri heard from her daughter, Maggie, who abandoned her baby girl. Sherri stated, "She had this other baby and she brought it to me for me to feed it. She said, 'I want you so see how pretty my baby was. She's five months old.' Now, she's nineteen years old and she never made it back by here. Just put her down like that and went on and never come back."

The circumstances of grandparents' taking up caregiving responsibility of their grandchildren affect the lives of the children, the grandparents, and the family as a whole. In Sherri's situation, her grandson Shun refused to return to his biological mother when Sherri wanted him to. Emotionally, Sherri shed light on what these grandchildren were going through. She narrated, "And when time for me to send him back home, he cried. He didn't want to go. And I looked at him. Now the child is crying cuz he don't want to go where mama is. He said he never could just go in and get food because she never keep nothing in the Frigidaire for him. He said when she cooked, she just cooked enough to go on everybody's plate around and that's it." Perhaps one of the reasons the grandchildren enjoyed staying with Sherri is the way she cares for them. She explained how she cooked enough food to go round to everyone. She stated that the grandchildren know that she cooks and provides them with food to eat.

\section{Phillys and Derek}

Phillys is a 77 year old single African American woman. She has $10^{\text {th }}$ grade education, is retired, and stays at home with her one grandson, Derek. He is 13 years old and enjoys middle school where he is in the $8^{\text {th }}$ grade. Derek has no siblings and lives alone with his grandmother.

Grandparents take up the responsibility of their grandchildren for different reasons. Some may not be issues that their own biological children can fully control. Goodman and Silverstein (2002) found that two out of five grandmothers assume the role of taking care of their grandchildren due grandparents' biological children's mental or emotional problems. This current study echoes similar findings that relate mental illness as one of the reasons for grandparenting. Phillys, who assumed custody of her grandchild when he was two 2 years old, admitted that she took custody of him because of his parents' mental illness, "Now both of them is mental, but Derek is not."

When sharing the reason she assumed the role of caregiver for Derek, she admitted that her daughter's mental illness was the ultimate reason. "And by her being mental, she didn't even know how to put diapers on the baby. And they was gonna put him in a home. And I told them 'no, I would keep him'." Phillys, Derek's maternal grandmother, took over the custody of him from his paternal grandmother who was terminally ill with cancer. Phillys claimed that the paternal grandmother signed over 
Derek to her because her illness prevented her from taking care of him.

\section{Telena and Bob}

Telena is a 72 year old widowed African American woman who completed $12^{\text {th }}$ grade and retired many years ago. She has several health issues including having two strokes, is no longer active, and hardly gets around. Telena has one grandson, Bob, who is 16 years old, in 10th grade, and looking forward to getting his high school diploma. He has three older sisters who are 24, 20, and 18 years old.

Telena took custody of her grandson because of the death of her daughter, Bob's mother. It was not easy for Telena to narrate the circumstances that led to her grandparenting. She described the death of her daughter who took ill on Friday and died on Monday morning. For Telena, it was more than a tragedy as she lamented how she died. The events that led to her death were still fresh on her mind. For a mother that has so much value for education and family dignity, her daughter's drinking problems were shameful for her. She related how her daughter's drinking led to her losing custody of her son and eventually led to her death.

She described an unfortunate event that made her take custody of Bob when he was three years old. Bob, who she described as very smart, got up one early morning with three pennies in his hand and headed to a neighborhood store. When Bob found out the store was closed, he sat in front of the store waiting for it to open. A neighbor who had watched for a long time called the police. Telena's daughter was found drowsy from drugs. She did not realize that her son had opened the door and headed to a nearby store. Her daughter lost custody of her son. Telena stepped up to assume custody of Bob and took him home with her to join nine other grandchildren whom she has custody of. Telena claimed that at one point she had custody of her 16 grandchildren due to different reasons and circumstances.

\section{Kim and Kena}

Not all grandparents took custody of their grandchildren because of unfortunate events. Many grandparents took up the custody to help their own biological children who may be going through some financial instability. The sentiment of helping their children has contributed to grandparenting. Kim took custody of Kena when she was born to help Kena's parents get back on their feet. Kim described it as helping her daughter, Latifa, and her husband pursue their lifelong dreams. She admitted that Latifa and her husband are active in Kena's life and that Kena goes to visit them frequently. Latifa is living in the East Coast with her husband and is in a professional school. She expressed, "Her parents are in Boston, Massachusetts. She's going to school. That's the one I tell you, um, is for the professional school."

Due to Latifa's schedule and her husband's work they could not afford the child 
care to keep Kena with them. Instead of Kim re-locating to the East Coast to baby sit Kena, she decided to remain in Memphis so that Kena could live with her and attend elementary school. Kim was particularly proud of Kena who has won several academic awards in the gifted school she attends. Kim's situation represents the least percentage of grandparents who take custody of their grandchildren to help stabilize their own biological children's economic situation. Kim felt blessed and happy that she is here to help her daughter become a better person. This finding is inconsistent with Renwick (1993) who found that grandparents experienced anger, shame, and embracement as they raised their grandchildren. According to Renwick (1993), these feelings would arise because most of these grandparents felt that "they have messed up in raising their own children" (p. 16).

Historically, African American grandparents have been known to take up the responsibilities of keeping the family together. One such responsibility includes raising not only their own children but also their extended family, orphans, and non-relatives. Most times, these responsibilities are carried out with joy and pride. It is different today. Although such a norm can be expected, it should not be viewed as what grandparenting is today (Cox, 2002). Grandparents in this study had different reasons for assuming custody of their grandchildren. One grandparent took custody of her grandchildren as a way to make sure that all her grandchildren were not separated by the foster care system. It can be emphasized not all grandparents' journey to grandparenting was due to unfortunate circumstances. A grandparent took custody of her grandchild in furtherance of her biological child's desire to attain economic stability through completion of her education. Finally, physical instability such as mental illness and substance abuse coupled with parental negligence lead to the some grandparents taking responsibility for their grandchildren.

\section{Theme 2: Financial Stress and Financial Needs}

Custodial grandparenting is a full time responsibility and definitely comes with its challenges. There is increased financial pressure and stress associated with grandparents raising grandchildren on a limited income. In the United Stated, 19\% of grandparent caregivers live below poverty level (U.S. Bureau of Census, 2002). The same data showed the poverty rate of African Americans as $22.7 \%$. Grandmothers were less likely to own their own home compared with grandfathers, had lower rates of employment than grandfathers, and were twice as likely to be poor compared with grandfathers. Several of the participants described the kinds of help they needed to ease the challenges of custodial grandparenting. Almost as often, most grandparents echoed financial help as the resource that would help them take care of their grandchildren. Most grandparents reported that they were living on their social security checks and small governmental assistance for the grandchildren.

To offset some of the financial stress encountered by the grandparents, they utilized an informal social support structure. This included but was not limited to family, friends, neighbors, and churches. Grandparenting can be a stressful life event for 
grandparents. Social support plays a vital role in alleviating this stress. According to Choi and Wodarski (1996), social support has served as a buffer for stressful life events such as divorce, death, unemployment, or spouse illness. The Shelby County Relative Caregiver Program was the one formal support that grandparents were very proud of. Several grandparents described how the program assisted them financially and otherwise. Many were pleased with their family advocate for taking time to care. The grandparents used the Relative Caregiver Program as a cushion for the increased responsibility and stress associated with grandparenting. According to the grandparents, the Relative Caregiver Program provided support similar to that described by Cohen and Wills (1995) as "regular positive experiences and a set of stable, socially rewarded roles in the community" (p. 311). Despite the formal and informal social support from grandparents' family, friends, neighbors, church, and the Relative Caregiver Program, some grandparents experienced extreme financial stress.

The theme of financial stress and financial needs captures the financial responsibilities of custodial grandparents as they raise their grandchildren. This wasone of the major concerns or stressors that the grandparents described as needing to be addressed so that they could take care of their grandchildren. It can be also viewed as one of the causes that could make a grandparent feel overwhelmed, frustrated, or even socially isolated. With grandparents living on a fix income with "little checks" coming in for their grandchildren, most were stretching their financial resources as best as they could . Categories emerging from the codes that eventually led to this theme include earlier constraints, cost of living, and lack of support. These categories lean more to grandparents' fixed income and the inability of the grandparents' own biological children to help financially with the caregiving. In the cases presented in this study, all grandparents were on a fixed income. Some received small social security checks. For most grandparents, it was hard making ends meet. Even more difficult was providing food and at the same time buying brand name clothes, electronic gadgets, to mention but a few, for their grandchildren. Perhaps the pre-existing constraints of their financial instability compounded their financial stress when they assumed custody of their grandchildren.

\section{Desiree and Charles}

Desiree is a 67 year old widowed African American who attended college and completed an associate degree. She retired many years ago. She lives with her grandson, Charles who is a 17 year old male. Charles is in the 11th grade and is looking forward to receiving his high school diploma. He has no siblings and lives alone with his grandmother.

When Charles' mother died very young of a terminal illness, Desiree was faced with the overwhelming responsibility of how to raise her three year old grandson. The financial stress was unbearable as she continued to give her best to raising Charles. As Charles advanced in age, Desiree's responsibilities increased along with the financial stress. Gibson (2005) examined the challenges that grandparents face in raising their 
grandchildren. Her study showed that financial stress was seen as more of a hardship than the discrimination associated with intergenerational parenting. Also, Gibson found that grandparents who were living in poverty and assuming the new role of raising their grandchildren experienced more financial stress.

Desiree described her experience of intergenerational parenting as hurting the pocket book. She admitted that she receives a little money that goes toward feeding herself and her grandson. She barely has enough to provide clothing for her grandson. She explained, "We just have beans and cornbread, some tea or something. Some cool aid or something like that. He don't ever complain. He just eats what's here. That's all we can do. No, we ain't rich. We don't have no money. And they (the Relative Caregiver Program) really help me with him and helped me with my light. You know helping me with my light bill. Last year, they had to give me \$500 on my light bill."

Desiree's account provided insight into the suffering of millions of grandparents raising their grandchildren today. Waldrop and Weber (2001) found that a majority of custodial grandparents' problems were associated with financial hardships. This hardship put extra strain on the family system and also affected the child involved.

\section{Ann and Ruby}

Ann is a 68 year old widowed African American woman who completed the $8^{\text {th }}$ grade and is now retired. She has custody of her 12 year old and 8 year old granddaughters and her 10 year old grandson. Of these three grandchildren who live with her, her granddaughter, Ruby, helps her the most. Ruby is 12 years old and is in the $6^{\text {th }}$ grade. Ruby does not have any siblings. Ann has custody of grandchildren from her other biological children; these grandchildren are Ruby's cousins.

Ann, like many grandparents, took custody of Ruby unexpectedly. Ruby's father is incarcerated and her mother's whereabouts are unknown. Ann took custody of her grandchildren when her daughter took them to a friend and never came back for them. Since then, Ann has struggled financially to raise her grandchildren.

She lamented about how hard it was trying to send the children to school because of her fixed income. She continued, "Okay because it was hard with me trying to send them to school. For them to have the stuff that they need and all. Well, I don't work and the only little check I get. Well, when I get my check, it's $\$ 657$ and that's all I get. I don't have any more money. Then they ADC gives them \$232 and that's the money we have all the month". Although Ann gets help from her sister and her daughter, life has been tough on her. She advised that she would appreciate it if the government could increase the pay to the grandchildren to $\$ 25$ a week. Transportation was a concern to her as she did not have a car. At the time of interview, she wondered how her grandchildren will go back to school because her daughter that has been helping her found a job. When asked why they could not take a school bus, she answered that they are in optional school which requires parents to drop the kids off by themselves. Clearly from Ann's narrative, she is in a 
financial crunch and is not very happy about the whole financial situation. She admits that the Relative Caregiver Program helps her and she owes them her gratitude. She explained, "I wouldn't been able to buy those clothes for them to start to school. I tell you, those (Relative Caregiver Program) caregivers, they are really nice about it because they come get them and they takes them to the basketball. They take them and try to get them off me a while. They good about that. And that's why I say, you know, since they have been helping me, it's a lot easier than it was for me. Ms S. just bought some clothes for them to start school in."

\section{Telena and Bob}

Telena is a 72 year old widowed African American who completed the $12^{\text {th }}$ grade and retired many years ago. She has several health issues including having two strokes, is no longer active, and hardly gets around. Telena has one grandson, Bob, who is 16 years old. Bob is in the $10^{\text {th }}$ grade and is looking forward to receiving his high school diploma. He has three sisters who are 24, 20, and 18 years old.

Grandparents, especially the grandmothers in the African American community, have the role of providers for their children and grandchildren. Many are lacking in their resources and capabilities to manage these responsibilities as they are overwhelmed by the financial stress of raising their grandchildren. In a qualitative study, Gibson (2005) interviewed 17 African American grandmothers about their grandchildren's success, absence of biological parents, adult success, and socio-economic support. The findings revealed how grandparents were taking jobs to earn money to provide for their grandchildren.

Telena who took custody of Bob when he was three years old has been struggling to take care of him and her other grandchildren. She sometimes relies on her daughter who helps whenever she can. Telena's concerns were consistent with Gibson's (1999) findings in an earlier study that examined the experiences of African American grandmothers raising their grandchildren. A total 12 African American grandmothers were interviewed. Grandmothers expressed concerns regarding a lack of finances to care for their grandchildren emerged from grandparents' concerns regarding their new grandparenting roles.

Telena explained that there is a different type of financial stress with this generation as compared to when she raised her own children years back. She continues, "It's different now because when I raised the first eight, time wasn't as hard as it is now. I got to raise these here different because when I had the others I was working. Things I could give the others, I can't give these here because I just simply don't have the money. And the thing about it, the three I got they only give me \$256 and \$398 stamps. That ain't gonna feed no child high as groceries is. So I got to take my money, which I don't get but $\$ 700$ and take care of them. But I don't mind. I don't mind because they Lord ain't gonna let me suffer." 


\section{Clara and Kia}

Clara is a 67 year old single African American woman who completed the $12^{\text {th }}$ grade and recently retired. She has custody of her five grandchildren, four granddaughters who are 17, 16, 15, and 11 years old and a 13 year old grandson. Her 15 year granddaughter, Kia, helps her most with care giving. Kia is in the 9th grade. Kia's siblings include two brothers who are 18 and 10 years old and three sisters who are 29, 15 , and 7 years old.

Clara elaborated on the struggles that she faces in her grandparenting role. The case of Clara and Kia illustrates one of the themes that recurred in the grandparent interview responses. When asked about her responsibility to Kia, Clara responded, "Money, as far as taking care of her (Kia), I have a problem with money, the money, and transportation. We don't have transportation. So I have a problem with transportation and money because it takes a lot."

This comment shows the problems most grandparents face in raising their grandchildren. In their work, Graff et al. (2007) found that custodial grandparents were in great need for financial help in raising their grandchildren. The study highlighted specific financial needs by this population. In this case Clara openly explained the financial help she needed to raise her grandchildren. Although she did not identify where she believes the help could come from, she wanted her grandchildren's educational needs met. She stated, "They('re) in school. They need supplies. They need uniforms and I've been helped with that, you know. And if they're having a project at school, then we have to buy everything they need for the project. And it takes money, sometimes, that I don't have. So I have to take from one place and put it there and then I have to try to get that back. Like for instance, the house rent or light bill or something like that. I just get enough a month to pay for that. You know, so mostly that's what I'm having problems with."

\section{Patricia and Ryan}

Patricia is a 68 year old African American widow who lives with four grandchildren who are in her custody. She completed the $12^{\text {th }}$ grade and is now retired. She has custody of two granddaughters, ages 11 and 10, and two grandsons, ages 15 and 13. Her 15 year grandson, Ryan provides care to Patricia and helps her more than the other three grandchildren. Ryan attends a local high school where he is in the $10^{\text {th }}$ grade.

When asked if she has comments to add regarding taking care of her grandchildren, Patricia replied: "The uhm, you know the only thing that I can say that, ya'll need to try to get more money for the grandparents. To help out with the grandparents. With raising 5, with 5 kids in my household, it takes every penny that I, come in here for these kids. I don't have a lot of money for myself. What I get, I have to put it in here to care for them to go to school and feed them and do what I have to do for them." 
Patricia further explained where she expected her help to come from. She lamented how the government does not help the grandparents in raising their grandchildren. She admitted that the government refused to give her food stamps to feed her grandchildren. She reflected on how the grandparents are left-out individuals that actually need help. She blamed the government for giving all kind of assistance to the young girls. Patricia believed that as a grandparent, she worked so hard all her life for her life savings. It seems very unfair to her to use her savings to raise her grandchildren.

Patricia concluded by stating: "And they think that the grandparents done worked all, we done worked all our life and we got to use it on these grandkids. That's one thing that you really need to look at because a lot of grandparents don't draw what I draw. A lot of them. If I hadn't worked so hard and social security and retirement. If I had a house note, I couldn't do it. And right now, I got my taxes to pay. Back taxes. I been thinking all day. And I just put that boy in college and now I got to scrap the tax money up and pay it. That what happens with the grandparents. We are on a limit income. Now that's what somebody needs to push help for grandparents."

Roger and Jones (1999) reported that financial responsibility of raising a grandchild was one of the main stressors grandparents experience. The cases in this theme echo views. Only one grandparent whose narrative was used to illustrate this theme has an associate degree. Other grandmothers have a high school education or less. At the time of interview, one grandparent just retired, however, she expressed that she did not have enough even when she was working. She barely made it every month with paying her bills, feeding, and clothing the grandchildren. This supports the fact that there were pre-existing financial constraints or constraints before the grandparents took custody of their grandchildren. Financial stress increases as grandparents take up grandparenting responsibilities. Circumstances leading to the grandparents taking up a caregiving role and the absence of their biological children in their grandchildren's lives contributed to increased financial stress. One of the grandparents stated that she does not have enough money for herself. Another grandparent stated that she simply does not have money. Although none of the grandparents in the study have returned to the workplace in order to have money to raise their grandchildren, Young and Smith (2000) reported that some grandparents have resorted to returning to the workplace. The authors reported that retired grandmothers have returned to work to help them fulfill the need and education of their grandchildren.

\section{Theme 3: Grandparent and Grandchild Perception of Caregiving Role}

Grandparents' perception of their role as grandparents is changing. There will be a major difference when earlier grandparent perceptions are compared to their perceptions of their role today. Historically, grandparents viewed their role as one of occasionally assisting their grandchildren, especially during the grandchildren's visit over summer vacation. In most situations, this still applies today; however, the perception is entirely opposite for custodial grandparents. 
With grandchildren, grandmother is viewed as the loving person who gives them hugs and kisses. This affection may be viewed from a distance if grandchildren visit their grandparents only during summer vacation. The reverse may be the case today for custodial grandchildren who live with their grandparents. The grandchildren's perception of their relationship with grandparents depends on many variables, variables that may be different when grandchildren are custodial grandchildren.

Wilson (1984) explored mothers' and grandmothers' perceptions of parental behavior and interactions between grandchildren and their grandmothers using the Bronfenbrenner's Parental Behavior Scale. He conducted interviews with grandmothers, mothers, and children between 8 and 14 years of age in 60 African American families. $\mathrm{He}$ found that grandmothers perceived their grandparenting role as controlling and demanding.

On the part of grandparents, Johnson (1988) reported that grandmothers tend to demarcate the boundaries between parenting and grandparenting. They see clear distinction on what is required from parenting as well as grandparenting. Although parenting and grandparenting may involve children and grandchildren alike, they both offer the similar benefits to a child. According to Platt-Jendrek (1993), parenting entails getting involved in the day-to-day activity of a child. It also consists of parents taking up decision making responsibilities for the well-being of their child. This description is the same with grandparenting as most custodial grandparents acting in this capacity view themselves as parents.

The theme of grandparent and grandchild perception of caregiving roles includes both positive and negative expectations related to symbiotic caregiving. For grandparents, these perceptions of caregiving role come with caregiving role satisfaction. The same perception applies to the grandchildren. The categories of codes that merged into this theme include motivation, feelings, and life satisfaction.

Many of the grandparents and grandchildren in the present study stated that grandparenting had positive rewards. Some of the participants saw their role as either grandparent or grandchild as satisfying and gratifying. This is consistent with the findings of Roger and Jones (1999) which showed that grandmothers had a positive attitude towards caring for their grandchildren. They also expressed positive rewards coming from this role. Due to the situation their grandchildren were in or due to the circumstances leading to grandparents assuming the custodial role, many grandparents reminisce about the best possible decision to assure that their grandchildren will be adequately taken care of. Similar sentiments were found in Roger and Jones (1999) study. Grandparenting is not only rewarding but adds a whole new meaning to the grandparents' lives. Many grandparents believe that their grandchildren are the reason for their being here on earth or their grandchildren keep them going (Graff et al., 2007) and keep them young at heart. Williamson, Softas-Nall, and Miller (2003) reported that grandmothers see parenting their grandchildren as a new dimension to life which makes them feel young again. 


\section{Phillys and Derek}

Phillys is a 77 year old single African American woman. She has a $10^{\text {th }}$ grade education, is retired, and stays at home with her one grandson, Derek. He is 13 years old and enjoys middle school where he is in the $8^{\text {th }}$ grade. Derek has no siblings and lives alone with his grandmother.

Phillys lives with Derek in a modest home built for them by the government. Derek attends a nearby middle school which he travels to by bus using the public transportation system. Derek's grandmother explained that he had an option to attend the neighborhood school within his district but she opted for a gifted school. She believes the gifted school will give Derek a better life that she and Derek's parents did not have.

Phillys lives with Derek in a modest home built for them by the government. Derek attends a nearby middle school which he travels to by bus using the public transportation system. Derek's grandmother explained that he had an option to attend the neighborhood school within his district but she opted for a gifted school. She believes the gifted school will give Derek a better life that she and Derek's parents did not have.

Phillys' perception of assuming caregiving responsibility for Derek is unique but still similar to other grandparent caregivers. Phillys assumed the responsibility of Derek because his parents have mental illness and are unable to take care of him. Phillys sees so much potential in her 13 year old grandson. She took the role of parenting rather than grandparenting. When other grandparents are enjoying the luster of their golden years, Phillys is parenting the second time. She perceives Derek as her son rather than as her grandson. She explained, "Well, he doesn't... By caring for him, it's done got just like my own child because I been had him every since he was 2 and he is 13 now. I taught him to go to the bathroom because when I got him, he was still in diapers. Taught him how to go to the bathroom. And I taught him how to read and write and care for hisself, how to bath hisself." She further stated, "You know I enjoy. You know his company too. I don't want to be in this house by myself. I just thank God that I got him for company. He looks out for me. He goes to bed early. I go to bed early too. I like that. So, I just thank God for him. I try to do everything I can to make him happy. "

Similarly, Derek's perception of his caregiver role is more than caregiving for his grandmother. He sees it as an opportunity to make a difference to the woman who raised him. He explained, "What caused me to help her was like all the years she has spent raising me. I should, like, repay her for like, taking care of me. That was years and I'm still doing that now." Also, he sees his caregiving role as a family obligation. He explains how his aunty advises him to make sure that his grandmother adheres to her prescribed diet. Derek stated, "Like she always tells me to make sure that my grandma does not eat anything that's too salty or too seasoned for her. And make sure that she also take her medicine." The opportunity to help his grandmother and fulfill a family obligation can be inferred from his statement description about taking care of his grandmother. "It's a blessing because I'm helping out a person, like one of the oldest people in our family. " 
Derek's perception of his caregiving role in his response below shows that he sees care giving more than caring for this grandmother. Derek described a filial obligation toward his grandmother. "Well, I started helping her when I was little. When I was little, she... she always talking about how she used to take care of me and when I got a little bit older and I learned how to talk I said, 'Now that you took care of me, it's my time to take care of you.' So uhm, I've been taking care of her for a long time ever since I was little. We were living in an apartment then, just me and her. And she got kinds of sick then. So, I was doing stuff for her then. And I wasn't probably no taller than a stool. So, yeah I've been helping her for a few years."

A study by Dellmann-Jenkins et al. (2000) focused on the service needs of young adult children and grandchildren in a primary caregiver role. Participants included 43 children and grandchildren aged 40 years and younger. Their responses to open-ended questions generated three main themes of rewards, one of which was generational reciprocity. This theme of generational reciprocity is consistent with Derek's perception of assuming the role of caregiver to his grandmother. Derek noted, "When I was little, she took care of me. She could hardly care for herself. Like she didn't hardly have no clothes, but instead she was putting my clothes on my back and paying for me to wear and go to school in. She didn't really have clothes for herself. She was so busy about trying to get me to the hospital, she was sick herself. Like she didn't let me know, but I know. I knew. So I was steady trying to help her in any way I could. And like, if she was feeling down some days and she didn't even want to get out the bed, I'll try to go up there... Might burn you everything, but I would try to fix her something to eat." He continued to explain, "Well, she put a roof over my head. She feeds me. She takes care of me. She buys me shoes. She put me in check when I get out of line. She disciplines me. She puts me in church. She loves me very dearly. Whenever, if I want to do anything, she will always say, 'I'm right behind you 100\%.' Once I told her about the dance thing, she was like, 'Well whatever you do, I'm behind you 100\%.','

\section{Patricia and Ryan}

Patricia is a 68 year old African American widow who lives with four grandchildren who are in her custody. She completed $12^{\text {th }}$ grade and is retired. She has two granddaughters who are 11 and 10 years old and two grandsons who are 15 and 13 years old. Her 15 year grandson, Ryan provides care to Patricia and helps her more than the other three grandchildren. Ryan attends a local high school where he is in the $10^{\text {th }}$ grade.

Patricia expressed that she had some regret about how she raised her own children. She recalled a couple of times that she never saw her children before they went to bed. She worked in the hospital where her shift started at about $2 \mathrm{pm}$. She would be on the way to work when her kids came home from school. She left work at 11:00 pm to get home when her kids were already in bed fast asleep. Her perception of her role of raising her grandchildren may be quite different from others. She explained, "You know, he's a 
little; he's a boy that loves me. Tells me everyday and night and night (that) he loves me. (He) hugs me. You know what, he's just... I have to tell it. He loves his mama. I have had more time. I didn't have that time with my kids that I (have) had with him. I was on the go working night and day when I had my kids. It was just, I raised them. (I) sent them to school. But I didn't have no time. I was always at work. I worked at night, 3-11 and 11-7. When I was coming in they were going to school most of the time. But this is the closest that I've been with kids. With them cuz my husband had them in the afternoon when I was (working) 3-11. I just didn't have all this close(ness). It's just something, you know, this is ... raising them; I feel like this is what I should have had with my own kids. That I didn't have. The only thing I did was wash and hang their clothes up and called them all in the evening or at night. Ok, get your work. Make sure you take your bath so you can go to bed. When I got home, they were sleep."

Ryan understands the symbiotic relationship that exists between him and his grandparent. When asked what made him decide to help his grandmother, he responded, "Because she help(s) me." In addition, Ryan stated, "She do(es) a lot of stuff for me. She's got too old to be doing all that stuff... I feel comfortable doing anything she asks." He also acknowledged that his grandmother takes care of him and keeps him out of trouble.

\section{Rhonda and Harry}

Rhonda is a 68 year old widowed African American woman. She has a $10^{\text {th }}$ grade education and now works as a part-time house keeper in a residential home. Rhonda has three grandchildren, two grandsons, ages 10 and 5, and a granddaughter, age 7. Harry is a 10 year old male who attends a local elementary school where he is in the $5^{\text {th }}$ grade. Harry has two brothers who are 18 and 10 years old and three sisters who are 29, 15, and 7 years old.

Rhonda has custody of all three of her grandchildren. She took the custody of Harry and then gained custody of the other two grandchildren later. She narrated changes Harry went though thinking that the other two grandchildren will eventually take over his relationship with his grandmother. Rhonda expressed her love for Harry. Pruchno (1999) reported that grandparents' care giving satisfaction is enhanced when they keep a positive and loving relationship with each other. With all the grandparents interviewed in this current study, none of their biological children lived in the households. The absence of the grandchildren's parents may have contributed to a more positive symbiotic relationship in the grandparent-grandchild dyad.

Rhonda's perception of her role is that of parenting. She sees herself more as a parent to her grandchildren. She takes it upon herself to ensure that they learn lifelong lessons as they become responsible adults. She explained, "I want him to grow up knowing that, the responsibilities in life. That you can't just grow up idle in this world and be a do nothing person. I try to instill in all three of them to want to be somebody. To want to do something with their life. Don't just grow up and not have no goal and don't 
look forward to being nobody. And I want them to grow up and be responsible kids." Grandparents' perceptions of the assumption of a caregiving role influences their satisfaction with the role. According to Roger and Jones (1999), grandparents find satisfaction in their caregiving when they know that their grandchildren are adequately cared for. Although Harry was unexpectedly thrust into the care of Rhonda due to his father's incarceration, Rhonda has done all she could to raise a well-mannered child who she bragged about before the interview began.

Sometimes, she finds herself defining who she is to all her custodial grandchildren. Her role perception is evolving depending on the age of each grandchild. As they advance in age, she lets her grandchildren understand her relationship with them. On each occasion, she reminds them that she is the grandmother and the mother. She did express openly that she loves her grandchildren and that they have a good relationship. She noted, "It's a good relationship. He knows that (I am his) grandmother. I'm not (his) mom. I'm just a substitute for (his) mom. That's their mother right there. That big picture right there that big picture you see up there" (Rhonda pointing at a family picture on the wall).

The ambiguity that Rhonda feels about her perception of her role in raising her grandchildren is not isolated but unique to many custodial grandparents. Rhonda understands that she is just a grandmother to her grandson, Harry, and that his biological mother is still out there. The efforts that Rhonda takes to explain to her grandchild her

role may not be an easy task because at certain age and cognitive levels, children may not be able to appreciate the differences between grandparenting and parents. This is may be reflective of grandchildren whose grandmothers took custody of them at a very early stage in their lives. It is not surprising that grandchildren and grandparents may echo the same sentiment of role ambiguity. Harry, Rhonda's grandchild, does perceive his caregiving role as one that will make him more responsible. He derives joy knowing that he is helping his siblings and grandmother. He explained, "I just love helping my grandma. It made me be more responsible."

\section{Brenda and Rachel}

Brenda is a 78 year old widowed African American who completed high school and retired many years ago. She lives alone with her two granddaughters, ages 20 and 14 . Rachel is 14 years old, in the $9^{\text {th }}$ grade, and has one sister who is 20 years old. Brenda assumed custody of Rachel when she was born. Rachel's father is deceased and her mother's whereabouts are unknown as of the time of the interview. Rachel helps to take care of her grandmother always. Brenda claimed that assuming custody of Rachel affected her lifestyle. She was unable to go places that she previously went. Rachel's presence meant that she had to take Rachel with her all the time. Brenda stated that she was not sure if taking custody of Rachel affected her blood pressure, but she further explained that likes her granddaughter and they get along well. She claimed that she and Rachel do things together. 
Brenda, like some grandparents, was unexpectedly thrust into taking responsibility for the care of her two grandchildren without coping strategies (Cox, 2002). According to Brown, Jemmott, Outlaw, Wilson, Howard and Curtis (2000), grandparents' expectation and perception is more of occasional assisting with taking care of their grandchildren. Grandchildren visit during vacation time and special occasions to enjoy time with their grandparents. The current norm of custodial grandparenting is not a traditional expectation of their roles. With this situation, grandparents are perplexed as they try to understand their perceptions of role assumption as custodial grandparents.

Perception of assuming the role of custodial grandparent may differ depending not only on the circumstances leading to the assumption of this role but also when this role assumption began. Brenda is a grandparent who has had responsibility for her granddaughter since her granddaughter's birth. According to Brenda, Rachel was brought directly from the hospital where she was born to her house. She described, "We've been together all the time. She was here in the house with me all the time. You know, born and came from the hospital to the house. She (has) been raised up here with me all the time.

Rachel was very ambivalent about her role as caregiver. She is adamant about the way she wants to be raised by her grandmother. She complained that her grandmother is overprotective and does not allow her to enjoy her life. It is worth noting that Rachel is 14 years and going through adolescence. She asserted, "Well, I don't really think I do anything bad. It's just that I consider her kind of overprotective. And she (is) just worried about me all the time. And when I try to do certain things, she'll probably say 'No'. Or she'll want to know who I'm with and stuff like that. And she just want(s) to make sure I'm safe. That kinda does get on my nerves, cuz I want to go. I just don't want to be in the house all the time." Rachel stated that she understands that her grandmother loves her and does all of these out of love. However, it is hard for her to comprehend because she says that her grandmother "needs to loosen up sometimes." Rachel continued to lament over the fact that her grandmother should try to understand her and know where she is coming from. It is hard and boring she stated, "Just try to understand me more and try to get where I'm coming from. I know that she already has her mind set, but I want her to think about how I feel sometimes, you know. Being in the house all the time is not really fun. Basically, it's kind of boring."

\section{Desiree and Charles}

Desiree is a 67 year old widowed African American who attended college and completed an associate degree. She retired many years ago. She lives with her grandson, Charles who is 17 years old. Charles is in the $11^{\text {th }}$ grade and is looking forward to receiving his high school diploma. He has no siblings and lives alone with his grandmother.

Desiree became a new mother when her daughter, on her dying bed, asked her mother to raise her son Charles. Crying, Desiree narrated how her daughter, a very 
outgoing and promising young lady became suddenly ill at work and was taken home. In two days she was diagnosed with a terminal illness. To Desiree it did not seem real that cancer kills just like that. In less than two years after her diagnosis, Desiree's daughter Mercy died. Desiree who was overcome with emotion said, "My daughter when she was on her dying bed, she told me to take everything that she had and take him. She left me with him. You know I had to change my life. You know the things I was doing. You know, trying to work too. But I still went on the work because the children here, they helped me with him until I retired from work."

Desiree described how she became a new mother. Her perception of her role at that moment was to accept Mercy's little baby and nurse him as her own child. It was difficult for her and her husband, but they continued going. They hoped, prayed, and relied on God for the future of Charles who recently reached his $17^{\text {th }}$ birthday. As Desiree continues to take care of Charles, she is fortunate to have the support of Charles' father who is very active in Charles' life. She explained that her daughter and Charles' father were friends who happened to have a child together. Mercy never married Charles' father, but he has been active in Charles' life. This situation makes Desiree have a different perception of her role as a custodial grandparent. She noted, "It was. It was. It was hard. Losing a daughter and then turning around (and) rais(ing) him. She didn't have but one child. And then turning everything all way around again. Because my children were up and grown. All my children had gone to college and (were) out of school. Then but we had to turn around... "It hurt her so bad. That was a hard pill to swallow. Sometimes we still think about her. We couldn't hardly take that. Almost a baby. A little newborn baby. I think he was on (the) bottle, you know. And you know, your life turn(s) upside down when you have to stop doing what you got to do and go back to raising him. So I just raised him on up just like I did them (my children). My husband told me, he said 'Well, let's just take him and raise him up just like we did ours.' So that's what we did. And today, (He says, 'Mom this. Mom that.' And you know, he's smart. We don't have no trouble out of him. He go(es) to school every day, rain, snow or whatever. And he be with his daddy on the weekends."

Desiree is happy that Charles' father is in his life and that helps her out during the weekend. She said that her grandson looks forward to going to see his father. His father's presence has not been a distraction between Charles and his grandmother. This is contrary to previous literature on interaction between grandparents, grandchildren, and their biological parents. According to Gibson (1999), African American grandparents experience difficulties when they are caught up up in providing for the grandchildren and the grandchildren's biological parents are involved in their lives.

Charles perceived his role as both a grandchild as well as a helper. He said that he enjoys helping his grandmother and he derives happiness from helping those less fortunate than him. He stated, "You('re) supposed to help elderly people. People that can't (help) themselves too much." He appears to have accepted his life and his fate as a young child who lost his mother, is being raised by a grandparent, and is shuttled between his father's home and his grandmother's home. He appreciates the role that his grandmother plays in his life. Desiree's perception of her role is one of a teacher (i.e., helping with his school work) and advisor (i.e., dealing with his friend issues and dating). 
Desiree recalled that Charles is dating a girl that she feels is in a higher financial category than they are. She also reported that the girl is from a different race. It worries her when the girl comes to her neighborhood to see her grandson. She has assumed the role of advising her grandson on living a responsible life. Emick and Hayslip (1996) noted that African American grandparents play the roles of teacher and supporter in matters dealing with employment, dating, and family problems.

In conclusion, feeling of emotions, motivation, and life satisfaction may be how grandparents and their grandchildren perceive their roles as caregivers. The members of the dyad are thrust into their circumstances due to no fault of their own. In addition, these circumstances are beyond their control. In the cases presented under this theme, grandparents perceived their roles as both grandparents and parents to their grandchildren. Their life satisfactions come from taking up a caregiving role when they view it as helping their grandchildren become responsible adults. One grandparent stated that she feels good with assuming a caregiving role as she is helping her grandchild become someone in life. Most of these grandparents are motivated to give the best that they can afford to their grandchildren.

Grandchildren's perception of caregiving is not far from their grandparents. One grandchild perceived his caregiving role as an opportunity to make a difference in the life of a woman that has raised her. Many perceived their caregiving role as a helper. One grandchild stated that he expects others to help him when he at the same situation as his grandmother. Although one granddaughter perceived her role as a helper to her grandmother and a role that was born out of love, her caregiving role is still buried under her current stage of adolescence. The granddaughter described remaining at home with her grandmother as basically boring.

\section{Theme 4: Grandparent and Grandchild Caregiving Activities}

According to White and Brinkerhoff (1981), Midwestern U.S. parents tend to assign household chores to their children. Parents claimed that these chores helped in their children's moral development and the development of a work ethic. Blair (1992) described two reasons parents were motivated to encourage their children to engage in household chores. Parents saw it as a "socializing experience" where the children could develop their own personal traits. Another reason why children took up household chores was their response to circumstances around them. This is consistent with grandchildren who decided to take up caregiving responsibilities because of their grandparents' physical disposition. Grandchildren performed instrumental tasks such as cleaning, cooking, grocery shopping, and running errands, to mention but a few. This finding is consistent with the results of Blair's (1992) examination of data from the 1988 National Survey of Families and Households. Blair reported that children between the ages of 5 and 18 years performed more than $10 \%$ of household chores. These household tasks included washing dishes, cooking, laundry, and cleaning. Some grandchildren take up caregiving responsibility because of the physical disposition of their custodial grandparent.

This theme explains the caregiving activities that grandparents engage in and 
grandchildren perform at home. The caregiving activities of young custodial grandchildren are many times underestimated or unknown. Instrumental tasks, sibling tasks and miscellaneous tasks were the categories of codes that contributed to this theme. Although some of these tasks may be directly related to their grandparents, grandchildren helped take care of their siblings. Instrumental tasks are illustrated above and included cleaning, cooking, grocery shopping, and running errands. Sibling tasks included babysitting siblings and helping siblings with home work, to mention but a few. Miscellaneous tasks included helping grandparents with medications, medical care, keeping grandparents company, reading to grandparents when they have poor eye sight, and ensuring that grandparents adhere to dietary and medical treatment ecommendations.

Traditionally, African American grandparents, especially grandmothers, give higher priority to the needs of their children than their own (Ruiz, 1999). Being the primary caretakers of their custodial grandchildren was one of the activities performed by the grandparents. Contrary to the tradition of grandparents occasionally assisting with grandchildren's care, grandparents in this study performed numerous activities to keep normalcy in the lives of their custodial grandchildren. These activities were not limited to child rearing or parenting but included helping with school-based activities, the grandchild's social events, home work, doctor's visits, and parenting grandchildren with special needs.

\section{Phillys and Derek}

Phillys is a 77 year old single African American woman. She has a $10^{\text {th }}$ grade education, is retired, and stays at home with her grandson. Phillys has one grandson, Derek, who is a 13 year old. Derek enjoys middle school where he is in the $8^{\text {th }}$ grade. He has no siblings and lives alone with his grandmother.

Phillys took responsibility for Derek due to his parents' mental disabilities. Phillys stated that she has been a caregiver and parenting for Derek since he was a toddler, "He was 2. I done had him every since he was 2. "Phillys provided for Derek in various ways not limited to parenting. She also stated that "By caring for him, it's done got just like my own child because I been had him every since he was 2 and he 13 now. I taught him to go to the bathroom because when I got him, he was still in diapers. Taught him how to go to the bathroom. And I taught him how to read and write and care for hisself, how to bath hisself. Now that's one thing he do, he brush his teeth behind every meal. So, you know I told you about he had to go today to get his teeth clean. I got to get him there and then I catch different peoples that hauls folks and get them to take him a lot, take us a lot of time. Because I have to try to get in there and sign the papers and things. You know, for the doctor to see him."

In summarizing her responsibility to her grandson, Derek. Phillys explained, "See, I got responsibility. I got a child in there I have to teach him right from wrong and see if he got everything on. The school he go to up there...... He got to wear velvet laced up shoes. He have to have a belt on. They have to have their pants up on him. His shirts button correct and have to have a haircut. He got to go today get his haircut. He have to 
go to school decent. Have to wear undershirt under his top shirt all the time. And he have to have the shirts with the school name on them, but the pants just be black. He can wear black pants. But the shirts we have to get them from the uniform place where there be the name on it." Phillys claims to be very involved in her grandson's academic life. Derek also understands and appreciate his grandmother's caregiving activities for him.

Derek took up some of his care giving responsibilities to aid his sick grandmother who has multiple health problems. With his grandmother teaching him at an early stages how to perform some of the care giving tasks, it is no surprise that Derek does more than an average child of his age. "I have heart trouble and I have kidney problems. And I can't eat nothing that's salty. He has to fix food twice because he fix(es) mine without salt. He puts salt in his."

His grandmother's full description of Derek and his care giving tasks in her own words gives a vivid idea of Derek' responsibilities. She narrated, "Well, he do(es) more than the average child cuz the average child don't do nothing, but empty garbage or something like that. He have to mop. He'll cook. (He) clean(s) my bathroom up more often because a lot of times when I go in there, I been done used it before I can get my under clothes down. And then he got to get his bleach water and go back in there and take the mop and go over, you know, sometimes. You know I really hate for him to do that, but a lot of times, I can't do no better. Like this morning, I sitting on chair because I didn't want to pee on it. I had him laughing. I said, 'I ain't taking my medicine until she come and go and then I'm gonna take my medicine.' Just like when I do go to church. I have to take one of these things (She pointed to a disposable paper toilet seat cover on the table) over you put over the top of the commode. I'll take that in a paper sack. So, he gone in there first and give to the usher to put in the bathroom in a paper sack. And then if I have to use it, I can put it on the commode and put it back in the paper sack. When we get ready to come home, I go in the bathroom and sit it outside the window. And told him to go over there and get it and put it where we can carry it back. And you know, I know that he don't want to be doing that, but he act(s) like he don't mind. He have (a) Bible and he open up the services in church. He can read real good. He reads the Bible."

When intimate tasks such as this are involved, there is a tendency for the grandchild to be angry or embarrassed. Derek showed some embarrassment in doing this activity although he did not openly discuss it. He asserted, "The ones that I'm not sure about is like having to clean up the bathroom. But I'm alright with everything else that she tells me to do." He also stated that he performs care giving activities such as helping his grandmother cook and making sure that she gets the proper diet that is recommended for her medical conditions. He explained, "Like she (aunt) always tells me to make sure that my grandma does not eat anything that's too salty or too seasoned for her. And make sure that she also take(s) her medicine." In addition, he stated, "The things I do for my grandmother is like I cook for her sometimes. (I) go to the store when she needs something. (I) calls somebody when she can't call nobody. (I) usually tell her like who all calls her and help clean up and do chores around the house."

Despite the caregiving activities that Derek has, when asked if the activities affect him in any way, he stated that they do not affect his life, his academics, or relationship 
with his grandmother, "No, it doesn't affect any. It doesn't affect my school or relationships either." Derek's grandmother outlined some caregiving activities that Derek helps her with. She added, "And he keep(s) me company. (He) keep (s) your mind occupied. That make(s) you have a good mind when you have something to look forward to. But if you sit up in the house by yourself, just me, nobody to talk to nothing to do. You ain't got no responsibilities, you'll soon go down. See, I got responsibility. I got a child in there I have to teach him right from wrong and see if he got everything on."

\section{Pauline and Brian}

Pauline is a 69 year old single African American who lives with her grandson, Brian. She completed the $12^{\text {th }}$ grade and is retired. Pauline has custody of Brian who is 15 years old and in the $9^{\text {th }}$ grade. He has two brothers and 2 sisters whose ages are 24,20 , 18 , and 13 . Brian helps to take care of his grandmother who is not mobile by providing her with extensive care.

Pauline took up grandparenting of Brian due to the death of Pauline's daughter. Pauline stated that her daughter was on drugs and "on the street" all the time. This led to her being murdered six years ago. Pauline's caregiving activities for Brian not only include grandparent but stretched to taking Brian to doctor's appointment for his medical condition when her son was there to help. She states, "He (Brian) had asthma real bad. When he wasn't running to the doctor with him, I was." Pauline also stated how she takes Brian for yearly physical examinations and actively involved in his school activities. Grandparenting for Pauline includes Brian being raised to be a responsible individual. She explained how she trains Brian, "Well, I'm 69, but I don't feel 69 mental wise. Just physical wise because my body... Cause I still put my foot down slowly and he listens. I still got rules and he listens. It's not affecting me at all." She is very satisfied with the person Brian has become so far. She stated, "And now he's showing me some of the things that I taught him. I need him now and he's able to do it."

Pauline admited that due to her medical conditions, she can hardly perform her activities of daily living. She relies on Brian to help her. Pauline assumed custody of Brian when he was 9 years old due to the death of his mother. Brian started helping Pauline when he turned 13 years of age. Pauline stated, "Yeah, I had arthritis when I got him, but it got worse and now I got a wheel chair that I use sometimes and a walker. And I can't do some of the things I used to do. And he sometimes clean(s), (he) help(s) me clean. He cleans the house. Mop. Sweep." Pauline further stated, "Well, when I don't feel...like I need something, clothes or something hanging in the closet, he'll bring it to me. He helps make my bed and sometimes he has to help put my shoes on. Help me to get my shoes on."

Brian specifically explained the caregiving tasks that he has at home. He admitted that he can take control of the house when his grandmother is not doing well medically. He claimed, "Uhm, like when she's hungry and says she hungry. There's nothing in the kitchen, I will walk all the way over there... Walk up to Papa's grocery store and I'll get her something to eat. When she needs her medicine, I'll walk all the way down to 
Walgreen's and get her medicine for her. And like around the house, if she's had surgery a stomach surgery sometimes the doctors will need some(one) to do it at home, so they teach me. I wanted to learn how to go inside her stomach and remove the bandages and the foam and replace that with other like foam and do it all over again. So like I help her with her clothes when she washes up and stuff like that. If she need(s) anything, I'll go get it for her."

When Brian was asked if he had any caregiving responsibility that he felt uncomfortable doing for his grandmother, he hesitated and then explained, "Well, I didn't feel comfortable... Like I had to stick my hand in her stomach because that was kind of creepy, at first. But I got used to it and I know that I had to do it because it would make my grandma better. So, I had went on and did it and I'm comfortable with it now. " He continued, "Before we moved out here to Jackson. She was very sick one day and I asked her, 'Did you want me to call the doctor?' And she was like, 'No, I'm okay.' But later on that night, when we fixing to go to sleep and I went back into her room and check(ed) on her. She was sweating real bad. So, I called the doctor and they came up there and checked on her."

Pauline's medical conditions affected Brian although he repeatedly stated that his caregiving activities did not affect him in anyway. However, he told a story which started with, "Well I know that it's hard for me to try to go to school and worry about my sick grandma at home." He continued to narrate that when his grandmother was very sick, he

did not want to go to school and leave her alone. He was afraid that something bad would happen to her. His grandmother decided that he needed to go to school. He claimed that he reluctantly went to school but his entire mind was at home. He remembered not concentrating at school but leaving privately to use a cell phone to call his grandmother. He further stated, "And there have been times when she was real sick at school. I have, I had to check me out of school. And I had ran from my school all the way home, just to see how she was doing."

\section{Brenda and Rachel}

Brenda is a 78 year old widowed African American woman who completed the $12^{\text {th }}$ grade and retired many years ago. She lives alone with her two granddaughters, ages 20 and 14 . Rachel is 14 years old and is in the $9^{\text {th }}$ grade. Brenda assumed custody of Rachel when she was born. Rachel's father is deceased and her mother's whereabouts are unknown as of the time of the interview. Rachel helps to take care of her grandmother always. Brenda claimed that assuming custody of Rachel affected her lifestyle. She was not able to go places as she previously did. Rachel's presence meant that Brenda had to take her all the time. Brenda stated that she was not sure if taking custody of Rachel affected her blood pressure but she further explained that she likes her granddaughter and they get along well. She stated that they do things together.

Brenda's caregiving tasks to her custodial grandchildren are rooted in her religious belief. Her faith in God has influenced the way that she is raising Rachel. She 
asserted, "They are practically good children because I raised them in church. They both go to church.... "Explaining her caregiving responsibility to Rachel, Brenda stated. "No, because we've been together all the time. She was here in the house with me all the time. You know, born and came from the hospital to the house. She been raised up here with me all the time," She enjoys the taking care of Rachel and Rachel's presence in her life.

Brenda claimed that her granddaughter provides her with company in the house. She explained, "They are company to me. If they weren't here, I'd be here alone. And I'd rather have them as company because people are doing so much to elderly people. So, they really (are) not affecting my life. I enjoy them and I hope they enjoy me. Uhm hun." Brenda also enjoys the caregiving task of cooking that her granddaughter Rachel performs. When asked if her Rachel cooks, Brenda noted, "Now she can cook cookies. She buy(s) cookies in a roll and cut(s) them up and put(s) them in the oven. And she can cook an egg or make some toast or something like that. She don't go deep into cooking, which she does need to know how to do that of course."

Rachel's caregiving tasks are consistent with Bird and Ratcliff's (2000) reports. These authors related that children participate in family tasks that are grouped into mealpreparation, childcare, maintenance-and-repair, management of family activities, financial management, cleaning, and lawn-and-garden tasks. Rachel claimed that she helps her grandmother check her blood pressure. "I help her with her blood, take her blood pressure and stuff with the little thing. And I help her get up, out of chairs. I have to pull her up all the time." In addition, she stated, "When she ask(s) me to do something, I'll do it. Like, if she want(s) me to wash the dishes, I'll do that. Sometimes, I'll do it when she doesn't ask me. I'll just wash the dishes or I'll mop the floor. Clean up the bathroom. I'll clean up my room. Things like that or like if she forget(s) something, I'll have to remind her sometimes. Like with medications. Like she's supposed to do something."

\section{Clara and Kia}

Clara is a retired 67 year old widow with three grandchildren, two granddaughters and a grandson (ages 15, 10, and 7). Kia is the grandchild that helps Clara the most. Kia is 15 years old and is in the 10 grade. She has two brothers ages 18 and 10 and two sisters with ages, 29, 15, and 7. Clara assumed custody of Kia when she was a baby. Clara stated, "She's been with me every since she was first born." When asked where the parents of Kia are, she reluctantly said that they are "on drugs." She explained that it was tough for her at first but over time she became accustomed to the situation. She noted,

"Well it's been a blessing and it's been a burden. And I guess because it wouldn't been so burdensome had I been in real good health. And because a lot of things, you know, we're in the house a lot and I can't see that they get out and have the activities like they should. And it's sort of been a burden for them. Because you know, they don't get out as much as I know that they should." 
In this grandparent/child dyad, Clara's grandparenting activities include tasks she performs to make sure that Kia grow up to be a productive adult. She noted, "From how they was raised, they didn 't... It's a lot that I am trying to instill in them now, but they're doing better because they practically raised themselves." Clara took custody of Kia because her daughter's drug abuse. Clara did expressed concern that her granddaughter may have been affected with drugs injected by her biological daughter. She described Kia's behaviors because of this assumption: "...the 15 year old, she kind of, how can I say, they were kind infected about, with the drugs from their mama being on it. So they're kind of hyper. She's not bad or nothing like that. But concentration, you know." Brenda, like other grandparent parenting their grandchildren, is involved in their academic lives and school activities. She expressed her desire to help her granddaughter for school and the coming school year. At the time of interview, Kia was on summer vacation and was looking forward to starting eleventh grade. Clara noted, "I think getting ready back, ready for school. And I think that's probably why I feel like getting back into this school thing."

Certain caregiving tasks that the grandchildren perform are not directed towards the grandparents only. Grandchildren assume the task of taking care of their siblings when grandparents cannot. This finding is consistent with Bird and Ratcliff's report (1990) which shows that grandchildren perform caregiving activities such as caring for siblings. Clara explained that Kia carries out instrumental tasks such as washing dishes, cleaning the house, and helping with her siblings. Clara explained the help that Kia provides at home as, "She do(es) the dishes. She has two brothers, one brother, one sister, and she helps me. She helps me a lot by doing their hair. She braids and she helps me do their hair. And well, like all kids, sometimes they're helping and sometimes they don't want to help. You know, but you know. I raised seven kids, so that's what they do. And far as, uhm she's the oldest. She's 15. And so I depend on her some."

Clara described an event earlier this year when she was hospitalized for more than a month. She stated that Kia helped with most of her medications. Her grandchildren help her by making certain that she takes her medications every night and morning. She stated that they were usually concerned that she takes her medicine when she is not feeling well. In addition, she explained how Kia helped with her intravenous medication. She noted, "I had to have intravenous, I guess you call when they put the needle in your arm and you take the infection medicine through your arm. Yeah, antibiotics. She would do that, the one out there because I had to have it I think for 50 something days because my toe got infected."

Clara admitted that she is fortunate that Kia takes over and helps her. She continued, "It's a lot that I am trying to instill in them now, but their doing better because they practically raised themselves. So she helps me like with the dishes. (She) help(s with) taking care of her brother. Seeing if they bathe and stuff like that cause sometimes I have chronic amnesia. So sometimes she do kind of take over and make sure that their hair (is) combed and they take a bath and stuff like that." Kia's responses were similar to the activities that her grandmother said that she performs. When asked to explain the types of tasks that she performs for her grandparent, she reported that she helps to clean the house, cooks, and makes herself available each time that her 
grandmother needs her. She went on to say that she reminds her grandmother to take medication, and she cleans the yard.

\section{Patricia and Ryan}

Patricia is a 68 year old African American widow who lives with four grandchildren who are in her custody. She completed the $12^{\text {th }}$ grade and is retired. She has two granddaughters who are 11 and 10 years old and two grandsons who are 15 and 13 years old. Her 15 year grandson, Ryan, provides care to Patricia and helps her more than the other grandchildren help her. Ryan attends a local high school where he is in the $10^{\text {th }}$ grade.

Patricia assumed custody of Ryan when he was 8 years old and his parents left him. Patricia claimed that they are out in the street. When asked why she believed that Ryan started caring for her, she responded, "They just get up and help me out. One thing, they think about my age. They (are) afraid of me dying. They don't want me to die cuz, they don't want to go anywhere else. They want to stay with me. And if I say my head or anything hurt(s), you can tell they get sad. They (are) afraid of me dying or they gonna have to go anywhere else."

Patricia knows that her grandson sometimes worries about her age, but this has not limited her in caregiving tasks she performs for her grandson. Patricia is Ryan's primary caretaker and has been performing caregiving tasks for Ryan since she assumed custody of him. She lamented how she practically raised Ryan and her other grandchildren, although she took custody of Ryan when he was 8 years old. She expressed, "They haven't been taught, you know, how to really care for theyself. But they doing good now, but when I first got them, they just didn't know about about they suppose to take a bath every night and how to care of themselves... but they have to be told a lot of things to do..., it is a lot of responsibility on me."

In addition, Patricia described how she has been taking care of her grandchildren and the caregiving tasks that she performs for them. She explained, "That's all I get. And I take care of them out of my retirement. I don't get no help." She went further to describe her grandparenting caregiving activities, "Since I had them, my whole life really been focused on them, sending them to school. Making sure they get there and their clothes and things are clean. That's all I have to focus on. And they have been in games, football games, every since I had them. I take them skating. I guess I been thinking I'm a little young parent because I've been running to football games, to the movie. You know, my life has been around them. You know."

She understands the challenges involved in raising grandchildren of Ryan's age. She noted, "What every little 11-year-old boy, you know they don't have a lot of experiences." However, she talked so highly of the young man that she has raised, "Good, he just like a old, old man. He just like a old... He respects me, you know. He respects me. And he just mannerable. He do what I say do. Don't talk back. I guess 
because I've been here with him all the time. I here. I pick him at school. All his life I've taken him to school, picked him up. I'm right here with him all the time. And just like... He's 15 years old, he don't run the street either. He go and play. He have to be here at a certain time. He's here. He's just been under my supervision all the time and he respects that. "Patricia admitted that she takes Ryan everywhere that she goes, "He go with me all the time."

Ryan helps his grandmother with caregiving activities. She explained that Ryan's responsibilities at home include helping take care of his siblings. He ensures that they are safe when they get out to play. Ryan helps her with mowing the lawn and is very involved in cleaning the house and washing the dishes. She continued, "Yeah. Yeah. Now they wash dishes. The one 12, he's a smart little boy. All of them is really smart. He mops and you don't have to tell him to do a lot of things. He'll get up and do it on his own. The things he knows to do, he'll ask me if he can mop the den and doing things. They're better." Clara stated that her grandchildren go to grocery stores - they make the grocery list together and she sends them to the grocery store. She described Ryan as "just like a grown man. The 15 year old can do anything. That boy can fix the commode, I don't even have to call a plumber. He can do all that. Well, my son is a supervisor at a Memphis company and he (has) been close with him (Ryan) ever since I've had him. He (Ryan) can do all plumbing. He can unstop the commode, the sinks. He do all of that. I mean, he's just like a 20 year old or 30 year old man. He can do all of that."

Ryan reiterated what his grandmother stated. When asked about his responsibilities at home, he noted that he takes care of his siblings and makes sure that they are not getting into any trouble. In addition, he does hardware repairs at home just as his grandmother described. Ryan asserted, "Clean up. Fixing her car. Fixing her table. And everything. The air conditioner and all that." He also explained, "About 3 or 4 weeks ago, her tail light was out and she was about to go pay a man about a hundred something dollars to fix it. So, I fixed it for free so that she won't have to pay nobody."

A societal definition of childhood may not include some of the caregiving activities performed by the grandchildren presented in these cases under this theme. Two unique cases include grandchildren who took up caregiving responsibilities that may be difficult for their peers to perform. One grandchild calls from school to check on his grandmother and make sure that she is doing fine. An overwhelming task of medical wound dressing was performed by the grandchild for his grandmother who has very deep wound resulting from a major surgery. In caregiving, grandchildren have the responsibility of making decisions concerning some aspect of their grandparents' lives. A grandchildren age 13 years prepares his grandmothers' food according to her salt restricted diet. For most of the grandchildren, cleaning, sweeping, mopping, and washing dishes were their daily responsibilities. Other embarked on babysitting their siblings to help their grandparents while another walked to the grocery store to keep up food stuff available for his grandmother and to the pharmacy to get his grandmother's medications. 


\section{Theme 5: Grandparent and Grandchild Symbiotic Relationship}

Symbiotic caregiving is a two way relationship that exists between grandparents and their grandchildren. It is a special bond and a reciprocal relationship-a relationship where a grandparent cares for her grandchild and the grandchild, in turn, cares for the grandparent. It comes as a result of the custodial bond that exists between the dyad. Categories emerged from the codes that led to this intergenerational bond theme, which includes grandparent physical well-being, circumstances leading to grandparenting, and love and affection. Most grandchildren started to care for their grandparent because of the love and the special bond that exists between them. The same holds for grandparents who, because of their love and affection for their grandchildren, assumed custody and began taking care of them. Some grandchildren assumed caregiving responsibility because their elderly grandparents faced challenges in caring for themselves or their grandchildren. Almost all grandparents found themselves in the symbiotic caregiving relationship because of the circumstances leading to their assuming custody of their grandchildren.

White and Brinkerhoff (1981) described grandparent and grandchild caregiving roles "reciprocal obligations" (p. 794). According to Abel and Nelson (1990), caregiving relationships that exist between caregiver and care recipient can be described as "encompassing both instrumental tasks and affection relations" (p. 434). Instrumental tasks are viewed as tasks that aid with activities of daily living such as feeding and bathing. Affective relationships consist of both social and emotional support. Although dyadic relationships between older adults and their caregivers have been studied, more emphasis has been placed on the type of caregiving responsibilities. Some of these caregiving dyadic relationships are often seen between spouses, parents, and adult daughters (Fast, Keating, Otfinowski \& Derksen, 2004; Peek \& Zsembik, 1997; Pyke \& Bengston, 1996).

The grandparent and grandchild relationship is more than a relationship. It is an intergenerational bonding where a grandparent and a grandchild share experiences (Kornhaber, 1996; Weber \& Waldrop, 2000). In the current study, most grandparents expressed positive feelings towards their grandchildren despite the circumstances that they found themselves. This is consistent with the report by Weber and Waldrop (2000) that grandmothers have positive and loving feelings towards grandchildren in the midst of difficulties with raising their grandchildren. Although grandparents' well-being may be affected by the circumstances and serious behavior or health problems of the grandchildren, they never wavered on their steadfast love for their grandchildren. Similarly, Hayslip, Shore, Henderson, and Lambert (1998) found that grandmothers tended to be close to their grandchildren irrespective of the negative effect of grandchildren's behavioral problems on their grandmothers' well-being. In the current study, some grandchildren voiced their relationship with their grandparents as being close. Pruchno's (1999) study supports these findings as she described the happiness in the grandchildren and their acknowledgment of closeness with their grandmother. 


\section{Phillys and Derek}

Phillys is a 77 year old single African American woman who has a $10^{\text {th }}$ grade education and is retired. She lives at home with her one grandson, Derek, who is 13 years old. He enjoys middle school where he is in the $8^{\text {th }}$ grade. Derek has no siblings and lives alone with his grandmother.

Phillys received custody of Derek when he was two years old because of mental illness of both parents. Since then, Phillys has nurtured Derek as if she were his mother. Unfortunately, she was involved in a motor vehicle accident in 1993 and also had two heart attacks. These events changed her life as well as Derek's life. With her health problems, Phillys needed personal assistance and instrumental care. Derek took on the responsibility of helping his grandmother when he was about eight years old. A symbiotic relationship was born. Both grandmother and grandchild indicated that they have benefited from this reciprocal relationship.

When asked about her experience and relationship with her grandson, Phillys replied, "By caring for him, it's done got just like my own child because I been had him every since he was 2 and he (is) 13 now. You know he loves me just like I'm his mother." This is an indication that both members of the dyad get along and enjoy each other's company. This is contrary to the findings in a previous study by Tompkins (2007), who explored the relationships between grandparents and grandchildren living in grandparentheaded households. She contended that the grandparent/grandchild relationship in these households does not "mimic a parent-child relationship or a grandparent-grandchild relationship" (p. 19) but is a third type of relationship. Phillys made reference to her grandson's perception of his relationship with her. She continued, "He love me just like I'm his mother. He really do(es). And I sit up. Sometimes, I have a pain. It bothers him. 'Mama, are you ok?' 'No, I'm ok.' And I'll be saying Lord forgive me for that. I really do because you don't want him to know how sick you is because he's worried."

Perhaps the symbiotic relationship that exists between this grandparent and grandchild is best described by Derek. He has a good idea, unlike most grandchildren, when he has a reciprocal relationship with his grandmother. He highlighted the fact that he is very lucky to have someone who loves him to take care of him. In addition, as young as he was when he started his caregiving responsibilities, he saw the need to help his grandmother because of her physical disability.

The filial relationship that exists between a parent and child is seen between Phillys and Derek. He captured the essence of this phenomenon. When asked what caused him to help his grandmother, he replied, "What caused me to help her was like all the years she has spent raising me. I should, like, repay her for like, taking care of me. That was years and I'm still doing that now." Derek acknowledged that there is a special bond between him and his grandmother. He understands the caregiving role that his grandmother plays in his life and the role that he plays in her life. Derek concisely summarized this reciprocal relationship. He stated, "It's like we have our special bond. When I ask her for something, she gets it; and when she asks me for something, I go do it 
the instant that she tells me to do it."

\section{Patricia and Ryan}

Patricia is a 68 year old African American widow who lives with four grandchildren who are in her custody. She completed the $12^{\text {th }}$ grade and is retired. She has two granddaughters who are 11 and 10 years old and two grandsons who are 15 and 13 years old. Her 15 year grandson, Ryan, provides care to Patricia and helps her more than her other three grandchildren do. Ryan attends a local high school where he is in the $10^{\text {th }}$ grade.

Dellmann-Jenkins et al. (2000) explored the reasons young grandchildren become caregivers for their grandparents. Structured and open-ended interviews were conducted with 22 young adult children and 21 young grandchildren. The author found that the feeling of motivation makes grandchildren maintain close relationships with their grandparents. The present study shows that both grandparents and grandchildren understand and value their symbiotic relationship. Patricia described her relationship with her grandchildren as, "Well you know what, with me, they are my grandkids? And I raised three and sent them to school. I cannot say that it affect(ed) me no kind of way because I haven't regret(ted) it. I haven't regret(ted) it one bit. I felt like this (is) what I need to do. This (is) what I had to do. So, if I didn't have them, maybe I would do, I don't even know what I would do if I didn't have them. I would probably be going on trips and things. But I haven't even thought about what I would be doing. Since I (have) had them, my whole life (has) really been focused on them."

Patricia explained how her grandchildren's relationship with her makes them worry about her. She continued that when they think of her age, they are afraid she may die. Perhaps it is interesting to note that they are afraid that if anything should happen to their grandmother, they will not have anywhere else to go. Furthermore, she explained that when she tells her grandchildren that she is hurting, she can see their reaction of sadness. Ryan described his grandmother as a nice and good woman. He stated that having her as his grandmother and helping her has been a blessing. When asked to explain, he stated that, "She takes cares of me. Keep me out of trouble."

\section{Pauline and Brian}

Pauline is a 69 year old single African American woman who lives with her grandson, Brian. She completed the $12^{\text {th }}$ grade and is retired. She has custody of Brian who is a 15 year old and in the $9^{\text {th }}$ grade. Brian has two brothers and 2 sisters who are ages, 24, 20,18, and 13. Brian provides care to Pauline and helps extensively to take care of his grandmother who is not mobile.

Pauline is limited in her ability to perform her activities of daily living. She relies on her grandson to help her. The symbiotic relationship between Pauline and her 
grandson is positive. It is one that Pauline is proud of. She states that her relationship with Brian has grown stronger since she has had custody of him. Pauline explained with pride how she loves her grandson to death. She claimed that nothing has changed since taking custody. She noted, "It's still the same. I love him to death. Nothing change(d). The older I get, the more I love him, and (I am) scared for him cause so much (is) happening. As I'm trying to keep up with him, but he's older and he's got to go. Sometimes, but I still be worried. " Pauline argued that having her grandson has not affected her relationship with him and explained, "Not at all. It hasn't affected me because what happened to me was gonna happen anyway. And caring for him and him being here helps me. I'm glad he was here and done growed up some. You know, where I won't have to be trying to do things for him that he can do for his self now. "Pauline tried to explain how her disciplinary action toward her grandson does not affect their relationship. She explained how her rules are strict and she still insists on what she wants her grandson to do. She asserted, "Well, I'm 69, but I don't feel 69 mental wise. Just physical wise because my body... Cause I still put my foot down slowly and he listens. I still got rules and he listens. It's not affecting me at all."

Brian explained his symbiotic relationship with his grandmother. He noted how she is always there to help and see that he gets the best in life. He elaborated on how his grandmother supports him and his dreams. He explained, "I mean my grandma, she would always come when I need her. She was like so nice to me, you know, she was caring for me. When I had to go to school and my mother was around, she would be calling my uncles trying to get me into a school that was close around her."

\section{Sherri and Shun}

Sherri is an 85 year old widowed African American. She has a $7^{\text {th }}$ grade education, is retired, and lives with her grandchildren. Her grandson, Shun, is a 16 year old male who attends a local high school where he is in the $10^{\text {th }}$ grade. Shun has five brothers whose ages are 22, 20, 15, 11, and 7, and two sisters who ages are 21 and 18.

Sherri described her grandchildren as the reason why she keeps going. She expressed her love for her grandchildren. She stated that the relationship that exists between her and her grandson is one in which he thinks of her as his mother. Sherri has made no effort to correct this perception. It could be inferred that Sherri may trying to support Shun's perception of their relationship as a parent-child relationship. She explained, "His relationship with me is like a child with his mother. And he do(es) anything. Anything he got, he offer(s) me some of it." She narrated a situation where her grandson returned from his job, "And the one while he was working and he was working, working at school, he always would bring his little check home. He said, 'Mama, you go and cash my check because I don't have ID's and I can't go in the bank and cash a check.' And he always say, 'Mama, what you want?' I say, 'Baby, it's not enough for me to want. You use that.' I say, 'You take it and you buy your clothes. Don't buy junk. Don't buy your friends. Don't take it and feed them and get rid of your money like that. You take your money and do yourself. If you want to save it, I'll show you how to go to the 
bank and deposit it. And if you don't, it's just enough for you to spend and get along with. You keep it in your pocket.' But when he come home, he always bring me something like, bring me a pop. He knows I drink Cokes. He'll bring me Coke. He went and bought candy or gum or something like that."

This is similar to report that the grandparent and grandchild relationship not only offers opportunities for an intergenerational bonding, but it also offers a sharing experience (Kornhaber, 1996; Weber \& Waldrop, 2000). Weber and Waldrop noted similar trends related to grandparents expressing positive relationships towards their grandchildren. Sherri explained the positive relationship that exists between her and her grandchildren as she explained, "Children keep you going. Keep you active. A lot of times, if it weren't for children, you wouldn't get up and move." Shun echoed the same sentiment of positive symbiotic relationship with his grandmother, Sherri. He stated, "I had started living with her and I did. It's a blessing. Because I'm helping her out. Well, I got closer to her."

\section{Mary and Carol}

Mary is a 69 year old widowed African American who completed $9^{\text {th }}$ grade and retired many years ago. She lives alone with her two granddaughters Carol (age 17) and Carol's younger sister (age 13). Carol has an older sister who is 20 years old. Carol is in the $12^{\text {th }}$ grade. Mary has had custody of Carol since she was 14 years old. Carol's mother is deceased and her father's whereabouts are unknown as of the time of this interview. Mary stated that Carol's mother did not reveal who Carol's father was before she passed away. Carol is extremely involved with helping her grandmother. Carol will be graduating from high school this May and plans to go to college this fall. Carol lamented the difficulty she has keeping up with school since she sometimes does not have the supplies she needs. She stated that she needs a computer at home because she sometimes has assignments that require the use of a computer.

Carol is always frustrated with not having a computer at home. Since she cannot drive and her grandmother does not have a car, it makes going to library very difficult. Ultimately, this makes learning very difficult. Her cousin, who is a second year nursing student, comes to help her when she can. In spite of all these challenges, Carol finds time to reminiscence on the times her mother was alive. She explained that people should not take things for granted. When asked what kind of relationship she has with her grandmother and if it has been affected by her care- giving role, she stated, "Well, it's not really affected in a bad way. It's actually affected in a good way. I learn from this experience. She gives me strength to move on, you know. Do what I have to do to survive in this world."

Her grandmother, Mary has this to say regarding her two grandchildren and the love she has for them, "Yeah, they have to have a future. They got to get up and go and do something to, you know, try to help themselves because I won't be with them always. They have to get up and try to help themselves. That's what I'm trying to teach them to 
get up and move around. Go to school and try to get some education. See the other one, she draws. She's 20 years old, but she don't go to school. I don't know if she's got some issues, problems or what. But she draws well." When asked about her relationship with her granddaughter since she started caring for her, she replied, "Yeah, I think it's made it stronger. Of course, I've always been close to them. Been around them all they lives. Every since they've been in the world, I've been around them, you know. Spend a lot of time with them...Yes, it just look like it's all my responsibility now. You know, to try to do for them."

With formal custody, the grandparents assume custody of their grandchildren. This assumption comes as a special bond, a reciprocal relationship between grandparents and their grandchildren. In the cases representing this theme, grandparents are raising their grandchildren due to variety of reasons such as death of their own children, mental instability of grandchild's parents, negligence of the biological children to mention but a few. The symbiotic relationship is described by a grandparent as caring for her grandchild as her own child. One grandmother saw it as mother/child relationship. Some grandchildren saw it as a way to re-pay their grandparents for taking care of them, while others saw it as their way of showing appreciation for their grandparents taking care of them. Each dyad relationship may be different but grandparents and their grandchildren form special bond not even the grandparent's biological children can break. The earlier and the more we understand this bond and nurture it, the more support health professionals can give to this relationship between grandparents and grandchildren who are caring for each other. The greater the understanding of and ability to nurture this relationship, the more likely society will benefit from the social and economic implications of this symbiotic relationship.

Member checking was conducted to validate data after transcription, data analysis and coding. Member checking allows for validity and credibility of participants interview responses. Some participants are not comfortable for researcher to conduct member check. Unwillingness to participate is one of the short comings of member checking as reported by Lincoln and Guba (1985). Grandparents and grandchildren who were reluctant to talk about the circumstances leading to the custodial grandparent/grandchild arrangement and grandparents who experience obvious daily stress in their lives were not chosen. Discussion of these circumstances during the interview seemed to result in closure for some grandparents and grandchildren. Returning to these individuals could be counterproductive as they may not want to discuss these topics again or may not be unwilling to participate. The three grandparent/grandchild dyads that were chosen were not overtly concerned or bothered by their situations or the circumstances leading to the custodial grandparent/grandchild arrangement and easily shared information during the initial interview.

\section{Summary}

The purpose of this study was to understand the symbiotic relationship that exit between grandparents and their grandchildren. It also elaborates on the experiences of 
this relationship and its effect on the lives of this population. Through analysis of these cases, themes evolved from the grandparent/grandchild dyad. Additionally, the effects of these experiences were explored through the dyad interview. 


\section{CHAPTER 5. DISCUSSION}

\section{Introduction}

This chapter will discuss the study findings with related literature, limitations, and implications and recommendations for practice and research. This qualitative case study examined the symbiotic caregiving relationship between custodial grandparents and their grandchildren.

\section{Summary of Study}

The purpose of this study was to describe the symbiotic caregiving relationship of African American custodial grandparents and their grandchildren. Symbiotic caregiving is defined as two way caregiving activities and experiences that exist between both grandparents and grandchildren or between custodial grandparents and their grandchildren. The four questions guiding this study were:

1. What are the circumstances leading to symbiotic caregiving among custodial grandparents and their grandchildren?

2. What are caregiving activities that custodial grandchildren engage in?

3. How does caregiving affect their lives?

4. What is the nature of relationship between grandparents and grandchildren as symbiotic caregivers?

Using qualitative case study methodology, each research question guided the researcher toward collecting rich and in-depth data regarding the symbiotic caregiving relationship that exists between grandparents and their grandchildren. Data were analyzed simultaneously with data collection. Multiple case analysis method was used for data analysis. Broad categories were used to understand symbiotic caregiving. Themes emerged from the categories to give meaning to the purpose of the study. To give validity and credibility to the five themes of this study, member checking was conducted. Three grandparents and three children were selected. Participants validated and concurred that the data that the researcher collected at initial interviews were what they relayed to the researcher.

\section{Discussion}

The qualitative case study looked to understand symbiotic relationship that exists between African American grandparents and their grandchildren. These grandparents were all grandmothers; no grandfather participated in this study. This was because about $90 \%$ of the grandparents who are enrolled in Shelby County Relative Caregiver Programare females. All grandparents lived with their custodial grandchildren. This is similar to Baydar and Brooks-Gunn (1998) reporting that about $12 \%$ of grandmothers 
lived in the same household with at least one grandchild. Most grandparents had a $9^{\text {th }}$ through $12^{\text {th }}$ grade education, which is consistent with Minkler and Fuller-Thomson's (1999) report that grandmother caregivers are more likely to be less educated and poor than their noncaregiving counterparts. Respondents' age ranged from 65 to 85 years, with a mean age of 71.4. This finding is contrary to the literature that reports that the average age of grandparent caregivers is middle age to 60 years old (Burton, 1992; Dowell, 2005; Kelly, 1993; Minkler, Roe \& Robertson-Beckley, 1994). More than half were widowed and a majority were retired. Grandchildren ranged in age from 10 to 17 years, with a mean age of 14 years. This is consistent with a report by Casper and Bryson (1998) that approximately 2.2 million children under the age of 18 years live with their grandparents.

Findings from the study helped to understand and may help to encourage and nourish this relationship. This multiple case analysis clearly showed that grandparents took custody of their grandchildren for different reasons and grandchildren perform varied caregiving tasks as a reciprocal gesture to their grandparents. Furthermore, grandparents attributed most of their motivation, inspiration, and encouragement to keep on going to the presence of their grandchildren in their lives. Financial instability appeared to contribute to the most identified needs of the grandparents. Grandparents relied on networks of family members and friends as means of support. They also employed the use of prayers and dedication as means of dealing with the responsibilities of raising their grandchildren. While the grandchildren did not identify a peculiar means of dealing with their caregiving, many relied on uncles, aunts, cousins, and other family members for help.

Several studies have attributed caregiving by grandchildren as having an impact in their physical, mental, social, education, emotional, and behavioral health. Similar findings were reported with the grandparents whose impact was on their health. The present study did not find similar patterns. It must be noted that this study did not specifically focus on the health of grandchildren and their grandparents. Grandparents did not attribute their health issues to assuming custody of their grandchildren. Grandchildren stated that taking care of their grandparents did not affect their physical, social, educational, or emotional life. Rather, they took enjoyment in helping as it was a blessing to have their grandparents there for them when their biological parents were no longer in their lives.

\section{Question 1: Circumstances Leading to Symbiotic Caregiving}

The findings of this study indicated that grandparents assume a custodial grandparenting role due to different circumstances. Each circumstance is unique. All relate to the stability or instability of the child's parents and the inability of the child's parents to adequately provide care and fulfill the parenting role. Circumstances leading to custodial grandparenting included parent abandonment of their children, substance abuse, death, negligence of their children, mental illness, incarceration, and economic instability. Similar findings were noted by Larsen (1990). It should be noted that thefindings of this study did not show single parenthood, teenage pregnancies, parental 
divorce, physical or sexual abuse (Kennedy \& Keeney, 1988) as reasons that grandparents assumed responsibility for their grandchildren.

Findings revealed that grandparents and grandchildren have different perceptions of their roles as caregivers. In addition, caregiving activities performed by the grandchildren can be grouped as instrumental and emotional tasks. Financial rescue was one of the needs that the grandparents reported they must have met to aid with raising their grandchildren. A positive symbiotic relationship was noted between grandparents and their grandchildren. Despite the financial stress that grandparents faced, they still maintain the intergenerational bonding or bonding with their grandchildren. Finally, some grandchildren and grandparents did not want to answer certain questions. For grandparents, questions such as the whereabout of the grandchild's parents were difficult for the grandparents to respond to. Also, not every grandchil felt comfortable discussing these issues. Millburn, Fabian, Schlossberg, and Pyle (1996) reported that grandmothers and grandchildren sometimes are shameful and may suffer humiliation by peers, friends, family members, and the society when grandchild's parents' bad behaviors lead to incarceration.

\section{Question 2: Custodial Grandchildren Caregiving Activities}

The average age of the grandchildren indicates that grandchildren between the ages of 8 and 17 years old are involved in care giving activities. The grandchild participants were selected by their grandparents as the grandchild who provides them with the most care and assistance. None of the grandparent participants selected a child outside this age group. The present study shows that grandchildren performed instrumental task such as cooking and cleaning, to mention but a few. This finding is consistent with Blair's (1992) results following examination of data from the 1988 National Survey of Families and Households. Blair found that children ages 5-18 performed more than $10 \%$ of household tasks. These household tasks include dishes, cooking, laundry, and cleaning. The results of the present study should be interpreted with caution and do not represent the experiences of all grandchildren being raised by their grandparents. The sample is small and regionally based within Memphis.

According to White and Brinkerhoff (1981), Midwestern U.S. parents tended to assign household chores to their children. The parents claimed that these chores helped the children's moral development and work ethic or habit. Similarly, grandparents in this study described the importance of their grandchildren learning to do chores and assuming responsibilities. Grandparents noted that these activities would contribute to their grandchildren's development by preparing them for adulthood and adult responsibilities.

The present findings indicated that custodial grandchildren performed caregiving tasks which could be grouped into categories that are similar to those described by Lackey and Gates (2001). The results from their study showed that grandchildren performed specific caregiving tasks which included (a) personal care (e.g., bathing, taking to bathroom, and dressing), (b) medical care (e.g., giving pills and changing 
dressings), (c) household care (e.g., cleaning, cooking, washing, baby-sitting, and grocery shopping), and (d) spending time (e.g., visiting with the person, praying, reading for the grandparents. With their study, the effects of caregiving on the family, school, friends, dating, and leisure yielded no implications as with the present study. The authors further reported that there was no positive or negative effect of caregiving on the grandchildren as it relates to the above and that grandchildren perceived and described caregiving as giving back to the grandparent who had done so such for them. These findings were echoed by the grandchildren in this study.

In the present study, average age of custodial grandparents was 71 years old. This differs from 60 years average age reported in the literature. According to Simmons and Dye (2003), most grandparent caregivers are between middle age to 60 years. Findings from this study suggested that some grandparents are assuming caregiving roles at an older age. The result indicates that grandparent perform different caregiving tasks for their grandchildren that it is not limited to daily up keep of their grandchildren. Grandparents are involved in the social, educational, and health lives of their grandchildren. The literature review showed negative feelings by grandparents towards raising their grandchildren (Pantier, 1993; Smolowe, 1990). This was not reported in the study, as grandparents' feelings toward caregiving role and tasks for their grandchildren were positive.

\section{Question 3: Effect of Caregiving on Grandparents and Grandchildren}

Grandparents are living on a fixed income. The findings from this study showed that grandparents are facing enormous financial stress. With the over $50 \%$ of grandparents in this study being retired and widowed, it is difficult for them to maintain families without financial support. These findings are consistent with Casper and Bryson's (1998) report which showed that grandparents are raising grandchildren alone, without a spouse, or without the parents of the grandchildren and they are less likely to be in the work force. Similarly, Minkler and Roe (1993) noted that grandparents who are not working or who are retired bear more financial stress than those who are working. Furthermore, younger grandparents tended to risk their financial welfare to raise their grandchildren. Some may quit a job to spend time with their grandchildren while others uses all their social security money on the children (Minkler, 1999). The study showed that financial stress was one of the stressors of grandparents face in raising their grandchildren. The grandparents in the present study reported not having money and sometimes not enough to help them with grandparenting. Some of the grandchildren related how they could do without certain things (e.g., school supplies) because their grandparent could not afford to buy these items. According to Denham and Smith (1989), most literature reported financial stress as one of the major needs of the grandparents.

In the present study, the effect of caregiving was noted with the grandchildren. Both direct and indirect effects of caregiving were seen in the grandchildren. Some grandchildren took up responsibilities not only to help themselves but also to help their grandparents. A grandchild recalled walking to school while another took public 
transportation to school. These behaviors resulting from the family not having money to pay for transportation created challenges for grandchildren to maintain a normal childhood. Some studies have looked at the impact of caregiving on the health, education, emotional, and social lives of young children. At the time of this study, no one has explored the financial burden children face as they care for their grandparents. One grandchild described the impact of knowing that his grandmother did not have enough money to repair her car. He proudly narrated how he helped his grandmother to save money by repairing her car and doing plumbing work.

\section{Question 4: Grandparent and Grandchild Symbiotic Relationship}

The study results also showed that grandparent caregivers began taking care of their grandchildren early in their grandchildren's lives. It was noted in a profile compiled by Fuller-Thomson et al. (1997) from the National Survey of Families and Household that 1 in 10 grandparents raised a grandchild for at least 6 months and may have started this task when the child was an infant.

Despite the circumstances and the timing of grandparents assuming a caregiving role, they still love their grandchildren unconditionally. Findings from the present study showed that grandparent and grandchild caregivers have a positive reciprocal relationship. This is a relationship where both members of the dyad take care of each other and understand the importance of each other in their lives. Most grandparents see their grandchildren as the reason for "living" or "being alive" while the grandchildren see their grandparents as the reason for their survival. The symbiotic relationship is beneficial, reciprocal, and appreciated by everyone involved. It was noted in the literature that grandparents continue to love their grandchildren and are determined to care and provide for them irrespective of their physical limitations (Whitley, Kelly, \& Sipe, 2001). Obviously, there is an expected filial relationship that can exist between parents and children. Such relationship can be seen in the grandparent and grandchild symbiotic relationship.

Grandparent and grandchild relationship is more than a mere relationship. It is an intergenerational bonding where a grandparent and a grandchild share experiences (Kornhaber, 1996; Weber \& Waldrop, 2000). In the current study, most grandparents expressed positive feelings towards their grandchildren despite the circumstances surrounding custody. This is consistent with Weber and Waldrop (2000). The authors reported that grandmothers have positive and loving feelings towards their grandchildren in the midst of difficulties of raising their grandchildren. Although grandparents' wellbeing may be affected by the circumstances and serious behavior or health problems of the grandchildren, they never wavered on their steadfast love for their grandchildren. Similar findings were noted by authors Hayslip et al. (1998), who found that grandmothers tended to be close to their grandchildren irrespective of the negative effect of grandchildren's behavioral problems on their own well-being.

Some grandchildren voiced their relationship with their grandparents as being 
close. In a study by Pruchno (1999), the author echoed the happiness in the grandchildren and their acknowledgment of closeness with their grandmother. In previous literature, Pruchno and McKenney (2002) noted that a positive relationship between grandparent and grandchild leads to enhanced and satisfied grandparent well-being and grandchild satisfaction.

\section{Additional Finding: Perception of Assumption of Caregiving Role by Dyad}

In addition to the findings, grandparents and their grandchildren shared their perceptions of assumption of roles as caregivers. Each case selected for consideration in the previous chapter represents grandparent and grandchild perceptions. Blair (1992) described parents' motives for children to engage in household chores as based on two reasons. Parents saw chores as a "socializing experience" where the children can develop their own personal traits. Another reason children may take up household chores is their response to circumstances around them. This is consistent with grandchildren who decided to take up caregiving responsibilities because of grandparents' physical disposition.

Studies have shown that grandchildren view their roles as more than mere caregiving. Some grandchildren saw their role as reciprocal. They echoed their desire to reciprocate to the grandparent who has given up so much to care for them. In addition, some grandmothers noted how their grandchildren perceived them as their mothers rather than grandparents. African American grandparents tend to place their own lives and happiness behind in place of their grandchildren. Graff et al. (2007) reported that grandparents put their lives on the "back burner" to provide for their grandchildren. Similarly, Ruiz (2000) reported that African American grandmothers put the needs of their grandchildren before their own needs. White and Brinkerhoff (1981) describe this role as "reciprocal obligations."

Regarding grandparents' perceptions of their grandparenting role, the findings from this study revealed that grandparents viewed their role as being under the control of a higher being. However, they saw their role more as a parenting than grandparenting role. They assume the daily caregiving tasks related to their grandchildren. The majority of the grandparents were thrust into the custody of their grandchildren without adequate notice. This finding is consistent with Cox's (2002) report that some grandparents assumed a grandparenting role without advanced planning.

Traditionally, grandparents expect to spend short time segments with their grandchildren When grandchildren visit grandparents during vacations or special occasions, they stay for a short while (Brown et al., 2000). In the present study, grandparents perceived their roles as long-lived, or lasting a long time-more asgrandparenting than parenting. Grandparents emphasized to their grandchildren that they have their own mothers and they were only grandparents. It is interesting that they have this perception irrespective of them taking care of their grandchildren's physical care on daily basis. More especially, their biological children who are the parents of the 
grandchildren are not involved and, in some cases, do not show interest in or have contact with their children.

Although the grandparents had different perceptions of their roles, they saw symbiotic caregiving as having a positive reward. This is contrary to what has been reported in the literature as caregiving having no positive outcome or reward to both grandparents and grandchildren. In the present study, many of the grandparents described a positive caregiving relationship with their grandchildren. Grandparents found positive rewards knowing that taking care of their grandchildren assured them that they were adequately cared for. The same was seen with the grandchildren, who saw their roles as rewarding. as they helped a grandparent who had helped them in their circumstances. This is consistent with Pruchno and McKenney (2002), who noted that where a positive relationship exists between grandparents and grandchildren, there is bound to be caregiving satisfaction.

In addition, grandchildren viewed their grandparents are their parents since their own biological parents were not in their lives. Contrarily, the grandparents saw their custodial grandchildren as what they were-grandchildren. One of the grandparents expressed a view that irrespective of her daughter's negligence or what led her to take care of her grandson, she wants her grandson to know that he has parents and that she is just his grandparent. Reflecting on this, grandparents did want their grandchildren to understand their love for them but at the same time wanted them to look to a time when the grandchildren could be reunited with their parents in the future.

\section{Limitations and Strengths}

The following limitations were noted in this study. The grandparents may have perceived the researcher as an outsider, someone who was not within the Shelby County Relative Caregiver Program, but an intruder who may or may not contribute to or help with their present situation. On the contrary, the grandchildren may have looked at the researcher as an outsider who could lay a hearing ear to their experiences as young caregivers. In addition, there is limited generalization of the study to a wider geographic area as grandparents and grandchildren caregivers in the study lived within Memphis metro area. All grandparent caregivers were African American females. They were primarily widowed, retired, and had less than high school education.

Coupled with the sample size, convenience sampling was also a limitation of this study. A total of 18 grandparent/grandchild dyads were interviewed. The present study results are reflective of the dyads involved in the study and may not representative of other custodial grandparents and their grandchildren.

Researcher discretion was used in interpretation of the data. Due to qualitative analysis and lack of statistical analysis, the researcher was placed with a responsibility of interpreting the collected data. According to Yin (1994), giving a researcher the responsibility of interpretation of data is open to pattern restrictions or overt 
acknowledgement or recognition of patterns. In this study, the researcher cautiously approached patterns and used facts to draw conclusions.

Cases presented in this study were chosen as exemplary units rather than sample units. Replication is evidenced where two or more case dyads supported the same conclusion. Due to the complexity of the case study, data and frequency of all the patterns in the 36 interviews were not reported in the write up. Also, information obtained from the dyad may be subject to researcher bias. Similarly, some grandparents and/or grandchildren may be subject to recall biases as they may have relied on their recall and memory of certain events.

Challenges were encountered with recruitment of participants. Due to the circumstances leading to the grandparents taking custody of their grandchildren, many were reluctant to allow a researcher to visit and conduct interview. All participants were recruited through the Shelby County Relative Caregiver Program. Although the Relative Caregiver Program maintained a database with information on potential participants, the telephone service for half of these potential participants had been disconnected. Recruitment letters sent to grandparents without telephone service yielded no response.

Despite its methological limitations and challenges, the study has several strengths. Exploration of the grandparent/grandchild dyad as a contemporary population in caregiving was undertaken. At the time of this study, there were few studies on symbiotic caregiving and its positive outcome on both grandparents and grandchildren. In addition, no study was been reported using a case study design to explore symbiotic relationship between grandparents and their grandchildren. Although there have been studies on grandparents as caregivers, few have dealt with the positive aspects of the grandparent/grandchild caregiving relationship. Another strength of this study was the exploration of the relationship of grandparent caregiving responsibilities to grandchild and grandchild caregiving to grandparents. This study makes an important contribution to understanding the perceptions that grandparents and grandchildren have of their caregiving roles.

\section{Implications and Recommendations}

\section{Practice}

The studied population is the focus for practice implications. Caregiving responsibilities pose stress and sometimes bitter experiences for caregivers and care recipients. Grandparents and their grandchildren are not different in caregiving agenda when compared to other individuals, family members, parents, or friends providing caregiving to their loved ones, who are physically incapable, mentally disabled, debilitated or terminally ill. However, they bear strictly different relationships as symbiotic caregivers compared to the population described. Grandparents and grandchild experiences are not only different and similar across dyads, they are also unique. This 
study provides insight into these experiences. The study could be used to understand grandchild and grandparent's caregiving responsibilities, symbiotic relationships, and healthcare implications. The study suggests that healthcare professionals, especially providers, should be aware of the relationship that exists between grandparents and their grandchildren. Caregiving stress should be the focus of these providers as they help to alleviate the stress associated with care giving. As noted in the findings of this study, support networks that include family members, friends, and even healthcare providers are means to decreasing caregiver feelings of being overwhelmed.

For healthcare providers to help grandparents and their grandchildren effectively, all nursing oriented care should be individually tailored to each family's needs. According to Zarit (1985), support services for stress associated with caregiving should be individually based. Nurses, social workers, psychologists, therapists, andhealthcare providers are often in an ideal position to help grandparents and their grandchildren cope with the challenges of their new roles., These healthcare providers like networks of families or friends, can provide a wide range of supportive care. Supportive resources include mentoring programs for grandchildren, respite services, social gatherings, or social events offered through established, kinship care programs. Respite care provides the caregivers with a break or time away from caregiving responsibilities. This can provide an interactive and supportive environment for these dyads. Health providers should utilize and maximize available resources to help grandparents and their grandchildren.

In the present study, grandparents noted financial difficulties as a major area concern. Collaboration among nurses, educators, social workers, mental health professionals, psychologists and therapists can lead to partnerships among community organizations to provide affordable child care, a homework hotline for grandchildren, respite services, and transportation services . In addition, these available community resources can help strengthen the dyads' social support networks. This is in accordance with Minkler and Roe (1993), who noted that effective community-level support which can provide appropriate programs and services is needed by grandparent caregivers and their grandchildren. Finally, as grandparent-headed households increase in number, it is imperative that institutions recognize the reality of grandparents caring for their grandchildren rather than parents caring for their children and vice versa, rather than parents caring for their children (Minkler, 1999). Unless this is understood, providers may continue to lose the importance of integrating intergenerational concerns into practice. The economic impact of symbiotic caregiving is great, saving society funding by helping to decrease the financial commitment to the foster care system and nursing homes.

\section{Research}

With the increasing grandparent household, more research is needed to understand the grandparent/grandchild care giving relationship. Caregiving can be rewarding as well as stressful. Caregiving experiences affect families, healthcare 
providers, friends, and all involved with these experiences. Recommendations include replicating this study in different geographical regions and with grandparents and grandchildren of differing racial and ethnic backgrounds. These recommendations will ensure population of a broader geographical region. Furthermore, it will compass a more culturally diverse group. Additionally, replication with a larger sample would help address the limited transferability of the findings from this study. It is crucial to determine the experiences of each child in a grandparent household and compare those experiences to the experience of the child that provides the most care. Research is needed to determine how grandchildren who are former caregivers relate to grandparents after they have lived in grandparents' homes and have families of their own. Few studies have been conducted using both qualitative and quantitative methods to investigate the grandparent/grandchild caregiving relationship. It is important to carry out a quantitative research study to measure variables such as burden and stress experienced by symbiotic caregivers and other variables identified through qualitative research.

In the present study, many of the grandparents and grandchildren described a positive relationship between each other. A replication study is needed to understand conflict, if any, that may exist when a grandparent has her adult child living in the same household. Future research should look into the influence of biological parents on the grandchildren who are being raised by their grandparents. Most grandparents in this study were widowed. A study looking at married grandparents and unmarried grandparents and the influence of spouse on the symbiotic relationship is needed. Also, it is important to replicate a study that will compare the differences in caregiving as performed by female and male grandchildren to their grandfathers and caregiving by the male and female grandchildren to their grandmothers. Reward as a form of compensating grandchildren for their caregiving tasks should be explored to understand its impact on grandchildren's willingness to perform caregiving tasks over the long- term. Also, current grandchildren could be followed to understand the impact of young caregiving in their adult lives and beyond.

Future research should explore the different circumstances that lead to grandparents taking a parental role and compare the various circumstances and their impact on the grandparents and grandchildren. Longitudinal research is needed to gain insight and understanding of these circumstances. Further research is needed to fully understand the perception of all caregiving among all grandchildren in the household . Lastly, it will be important to explore and understand the role of grandfathers in caring for their grandchildren. 


\section{LIST OF REFERENCES}

Abel, E. K., \& Nelson, M. K. (1990). Circle of care: An introductory essay. In E. K. Abel $\&$ M. K. Nelson (Eds.), Circles of care: Work and identity in women's lives (p. 434). New York, NY: State University of New York Press.

Aldridge, J., \& Becker, S. (1993a). Children as carers. Archives of Disease in Childhood, $69,459-462$.

Aldridge, J., \& Becker, S. (1993b). Children who care. Childright, 97, 13-14.

Aldridge, J., \& Becker, S. (1993c). Punishing children for caring: The hidden cost of young carers. Children and Society, 7, 376-387.

Baydar, N., \& Brooks-Gunn, J. (1998). Profiles of grandmothers who help care for their grandchildren in the United States. Family Relations, 47, 385-395.

Becker, S. (2007). Global perspectives on children's unpaid caregiving in the family. Research and policy on 'Young Carers' in the UK, Australia, the USA and SubSahara Africa. Global Social Policy, 7, 23-50.

Biegel, D., Sales, E., \& Schultz R. (1991). Theoretical perspective on caregiving: Family caregiving in chronic illness. Newbury Park: Sage publications.

Bilchik, G. S. (2000). The age wave. Trustee, 53, 14-17.

Bird, G. W., \& Ratcliff, B. B. (2000). Children's participation in family tasks:

Determinants of mothers' and fathers' reports. Human Relations, 43(9), 865-884.

Blair, S. L. (1992). Children's participation in household labor: Child socialization versus the need for household labor. Journal of Youth and Adolescence, 21(2), 241-258.

Blau, T. H. (1984). An evaluative study of the role of the grandparent in the best interests of the child. The American Journal of Family Therapy, 12(4), 46-50.

Blustein, J., Chan, S., \& Guanais, F. C. (2004). Elevated depressive symptoms among caregiving grandparents. Health Services Research, 39, 1671-1689.

Bowers, B. F., \& Myers, B. J. (1999). Grandmothers providing care for grandchildren: Consequences of various levels of caregiving. Family Relations, 48, 303-311.

Bromley, D. B. (1986). The case-study method in psychology and related disciplines. New York, NY: John Wiley and Sons. 
Brown, E. J., Jemmott, L. S. Outlaw, F. H., Wilson, G., Howard, M., \& Curtis, S. (2000). African American grandmothers' perception of caregiver concerns associated with rearing adolescent grandchildren. Archives of Psychiatric Nursing, 14(2), 73-80.

Burnette, D. (1999). Custodian grandparents in Latino families: Patterns of service use and predictors of unmet needs. Social Work, 44, 22-34.

Burton, L. M. (1992). Black grandparents rearing children of drug-addicted parents: Stressors, outcomes, and social services. Gerontologist, 39(1), 49-58.

Burton, L. M., \& Dilworth-Anderson, P. (1991). The intergenerational family roles of aged Black Americans. Marriage and Family Review, 16, 311-324.

Butler, F. R., \& Zakari, N. (2005). Grandparents parenting grandchildren: Assessing health status, parental stress, social supports. Journal of Gerontological Nursing, 31(3) 43-54.

Casper, L. M., \& Bryson, K. R. (1998). Co-resident grandparents and their grandchildren: Grandparent maintained families. U.S. Census Bureau Population Divison. Working papers no. 26. Washington, DC: U.S. Census Bureau.

Child Welfare League of American. (2003). Tennessee: A state fact sheet for grandparents and other relatives raising children. Retrieved December, 7, 2007, from http://www. cwla.org/programs/kinship/2003statefactsheets/tennessee.pdf

Chiriboga, D. (1987). Social support. The encyclopedia of aging. New York, NY: Springer Publishing Company, Inc.

Choi, N., and Wodarski, J. (1996). The relationship between social support and health status of elderly people: Does social support slow physical and functional deterioration? Social Work Research, 20, 52-64.

Cohen, S., \& Wills, T. A. (1985). Stress, social support, and the buffering hypothesis. Psychological Bulletin, 98, 310-357.

Cox, C. B. (2002). Empowering African American custodial grandparents. Journal of the National Association of Social Workers, 47(1), 45-54.

Cree, V. E. (2003). Worries and problems of young carers: Issues for mental health. Child and Family Social Work, 8, 301-309.

Creswell, J. W. (1998). Qualitative inquiry and research design: Choosing among five traditions. Thousand Oaks, CA: Sage.

Creswell, J. W., \& Miller, D. L. (2000). Determining validity in qualitative inquiry. Theory into practice, 39(3), 124-130. 
Dearden, C., \& Becker, S. (1999). The experiences of young carers in the UK: The mental health issues. Mental Health Care, 21, 273-276.

Dearden, C., Becker, S., \& Aldridge, J. (1994). Partners in caring: A briefing for professionals about young carers. Leicestershire, United Kingdom: Loughborough University of Technology.

Dellmann-Jenkins, M., Blankemeyer, M., \& Pinkard, O. (2000). Young adult children and grandchildren in primary caregiver roles to older relatives and their service needs. Family Relations, 49, 177-186.

Denham, T. E., \& Smith, C. W. (1989). The influence of grandparents on grandchildren: A review of the literature and resources. Family Relations, 38, 345-350.

Denzin, N. K., \& Lincoln, Y. S. (2005). Introduction: The discipline and practice of qualitative research. In N. K. Denzin \& Y. S. Lincoln (Eds.). The sage handbook of qualitative research ( $3^{\text {rd }}$ ed., p. 1-32). Thousand Oaks, CA: Sage Publications.

Donelan, K., Hill, C., Hoffman, C., Scoles, K., Feldman, P., Levine, C., \& Gould, D. (2002). Challenged to care: Informal caregivers in a changing heath system. Health Affairs, 21, 222-231.

Doran, T., Drever, F., \& Whitehead, M. (2003). Health of young and elderly informal carers: Analysis of UK census data. British Medical Journal, 327, 7413.

Dowdell, E. B. (2004). Grandmother caregivers and caregiver burden. Maternal and Child Nursing, 29(5), 299-304.

Dowdell, E. B. (2005). Grandmother caregivers reactions to caring for high-risk grandchildren. Journal of Gerontological Nursing, 31(6), 31-37.

Early, L., Cushway, D., \& Cassidy, T. (2006). Children's perceptions and experiences of caregiving: A focus group study. Counselling Psychology Quarterly, 20, 69-80.

Eisdorfer, C. (1991). Caregiving: An emerging risk factor for emotional and physical pathology. Bulletin of the Menninger Clinic, 55, 238-247.

Emick, M. A., \& Hayslip, B. (1996). Custodial grandparenting: New roles for middle aged and older adults. International Journal of Aging and Human Development, $43(2), 135-154$.

Erikson, E. (1963). Childhood and society (2nd ed.). New York: Norton.

Esu-Williams, E. Schnek, K. D., Geibel, S., Motsepe, J., Zulu, A., Bweupe, P., et al. (2006). 'We are no longer called club members but caregivers': Involving youth in HIV and AIDS caregiving in rural Zambia. AIDS Care, 18, 888-894. 
Fast, J., Keating, N., Otfinowski, P. \& Derksen, L. (2004). Characteristics of family/friend care networks of frail seniors. Canadian Journal on Aging, 23(1), 5-19.

Feigin, J. R., Orum, A. M., \& Sjoberg, G. (1991). A case for the case study. Chapel Hill, NC: The University of North Carolina Press.

Flaherty, M. J. (1988). Seven caring functions of Black grandmothers in adolescent mothering. Maternal Child Nursing Journal, 17(3), 191-207.

Frank, J., Tatum C, \& Tucker, S. (1999). On small shoulders: Learning from the experiences of former young carers. London: The Children's Society.

Fuller-Thomson, E. \& Minkler, M. (2001). American grandparents providing extensive child care to their grandchildren: Prevalence and profile. The Gerontologist, 41, 201-209.

Fuller-Thomson, E. \& Minkler, M. (2005). American Indian/Alaska Native grandparents raising grandchildren: Findings from the Census 2000 Supplementary Survey. Social Work, 50, 131-139.

Fuller-Thomson, E., Minkler, M., \& Driver, D. (1997). A profile of raising grandchildren in the U.S. The Gerontologist, 27, 406-411.

Gage, J. D., Everett, K. D., \& Bullock, L. (2006). Integrative review of parenting in nursing research. Journal of Nursing Scholarship, 38(1), 52-62.

Gates, M. F., \& Lackey. N. R. (1998). Youngsters caring for adults with cancers. Journal of Nursing Scholarship, 30, 11-15.

Ghuman, H. S., Weist, M. D. \& Shafer, M. E. (1999). Demographic and clinical characteristics of emotionally disturbed children being raised by grandparents. Psychiatric Services, 50, 1496-1498.

Giarrusso, R., Silverstein, M., \& Bengston, V. (1996). Family complexity and the grandparent roles. Generations, 20(1), 17-23.

Gibson, P. A. (2005). Intergenerational parenting from the perspective of African American grandmothers. Family Relation, 54(2), 280-297.

Gibson, P. A. (1999). African American grandmothers: New mothers again. Affilia, 14(3), 329-343.

Girden. E. R. (2001). Evaluating research articles: From start to finish (2nd ed.). Thousand Oaks, CA: Sage. 
Goodman, M. R., \& Rao, S. P. (2007). Grandparents raising grandchildren in a USMexico border bommunity. Qualitative Health Research. 17, 1117-1136.

Goodman, C. C., \& Silverstein, M. (2002). Grandmothers raising grandchildren: Family structure and well-being in culturally diverse families. Gerontologist, 42, 676-689.

Graff, C., Nwokeji, S., Williams, J., Hardy, B., Davis, K., \& Roberts, R. (2007, November). Exploring strategies to improve the health of custodian grandparents. Poster session presented at the Annual Conference of the American Association of Intellectual and Developmental Disabilities, Washington: DC.

Gummeson, E. (2001). Are current research approaches in marketing leading us astray? Journal of Marketing Theory, 1(1), 27-48.

Harris, T. T. (2003). Burden and health in caregivers of persons with kidney disease. Unpublished doctoral dissertation, University of Tennessee, Memphis.

Harper, W. J., \& Hardesty, P. H. (2001). Differentiating characteristics and needs of minority grandparent caregivers. Journal of Ethnic and Cultural Diversity in Social Work, 9(3), 133-150.

Hayslip, B. Jr., Shore, R. J., Henderson, C. E., \& Lambert, R. L. (1998). Custodial grandparenting and the impact of grandchildren with problems on role satisfaction and ole meaning. Journal of Gerontology: Social Science, 53B, S164-S173.

Hinds, P. S., Chaves, D. E., \& Cypess, S. M. (1992). Context as a source of meaning and understanding. Qualitative Health Research, 2, 61-74.

Hunt, G., Levine, C., \& Naiditch, L. (2005). Young caregivers in the U.S: Report of findings. Bethesda, MD: National Alliance for Caregiving.

Inhelder, B. and Piaget, J. (1958). The growth of logical thinking from childhood to adolescence. (Translated by A. Parsons and S. Milgram). New York: Basic Books.

Jendrek, M. P. (1993). Grandparents who parent their grandchildren: Effects on lifestyle. Journal of Marriage and the Family, 55, 609-621.

Jenkins, S., \& Wingate, C. (1994). Who cares for young cares? Their invisibility is the first problem to be addressed. British Medical Journal, 308, 733-734.

Johnson, C. L. (1988). Active and latent functions of grandparenting during the divorce process. The Gerontologist, 28(2), 185-191.

Keigher, S., Zabler, B., Robinson, N., Fernandez, A., \& Stevens, P. E. (2005). Young caregivers of mothers with HIV: Need for supports. Children and Youth Services Review, 27, 881-904. 
Kelly, S. J. (1993). Caregivers stress in grandparents raising grandchildren. Journal of Nursing Scholarship, 25(4), 331-337.

Kennedy, J. F., \& Kenney, V. T. (1988). The extended family revisited: Grandparents rearing grandchildren. Child Psychiatry and Human Development, 19(1), 26-35.

Kivett, V. R. (1991). The grandparent-grandchild connection. Marriages and Family Review. 16, 267-286.

Kornhaber, A. (1996). Contemporary grandparenting. Thousand Oaks. CA: Sage.

Lackey. N. R., \& Gates, M. F., (2001). Adults' recollections of their experiences as young caregivers of family members with chronic physical illness. Journal of Advanced Nursing, 34, 320-328.

Larsen, D. (1990). Maturity grandparent: Redefining the role. Modern Maturity, 33(6), 31-36.

Lee, M. D. (2007). Correlates of consequences of intergenerational caregiving in Taiwan. Journal of Advanced Nursing, 59(1), 47-56.

Lee, S., Colditz, G., Berkman, L., \& Kawachi, I. (2003). Caregiving to children and grandchildren and risk of coronary heart disease in women. American Journal of Public Health. 93, 1936-1944.

Levine, C., Hunt, G., Halper, D., Hart, A., Lautz, J. \& Gould, D. (2005). Young caregivers: A first look at an unstudied population. American Journal of Public Health, 95, 2071-2075.

Lincoln, Y., \& Guba, E. (1985). Naturalistic inquiry. Newbury Park, CA: Sage.

Meredith, H. (1992). Supporting the young carers. Community Outlook, 5, 15-17.

Merriam, S. B. (1998). Qualitative research and case study applications in education. San Francisco, CA: Jossey-Bass.

Microsoft Corporation. (2003). Excel, version 11. User's guide. United States: Microsoft Corporation.

Microsoft Corporation. (2003). Windows XP Microsoft Word. United States: Microsoft Corporation.

Miles, M., \& Huberman, A. (1984). Qualitative data analysis-A source book of new methods. Beverly Hills, CA: Sage. 
Miles, M., \& Huberman, A. (1994). Qualitative data analysis-An expanded sourcebook. Thousand Oaks: Sage.

Millian, N, M., Fabian, E. S., Schlossberg, N. K., \& Pyle, M. (2004). Grandparents raising grandchildren. Jordan Institute for Family, 1(1) 1-4.

Minkler, M. (1999). Intergenerational households headed by grandparents: Contexts, realities, and implications for policy. Journal of Aging Studies, 13(2), 199-218.

Minkler, M., \& Fuller-Thomson, E. (1999). The health of grandparents raising grandchildren: Results of national survey. American Journal of Public Health, 89, 1384 1389.

Minkler, M., \& Roe, K. M. (1993). Grandmothers as caregivers. Newbury Park, CA: Sage.

Minkler, M., Roe, K. M., \& Robertson-Beckley, R. J. (1994). Raising grandchildren from crack-cocaine households: Effects on family and friendship ties of African American women. American Journal of Orthopsychiatry, 64, 20-29.

Montgomery, R., Gonyea, J., \& Hooyman, N. (1985). Caregiving and the experience of subjective and objective burden. Family Relations, 34, 19-26.

Musil, C. M. (1998). Health, stress, coping, and social support in grandmother caregivers. Health Care for Women International, 19, 441-455.

National Association of Social Workers. (1988). Grandparents as parents: Obligations/ rewards complicate the golden years. NASW News, 33, 6 .

Netskills, NVivo 7- Software for qualitative data analysis. (n.d.). Retrieved September 31, 2008, from http://www.netskills.ac.uk/content/products/workshops/event/ncl-jun08nvivo-r1/index.html

Nigel, T., Stainton, T., Jackson, S., Cheung, W., Doubtfire, S., \& Webb, A. (2003). 'Your friends don't understand': Invisibility and unmet need in the lives of 'young carers'. Child and Family Social Work, 8, 35-46.

Nwokeji, S., \& Graff, C. (2007, October). Symbiotic caregivers: African American custodial grandparents and their grandchildren. Poster session at the Annual Meeting of the Southern Nursing Research Society, Birmingham: AL.

Pakenham, K. I., Chiu, J., Bursnall, S., Cannon, T., \& Okochi, M. (2006). Psychosocial impact of caregiving on young people who have a parent with an illness or disability: Comparisons between young caregivers and noncaregivers. Rehabilitation Psychology, 51, 113-126. 
Palmer, E. (1990). Grandparents raising grandchildren. South County's Favorite Alternative, p. 8-10, 38-39.

Pantier, C. (1993, September). Many grandparents parenting again. Senior World, p. 4, 7.

Parse, R., Coyne, A., \& Smith, M. (1985). Nursing research: Qualitative methods. Bowie, MD: Brady Communications.

Patton, M. Q. (2002). Qualitative research and evaluation methods. Thousand Oaks, CA: Sage.

Pearlin, L., Mullan, J., Semple, S., \& Skaff, M. (1990). Caregiving and the stress process: An overview of concepts and their measures. The Gerontologist, 30(5), 583-594.

Peek, C. W. \& Zsembik, B. A. (1997). The changing caregiving networks of older adults. Research on Aging, 19(3), 333-362.

Pinston-Millburn, N., Fabian, E. S., Schlossberg, N. K., \& Pyle, M. (1996). Grandparents raising grandchildren. Journal of Counseling and Development, 74, 548-554.

Platt-Jendrek, M. (1993). Grandparents who parent grandchildren: Findings and policy implications. Unpublished master's thesis. Miami University, Department of Sociology and Anthropology, Oxford, $\mathrm{OH}$.

Poe, L. M. (1992). Black grandparents as parents. New York, New York. Springer Publishing Company, Inc.

Polen, M., \& Green, C. (2001). Caregiving, alcohol use, and mental health symptoms among HMO members. Journal of Community Health Nursing, 26(4), 285-301.

Poulshock, S. W. \& Deimling, G. (1984). Families caring for elders in residence: Issues in the measurement of burden. Journal of Gerontology, 39(2), 230-239.

Pruchno, R. (1999). Raising grandchildren. The experience of black and white grandmothers. The Gerontologist, 39(2), 209-221.

Pruchno, R. A., \& McKenney, D. (2002). Psychological well-being of black and white grandmothers raising grandchildren. Journal of Gerontology: Psychological Sciences, 57B, P444-P452.

Pyke, K. D., \& Bengtson, V. L. (1996). Caring more or less: Individualistic and collectivist systems. Journal of Marriage \& Family, 58(2), 379-383.

QSR International. (2007). NVivo 7. [Computer software]. Retrieved March 7, 2009, from http://www.qsrinternational.com/default.aspx 
Renwick, L. (1993, July 4), The grandparent trap. Los Angeles Times, p. 14-16.

Robson, C. (1993). Real world research: A resource for social scientists and practitioner-researchers. Oxford, UK: Wiley Blackwell.

Robson, E., Ansell, N., Huber, U. S., Gould, W. T. S., \& Young, L. (2006). Young caregivers in the context of the HIV/AIDS pandemic in Sub-Sahara Africa. Population, Space and Place, 12, 93-111.

Roger, A. Y., \& Jones, R. L. (1999). Grandmothers who are caregivers: An over-looked population. Child and Adolescent Social Work Journal, 16, 455-466.

Rosner, F. (1990). Fundamentals of biostatistics. Boston, MA: PWS Kent Publishing Co.

Ruiz, D. (2000). Custodial African American grandparents: Reasons for caregiving and assumptions of the caregiver role. African American Research Perspective, 6, 152-159.

Sadler, C. (2003). Too much too young. Nursing Standard, 18, 16-18.

Sayles-Cross, S. (1999). Aging, caregiving effects, and black family caregivers. In R.W. Johnson (Ed.), African American voices: African American health educators speak out (pp. 163-178). Sudbury, MA: Jones and Bartlett.

Schultz, P. R., \& Kerr. B. J. (1986). Comparative case study as a strategy for nursing research. In P. L. Chinn (Ed.), Nursing research methodology: Issues and implementation (pp. 195-220). Rockville, MD: Aspen.

Shifren, K. (2001). Early caregiving and adult depression: Good news for young caregivers. The Gerontologist, 41, 188-190.

Shifren, K., \& Kachorek, L. V. (2003). Does early caregiving matter? The effects on young caregivers' adult mental health. International Journal of Behavioral Development, 27, 338-346.

Simmons, T., \& Dye, J. L. (2003). Grandparents living with grandchildren: 2000. Washington, DC: U.S. Census Bureau. Retrieved December 7, 2007, from http://www.census.gov/prod/2003pubs/c2kbr-31.pdf

Siskowski, C. (2003). From the eyes: Family health situations influence students' learning and lives in Palm Beach County, grades 6-12 West Palm Beach, Florida. Retrieved August 5, 2007, from http://www.boca-respite.org/children.doc

Siskowski, C. (2006). Young caregivers: Effect of family health situations on school performances. The Journal of School Nursing, 22, 163-169. 
Smith, G. C., \& Palmieri, P. A. (2007). Risk of psychological difficulties among children raised by custodial grandparents. Psychiatric Services, 58, 1303-1310.

Smolowe, J. (1990, November 5). To grandma's house we go. Time, p. 86-90.

Stake, R. E. (2006). Multiple case study analysis. New York, NY: The Guilford Press.

Stake, R. E. (1995). The art of case study research. Thousand Oaks, CA: Sage.

Timberlake, E. M., \& Chipungu, S. S. (1992). Grandmotherhood: Contemporary meaning among African American middle-class grandmothers. Social Work, 37, 216-222.

Tompkins, C. J. (2007). Who will care for the grandparents? Exploring relationships between grandparents and grandchildren. Journal of Psychosocial Nursing, 45, 19-22.

U.S. Census Bureau (2002). U.S. summary: 2000. Washington, D.C: U.S. Census Bureau Department of Commerce. Economics and Statistics Administration. Retrieved September 23, 2007, from http://www.census.gov/prod/2002pubs/c2kprof00-us.pdf

U.S. Census Bureau, Census 2000 Supplementary survey profile, Memphis city, Shelby county pt. Retrieved January 20, 2009, from

http://www.census.gov/acs/www/Products/Profiles/Single/2000/C2SS/Tabular/155/15500 $\underline{\text { US47480001572.htm }}$

Waldrop, D. P., \& Weber, J. A. (2001). From grandparent to caregiver: The stress and satisfaction of raising grandchildren. The Journal of Contemporary Human Services, $85(5), 461-478$.

Watson, S. (1999). Meeting the needs of young carers. Nursing Standard, 13, 37-40.

Weber, J. A., \& Waldrop, D. P. (2000). Grandparents raising grandchildren: Families in transition. Journal of Gerontological Social Work, 33(2), 27-46.

Weiss, C. (1998). Evaluation methods for studying programs and policies ( $2^{\text {nd }}$ ed.). Upper Saddle River, New Jersey: Prentice Hall.

White, L. K., \& Brinkerhoff, D. B. (1981). Children's work in the family: Its significance and meaning. Journal of Marriage and the Family, 43, 789-798.

Whiteley, D. M., Kelly, S. J., \& Sipe, T. A. (2001). Grandmothers raising grandchildren: Are they at increased risk of health problems? Health \& Social Work, 26, 105-114.

Williamson, J., Softas-Nall, B., \& Miller, J. (2003). Grandmothers raising grandchildren: An exploration of their experiences and emotions. The Family Journal, 11(1), 23-32. 
Wilson, M. (1984). Mothers' and grandmothers' perceptions of parental behavior in three generational Black families. Child Development, 55, 1333-1339.

Yin, R. (2003). Case study research: Design and methods. Beverly Hills, CA: Sage.

Yin, R. K. (1994). Case study research: Design and methods. ( $2^{\text {nd }}$ ed.). Thousand Oaks, CA: Sage.

Young, D., \& Smith C. (2000). When moms are incarcerated: The needs of children, mothers, and caregivers. Journal of Contemporary Human Services, 81(2), 130-141.

Zarit, S. (1985). The hidden victim of Alzheimer's disease. New York, NY: New York University Press. 


\section{APPENDIX A. GRANDPARENTS' DEMOGRAPHIC DATA FORM}

\section{Grandparents' Demographic Data Form}

1. What is your name?

2. Do you have custody of a grandchild or grandchildren? Yes No

3. How many grandchildren do you have custody of?

4. Do the grandchildren you have custody of live with you? Yes No

5. What are the ages and gender of the grandchildren you have custody of?
Name
Age
Gender

6. What is your age? (years)

7. What is your race?

8. Marital status

Are you single? Yes No

Are you married? Yes No

Are you divorced? Yes No

Are you separated? Yes No Are you widowed? Yes No 
Are you living with partner or significant other? Yes

No

9. What is the highest grade you completed in school?

10. Work and employment status

Do you work full-time? Yes No

Do you work part-time? Yes No

Are you unemployed? Yes No

Are you retired? Yes No

Are you a homemaker? Yes No

11. If you are working, what is your occupation?

12. Do other persons live in the home with you? Yes No

If yes, how are they related to your grandchildren? 


\section{APPENDIX B. GRANDCHILDREN'S DEMOGRAPHIC DATA FORM}

\section{Grandchildren's Demographic Data form}

Person signing Assent/consent form:

Custodial grandchild: Yes

No

Grandchild lives with grandparents: Yes No

Location of interview:

1. Grandchild's Name:

2. Grandchild's Age:

3. Grandchild's Gender: Male Female

4. Grandchild's Race/Ethnicity:

5. Grandchild's Grade in school:

6. Number of Siblings:

7. Names of Siblings:

8. Ages of Siblings:

9. Genders of Siblings:

10. Performs caregiving to grandparent(s): Yes No 


\section{APPENDIX C. INTERVIEW SCHEDULE FOR GRANDPARENTS}

\section{Interview Schedule for Grandparents}

1. Please describe caregiving activities your grandchildren handle.

2. Why did they begin to handle these activities?

3. What were the circumstances leading to handling of these activities?

4. How long have they been handling each of these activities?

5. Where are the parents of your grandchildren?

6. When did you take over the care of your grandchildren, and why?

7. Please describe some of your grandchildren's experiences in caring for you.

8. Which caregiving activities are not appropriate for children, and why?

9. Has caring for your grandchildren drawn you closer to them?

10. Have your grandchildren's caregiving activities drawn them closer to you?

11. Have caregiving to your grandchildren affected your life in any way, positive or negative?

12. Who can you turn to for help in caring for grandchildren? What sorts of help do they provide?

13. How do you cope with the responsibilities of caring for grandchildren? 


\section{APPENDIX D. INTERVIEW SCHEDULE FOR GRANDCHILDREN}

\section{Interview Schedule for Grandchildren}

1. Please describe any caregiving activity you handle for grandparents?

2. How long have you been handling these caregiving activities?

3. What circumstances caused you to care for your grandparents?

4. Which caregiving activities do you not feel comfortable performing, and why?

5. Please describe some of your experiences in caring for grandparents?

6. To what extend is caregiving a burden or blessing to you, and why?

7. How does caregiving affect your physical, mental, educational, emotional, economic, and social lives? Please explain or give examples.

8. Who can you turn to for help in caring for grandparents? What sorts of help do they provide?

9. Has caring for your grandma and grandpa drawn you closer to them?

10. How do you cope with the responsibilities of caring for your grandparents? 
APPENDIX E. INSTITUTIONAL REVIEW BOARD APPROVAL 
Stella Enyichi Nwokeji, MSN, NP-BC

\section{CAMPUS}

Dear Ms. Nwokeji,

We are in receipt of your acceptance in response to our proviso letter dated April 24, 2008 concerning your project entitled "Symbiotic Caregivers: A Qualitative Case Study of African American Custodial Grandparents and their Grandchildren" (IRB \#8796).

The Administrative Section of the UTHSC Institutional Review Board (IRB) determined your application to be consistent with the guidelines for expedited review under category (7). It is approved for children under 45CFR46.404 in that the study involves no more than minimal risk (non-sensitive interview questions). Therefore, this application was approved in this regard as complying with proper consideration of the rights and welfare of human subjects, the risk involved, and the potential benefits of the study. This letter constitutes full approval of your application; questionnaires (Grandparent Demographic Data Form; Grandchild Demographic Data Form; Grandparent Interview Schedule; Grandchildren Interview Schedule] and consent form(s) [Grandparents \& Grandchildren], stamped approved by the UTHSC IRB on May 5, 2008 for the above referenced study. This project was approved for 12 months with an expiration date of April 24, 2009. The consent form(s) dated April 29, 2008 are also approved from the date of this letter through April 24, 2009.

The IRB has also determined that the informed consent form(s), incorporating the authorization of subjects to use their protected health information in research, complies with the federal privacy regulations as specified in 45 CFR160 and 45 CFR 164.

In the event that subjects are to be recruited using solicitation materials, such as brochures, posters, website based advertisement, etc., these materials must receive prior approval of the IRB. Any revisions in the approved application must also be submitted to and approved by the IRB prior to implementation. In addition, you are responsible for reporting any unanticipated serious adverse events or other problems involving risks to subjects or others in the manner required by the local IRB policy.

Finally, reapproval of your project is required by the IRB in accord with the conditions specified above. You may not continue beyond the time or other limits specified unless you obtain prior written approval of the IRB.
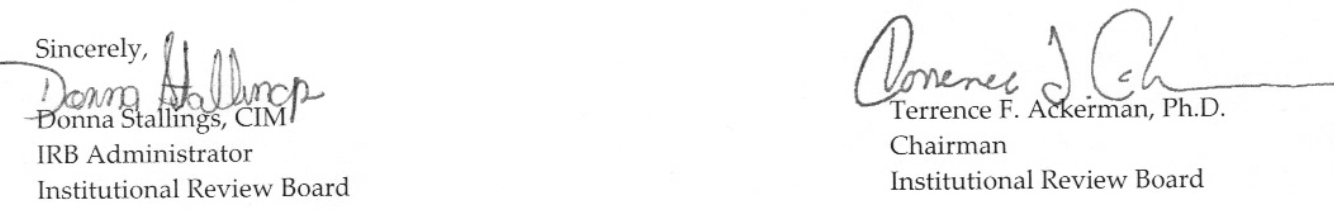


\section{APPENDIX F. CONSENT FORM}

\section{CONSENT FORM}

\section{TITLE:}

Symbiotic Caregivers: A Qualitative Case Study of African American Custodial Grandparents and their Grandchildren.

\section{PRINCIPAL INVESTIGATOR:}

Stella Enyichi Nwokeji, MSN, NP-BC

Boling Center for Developmental Disabilities

711 Jefferson Avenue

Memphis, TN 38105
CO-INVESTIGATOR:

J. Carolyn Graff, PhD

\section{INTRODUCTION:}

You and your grandchild are being given the opportunity to participate in a research study about your experience as a grandparent caring for your grandchild and your grandchild's experience in helping you. The purpose of the study is to learn about and understand your experiences taking care of the grandchild(ren) in your custody and your grandchild(ren)'s responsibilities helping you.

You will be one of 30 grandparents who will participate in an interview that will be conducted in your home or at a location that is convenient for you. Also you will be one of 30 grandchildren who will participate in the interview. The researcher will ask you questions about what you think about the care you give to your grandchildren and about the help your grandchildren provide to you. The time required to participate in this interview will be about $1 \frac{1}{2}$ to 2 hours. The study is expected to be completed in 12 months.

\section{PROCEDURES TO BE FOLLOWED:}

The procedure for this study will entail two processes. The same process will apply to your grandchildren if you agree and they agree to participate in this study. You will answer questions about your experiences caring for your grandchild (ren) and your grandchild (ren)'s experiences with helping you. Your interview will be audio-tape recorded. Your grandchild (ren) will not be in the same room while you are being interviewed.

Following this interview with you, an interview will be conducted with the grandchild you have identified who helps you the most. This interview with your grandchild will be audio-tape recorded. You will not be in the same room while your grandchild is being interviewed.

RISKS ASSOCIATED WITH PARTICIPATION:

Your risks for taking part in this research study are few. There is a possibility you may 
feel uncomfortable when you are answering questions and taking part in this research study. You may choose not to answer a question or you may decide to stop the study at any time. Your participation in this research study is voluntary.

\section{BENEFITS ASSOCATED WITH PARTICIPATION:}

You understand that there may be no direct benefits to you from this research study. You may feel pleased or relieved that you have shared information about your experiences as a grandparent. The information you share may help nurses and other health professionals understand your experiences as a grandparent caring for your grandchild(ren) and find ways to help grandparents cope with their caregiving responsibilities.

\section{ALTERNATIVES TO PARTICIPATION:}

You understand that you do not have to participate in this interview and answer questions if you do not participate in this research study.

\section{CONFIDENTIALITY:}

All information you share is confidential and will be kept in a locked file. Your research record will be labeled with a code number and your name will not be used on the research record. A master key that links your name and code number will be maintained in a separate and secure location.

Under federal privacy regulations, you have the right to determine who has access to your personal health information (called "protected health information" or PHI). PHI collected in this study may include your medical history, the results of physical exams, lab tests, $\mathrm{x}$ ray exams, and other diagnostic and treatment procedures, as well as basic demographic information. By signing this consent form, you are authorizing the researchers at the University of Tennessee to have access to your PHI collected in this study.

The Institutional Review Board (IRB) at the University of Tennessee Health Science Center may review your PHI as part of its responsibility to protect the rights and welfare of research subjects. Your PHI will not be used or disclosed to any other person or entity, except as required by law, or for authorized oversight of this research study by other regulatory agencies, or for other research for which the use and disclosure of your PHI has been approved by the IRB. Your PHI will be used only for the research purposes described in the Introduction of this consent form. Your PHI will be used until the study is completed.

You may cancel this authorization in writing at any time by contacting the principal investigator listed on the first page of this consent form. If you cancel the authorization, continued use of your PHI is permitted if it was obtained before the cancellation and its use is necessary in completing the research. However, PHI collected after your cancellation may not be used in the study. If you refuse to provide this authorization, you will not be able to participate in the research study. If you cancel the authorization, you will be withdrawn from the study. If you cancel the authorization, then you will be withdrawn from the study. Finally, the federal regulations allow you to obtain access to 
your PHI collected or used in this study.

Information about your participation in this study will be placed in your research record, not in a medical record. You will not be identified in any presentations or publications based on the results of the research study.

COMPENSATION AND TREATMENT FOR INJURY:

I understand that I am not waiving any legal rights or releasing the University of Tennessee or its agents from liability for negligence. I understand that, in the event of physical injury resulting from research procedures, the University of Tennessee does not have funds budgeted for compensation either for lost wages or for medical treatment. Therefore, the University of Tennessee does not provide for treatment or reimbursement for such injuries.

If injury should occur, efforts will be made to locate resources in the community to provide needed medical treatment. No compensation for injury or health care will be available through the sponsor of this study. I or my insurance carrier will be billed for costs associated with the medical treatment of a research related injury.

\section{QUESTIONS:}

You have read or someone has read this form to you. You have had the chance to ask your questions and the researcher has answered your questions about this research study to your satisfaction. You understand that if you have more questions about the research study, or you believe you have sustained a research-related injury, you may contact Ms. Stella Nwokeji at (901) 826-4622 or Dr. Carolyn Graff at (901) 448-6544 for answers to your questions.

You understand that you may contact Dr. Terrence F. Ackerman, Ph.D., the University of Tennessee Health Science Center Institutional Review Board Chairman at (901) 4484824 if you have any questions about your rights as a participant in this study or your rights as a research subject.

\section{PAYMENT FOR PARTICIPATION:}

For completion of the study, you will receive a payment of $\$ 30.00$ gift card for you in addition to $\$ 5$ gift card for your grandchild which will total $\$ 35$. These payments will be mailed to you and your grandchild about three weeks after you complete the research study. Other grandchildren in your home will be given school supplies in an effort to eliminate perceived preferential treatment of the grandchild participating in the interview.

\section{COSTS OF PARTICIPATION:}

You understand that there will be no costs to you for participating in this research study.

\section{PREMATURE TERMINATION:}

There are no anticipated circumstances under which your participation in this research study will be terminated by the principal investigator without your consent. 


\section{VOLUNTARY PARTICIPATION:}

You understand that your taking part in this research study is voluntary. You may stop this research study at any time. Your decision to stop the research study will not affect future benefits you receive through the University of Tennessee Health Science Center or the Relative Caregiver Program.

\section{CONSENT OF PARTICIPANT:}

I have read or have had read to me the description of the research study as outlined above. The investigator or his/her representative has explained the study to me and has answered all of the questions I have at this time. I have been told of the potential risks, discomforts, side effects, and adverse reactions as well as the possible benefits of the study.

I freely volunteer to participate in the study. I understand that I do not have to take part in this study and that my refusal to participate will involve no penalty or loss of rights to which I am entitled. I further understand that I am free to later withdraw my consent and discontinue participation in this study at any time. I understand that refusing to participate or later withdrawing from the study will not adversely affect my subsequent medical care.

I understand that I will receive a copy of this consent form.

Signature of Research Subject

Date

Signature of Person Obtaining Consent

Date

Signature of Witness

Date

Signature of Principal Investigator

Date 


\title{
APPENDIX G. ASSENT OF MINOR/CONSENT FORM
}

\author{
ASSENT OF MINOR \\ CONSENT FORM
}
Symbiotic Caregivers: A Qualitative Case Study of African American Custodial Grandparents and their Grandchildren.

PRINCIPAL INVESTIGATOR:

Stella Enyichi Nwokeji, MSN, NP-BC

Boling Center for Developmental Disabilities

711 Jefferson Avenue

Memphis, TN 38105

\section{INTRODUCTION:}

You are being given the opportunity to participate in a research study about your experience as a grandchild caring for your grandparent. The purpose of the study is to learn about and understand your experiences taking care of your grandparent.

You will be one of 30 grandchildren who will participate in an interview that will be conducted in your home or at a location that is convenient for you and your grandparent. I will ask you questions about what you think about the care you give to your grandparent and about the help your grandparent provides to you. The time required to participate in this interview will be about $1 \frac{1}{2}$ to 2 hours. The study is expected to be completed in 12 months.

\section{PROCEDURES TO BE FOLLOWED:}

The procedure for this study will entail two processes if you agree to participate in this study. You will answer questions about your experiences caring for your grandparent. Your interview will be audio-tape recorded. Your grandparent will not be in the same room while you are being interviewed.

\section{RISKS ASSOCIATED WITH PARTICIPATION:}

There are no risks to you for taking part in this research study. There is a possibility you may feel uncomfortable when you are answering questions. You may choose not to answer a question or you may decide to stop the study at any time. Your participation in this research study is voluntary.

\section{BENEFITS ASSOCATED WITH PARTICIPATION:}

There are no direct benefits to you from this research study. You may feel pleased or relieved that you have shared information about your experiences as a grandchild. The information you share may help nurses and other health professionals understand your experiences as a grandchild caring for your grandparent and find ways to help you cope with your caregiving responsibilities. 


\section{ALTERNATIVES TO PARTICIPATION:}

You do not have to participate in this interview and answer questions if you do not participate in this research study.

\section{CONFIDENTIALITY:}

All information you share is confidential and will be kept in a locked file. Your research record will be labeled with a code number and your name will not be used on the research record. A master key that links your name and code number will be maintained in a separate and secure location.

Under federal privacy regulations, you have the right to determine who has access to your personal health information (called "protected health information" or PHI). PHI collected in this study may include your medical history, the results of physical exams, lab tests, $\mathrm{x}$ ray exams, and other diagnostic and treatment procedures, as well as basic demographic information. By signing this consent form, you are authorizing the researchers at the University of Tennessee to have access to your PHI collected in this study.

The Institutional Review Board (IRB) at the University of Tennessee Health Science Center may review your PHI as part of its responsibility to protect the rights and welfare of research subjects. Your PHI will not be used or disclosed to any other person or entity, except as required by law, or for authorized oversight of this research study by other regulatory agencies, or for other research for which the use and disclosure of your PHI has been approved by the IRB. Your PHI will be used only for the research purposes described in the Introduction of this consent form. Your PHI will be used until the study is completed.

You may cancel this authorization in writing at any time by contacting the principal investigator listed on the first page of this consent form. If you cancel the authorization, continued use of your PHI is permitted if it was obtained before the cancellation and its use is necessary in completing the research. However, PHI collected after your cancellation may not be used in the study. If you refuse to provide this authorization, you will not be able to participate in the research study. If you cancel the authorization, then you will be withdrawn from the study. Finally, the federal regulations allow you to obtain access to your PHI collected or used in this study.

Information about your participation in this study will be placed in your research record, not in a medical record. You will not be identified in any presentations or publications based on the results of the research study.

\section{COMPENSATION AND TREATMENT FOR INJURY:}

I understand that I am not waiving any legal rights or releasing the University of Tennessee or its agents from liability for negligence. I understand that, in the event of physical injury resulting from research procedures, the University of Tennessee does not have funds budgeted for compensation either for lost wages or for medical treatment. Therefore, the University of Tennessee does not provide for treatment or reimbursement 
for such injuries. If injury should occur, efforts will be made to locate resources in the community to provide needed medical treatment. No compensation for injury or health care will be available through the sponsor of this study. I or my insurance carrier will be billed for costs associated with the medical treatment of a research related injury.

\section{QUESTIONS:}

You have read or someone has read this form to you. You have had the chance to ask your questions and the researcher has answered your questions about this research study to your satisfaction. If you have any questions about the research study, or you believe you have sustained a research-related injury, you may contact Ms. Stella Nwokeji at (901) 826-4622 or Dr. Carolyn Graff at (901) 448-6544 to answer to your questions.

You may contact Dr. Terrence F. Ackerman, Ph.D., the University of Tennessee Health Science Center Institutional Review Board Chairman at (901) 448-4824 if you have any questions about your rights as a participant in this study or your rights as a research subject.

\section{PAYMENT FOR PARTICIPATION:}

We will provide your grandparent with a payment of $\$ 5.00$. This payment will be given to you after you complete the research study.

\section{COSTS OF PARTICIPATION:}

There will be no costs to you for participating in this research study.

\section{PREMATURE TERMINATION:}

There are no anticipated circumstances under which your participation in this research study will be terminated by the principal investigator without your consent.

\section{VOLUNTARY PARTICIPATION:}

You taking part in this research study is voluntary. You may stop this research study at any time. Your decision to stop the research study will not affect future benefits you receive through the University of Tennessee Health Science Center or the Relative Caregiver Program.

\section{CONSENT OF SUBJECT:}

I have read or have had read to me the description of the research study as outlined above. The investigator or his/her representative has explained the study to me and has answered all of the questions I have at this time. I have been told of the potential risks, discomforts, side effects, and adverse reactions as well as the possible benefits of the study.

I freely volunteer to participate in the study. I understand that I do not have to take part in this study and that my refusal to participate will involve no penalty or loss of rights to which I am entitled. I further understand that I am free to later withdraw my consent and discontinue participation in this study at any time. I understand that refusing to participate or later withdrawing from the study will not adversely affect my subsequent medical care. 
I understand that I will receive a copy of this assent form.

Signature of Research Subject

Signature of Person Obtaining Consent

Signature of Witness

Signature of Principal Investigator

Assent of Minor
Date

Date

Date

Date

Date 


\section{VITA}

Stella Enyichi Nwokeji was born in 1975. She grew up in Nigeria and moved to the United States in 1995. She received a bachelor's degree at Union University, Germantown, TN, in December 2003 and a master's degree in nursing with a concentration in family nurse practitioner in May 2006 from the University of Memphis, Memphis, TN. Soon after that, she enrolled in the doctorate program at the University of Tennessee Health Science Center in Memphis, where she received a doctor of philosophy degree in nursing in May 2009. 